\title{
Bibliographie mit den verwendeten Kurztiteln
}

Die hier vorgelegte Bibliographie will mehr sein als nur eine Liste der verwendeten Literatur und ihrer Kurztitel. Sie soll dem Benutzer eine repräsentative Übersicht über die Mitte 2001 aktuelle indogermanistische Fachliteratur vermitteln. Es sind darunter auch Titel verzeichnet, auf die sonst nicht weiter verwiesen wird. Vollständigkeit ist in keinem Bereich angestrebt. Nicht alle Publikationen sind gleich gut. Aber es ist keine so schlecht, als daß man nicht etwas daraus lernen kann und sei es nur die Erkenntnis des ,so nicht“.

Eine eigene „Literaturgattung“ stellen die Rezensionen / Besprechungen von Büchern dar. Einzelne werden hie und da genannt, um immer wieder auf diesen Informationszweig aufmerksam zu machen. Wer sich in ein bestimmtes Arbeitsgebiet einarbeitet oder die neuesten Stellungnahmen zu einem bestimmten Problem sucht, dem sei wärmstens empfohlen, eben auch die Meinungen, Korrekturen oder Ergänzungen der entsprechenden Rezensenten einzusehen. Es wurde aber nie beabsichtigt, bei jedem Werk alle dazugehörigen Rezensionen zu nennen. Den Leser verweise ich speziell auf das von der Indogermanischen Gesellschaft herausgegebene Berichts- und Rezensionsorgan Kratylos (der jüngste mir zur Verfügung stehende Band ist 46 2001). Gelegentlich wird auch auf eine Notiz oder eine Bemerkung in der Idg. Chr. (s.u. s.v.) aufmerksam gemacht.

Grundlage für die Siglen der Zeitschriften sind die Vorgaben der Bibliographie Linguistique / Linguistic Bibliography. Ein paar für die Indogermanistik besonders einschlägige Titel erscheinen extra in der Liste. Für eine regelmäßige Lektüre und Konsultation empfehlen sich (genannt in alphabetischer Reihenfolge) u.a.: Diachronica, Glotta, HS (ältere Siglen ZVS bzw. KZ), IF, JIES, MSS und Sprache.

Die folgenden bibliographischen Angaben sind nicht immer ganz einheitlich gestaltet. In der Regel folgen am Schluß bei neueren Werken Hinweise, wenn sie in einer bestimmten Reihe erschienen sind (sei es nun ein Ergänzungsheft zu ZVS / HS, ein IBS-Band oder eine Akademieschrift). Bei Publikationen, die seit längerem bekannt sind, wird aber oft 
aus Gründen der Einfachheit nur Erscheinungsort und Erscheinungsjahr genannt und auch sonst auf bibliographische Zusatzdaten verzichtet.

AAWL $=$ Abhandlungen der Akademie der Wissenschaften und der Literatur in Mainz.

Adams Dictionary 1999 = D. Q. Adams A Dictionary of Tocharian B. Amsterdam / Atlanta GA 1999 (= Leiden Studies in IE 10).

Adams Tocharian $1988=$ D. Q. Adams Tocharian Historical Phonology and Morphology. New Haven 1988 (= American Oriental Series 71).

Adiego Studia Carica 1993 = I.-J. Adiego Lajara Studia Carica, Investigaciones sobre la escritura y lengua carias. Barcelona 1993.

Adrados Manual s.u. Manual de lingüistica indoeuropea

Aitzetmüller Abulg. Gramm. $1991=$ R. Aitzetmüller Altbulgarische Grammatik als Einführung in die slavische Sprachwissenschaft. 2., verbesserte und erweiterte Auflage Freiburg 1991 (= Monumenta Linguae Slavicae Nr. 30).

Akten 13. Österreich. Linguistentagung $1988=$ Akten der 13. Österreichischen Linguistentagung 1985 in Graz mit den Beiträgen der Tagung 1983 in Salzburg, hrsg. von Chr. Zinko. Graz 1988.

Allen Vox Graeca $1987=$ W. S. Allen Vox Graeca, A Guide to the Pronunciation of Classical Greek. 3. Aufl. Cambridge 1987.

Althochdeutsch I / II 1987 = Althochdeutsch, hrsg. von R. Bergmann, H. Tiefenbach und L. Voetz. Heidelberg 1987: Band I (Grammatik. Glossen und Texte); Band II (Wörter und Namen. Forschungsgeschichte).

Ambrosini Linguistica Indo-Europea I / II $1996=\mathrm{R}$. Ambrosini Introduzione alla linguistica indo-europea. I (La ricostruzione dell' indoeuropeo), II (Le lingue indo-europee orientali e centrali). Lucca 1996.

Ammann Untersuchungen I $1922=\mathrm{H}$. Ammann Untersuchungen zur homerischen Wortfolge und Satzstruktur. 1 allgemeiner Teil. Leipzig 1922; ders. 2. Teil: Die Stellung des Verbums, im einzelnen untersucht in IF 421924 p. 149-171 und 300-322.

Ancient IE Dialects 1963 [1966] = Ancient Indo-European Dialects, Proceedings of the Conference on Indo-European Linguistics 1963 in Los Angeles, hrsg. von H. Birnbaum und J. Puhvel. Berkeley / Los Angeles 1966.

Andersen (H.) Prehistorical Dialects $1996=\mathrm{H}$. Andersen Reconstructing Prehistorical Dialects, Initial Vowels in Slavic and Baltic. Berlin 1996. Rez.: Chr. Koch in Kratylos 452000 p. 146-154. 
Andersen (P. K.) Word Order Typology 1983 = P. K. Andersen Word Order Typology and Comparative Constructions. Amsterdam / Philadelphia 1983. Rez.: Ch. Lehmann in Kratylos 291984 [1985] p. 2530.

Anttila PIE Schwebeablaut $1969=\mathrm{R}$. Anttila Proto-Indo-European Schwebeablaut Berkeley / Los Angeles 1969. Rez.: J. Schindler in Kratylos 151970 [1972] p. 146-152.

AÖAW = Anzeiger der Österreichischen Akademie der Wissenschaften, philosophisch-historische Klasse.

Arbeitstagung Erlangen 1997 [2000] = Indoarisch, Iranisch und die Indogermanistik, Arbeitstagung der Idg. Gesellschaft 1997 in Erlangen, hrsg. von B. Forssman und R. Plath, Wiesbaden 2000. Rez.: B. Schlerath in OLZ 962000 p. 306-316.

Arbeitstagung (Osk.-Umbr.) Freiburg 1991 [1993] = Oskisch-Umbrisch, Texte und Grammatik, Arbeitstagung der Idg. Gesellschaft und der Società Italiana di Glottologia 1991 in Freiburg, hrsg. von H. Rix. Wiesbaden 1993.

Arbeitstagung (100 Jahre Tocharologie) Saarbrücken 1995 [1997] = Arbeitstagung 100 Jahre Tocharologie, Kolloquium der Idg. Gesellschaft 1995 in Saarbrücken, publiziert als TIES 71997.

Arens Sprachwissenschaft I + II $1969=$ H. Arens Sprachwissenschaft, Der Gang ihrer Entwicklung von d. Antike bis zur Gegenwart. Frankfurt a. M. 1969, I (Von der Antike bis zum Ausgang des 19. Jahrhunderts), II (Das 20. Jahrhundert).

Arlotto Introduction $1972=\mathrm{A}$. Arlotto Introduction to Historical Linguistics. Boston 1972.

Arumaa Urslav. Grammatik I 1964 II 1976 III 1985 = P. Arumaa Urslavische Grammatik. Heidelberg: Band I (Einleitung, Lautlehre mit Vokalismus und Betonung) 1964; Band II (Konsonantismus) 1976; Band III (Formenlehre) 1985.

ASNP = Annali della Scuola Normale Superiore di Pisa: lettere, storia e filosofia.

Aspects of Latin 1993 [1996] = Aspects of Latin, Papers from the Seventh International Colloquium on Latin Linguistics Jerusalem 1993, hrsg. von H. Rosén. Innsbruck 1996 (= IBS 86); s.u. s.v. IKLL (ICLL / CILL) VII 1993 [1996].

Aspekte baltist. Forschung $2000=$ Aspekte Baltistischer Forschung, hrsg. von J. Range. Essen 2000 (= Schriften des Instituts für Baltistik der Ernst-Moritz-Arndt-Universität Greifswald 1). 
Assmann Kulturelles Gedächtnis $1997=$ J. Assmann Das kulturelle Gedächtnis. Schrift, Erinnerung und politische Identität in frühen Hochkulturen. München 1997 (und Neuauflagen).

Aufrecht Hymnen des RV $1877=$ Th. Aufrecht Die Hymnen des Rigveda. 2 Bände. 2. Aufl. 1877 (und Nachdrucke).

Aura Jorro DMic. I 1985 II 1993 = F. Aura Jorro Diccionario micénico. Madrid, Bd. I (a-n) 1985, Bd. II (o-z) 1993.

Autobiographische Berichte $1991=$ Wege in der Sprachwissenschaft, Vierundvierzig autobiographische Berichte, Festschrift für M. Wandruszka, hrsg. von H.-M. Gauger und W. Pöckl. Tübingen 1991 (= Tübinger Beiträge zur Linguistik Band 362).

Bach Deutsche Personennamen 1943 = A. Bach Die deutschen Personennamen. Berlin 1943.

Baltische Sprachen $1994=$ Die baltischen Sprachen, Eine Einführung, von R. Eckert, Elvira-Julia Bukevičiūtè, F. Hinze. Leipzig / Berlin u.a.O. 1994. Rez.: F. Scholz in Kratylos 421997 p. 126-130.

Baltistik 1998 = Baltistik, Aufgaben und Methoden, hrsg. von A. Bammesberger. Heidelberg 1998 (= Indogermanische Bibliothek, Reihe 3, Band 19). Rez.: R. Matasović und W. P. Schmid in IF 1052000 p. 342-351; F. Heidermanns in Kratylos 452000 p. 154-162.

Bammesberger Abstraktbildungen $1973=$ A. Bammesberger Abstraktbildungen in den baltischen Sprachen. Göttingen 1973.

Bammesberger Germ. Verbalsystem $1986=$ A. Bammesberger Der Aufbau des germanischen Verbalsystems. Heidelberg 1986 (= Untersuchungen zur vergleichenden Grammatik der germanischen Sprachen, Band 1).

Bammesberger Laryngaltheorie $1984=$ A. Bammesberger Studien zur Laryngaltheorie. Göttingen 1984 (= Ergänzungsheft zur ZVS 33). Rez.: R. S. P. Beekes in Kratylos 311986 p. 70-75; F. O. Lindeman in IF 91 1986 p. 349-351. S. auch unten Laryngaltheorie 1988.

Bammesberger Pforzen und Bergakker $1999=$ Pforzen und Bergakker, Neue Untersuchungen zu Runeninschriften, hrsg. von A. Bammesberger. Göttingen 1999 (= HS, Ergänzungsheft 41).

Bammesberger Urgerm. Nomen $1990=$ A. Bammesberger Die Morphologie des urgermanischen Nomens. Heidelberg 1990 (= Untersuchungen zur vergleichenden Grammatik der germ. Sprachen Nr. 2).

Bartholomae Air. Wörterbuch $1904=$ C. Bartholomae Altiranisches Wörterbuch. Straßburg 1904. Der 2. photomechanische Nachdruck von 1979 enthält sowohl die Nachträge und Verbesserungen (Sp. 1881- 
1900), als auch die Nacharbeiten und Vorarbeiten von 1906. Berlin 1979.

Bartschat Methoden der Sprachwissenschaft $1996=$ B. Bartschat Methoden der Sprachwissenschaft. Von Hermann Paul bis Noam Chomsky. Berlin 1996.

$\mathrm{BCH}=$ Bulletin de Correspondence Hellénique.

Bechtel Gr. Dialekte 1921-1924 = F. Bechtel Die griechischen Dialekte, 3 Bde. Berlin 1921-1924.

Bechtel Hauptprobleme 1892 = Fr. Bechtel Die Hauptprobleme der indogermanischen Lautlehre seit Schleicher. Göttingen 1892.

Beekes Gatha-Avestan 1988 = R. S. P. Beekes A Grammar of GathaAvestan. Leiden 1988. Rez.: J. E. Rasmussen in Kratylos 361991 p. 109-116. Vgl. ferner dens. Historical Phonology of Iranian in JIES 25 1997 p. 1-26.

Beekes IE Nominal Inflection $1985=$ R.S.P. Beekes, The Origins of the Indo-European Nominal Inflection. Innsbruck 1985 (= IBS Nr. 46). Rez.: J. Schindler in Idg. Chr. 31a 1985 Nr.85.

Beekes Introduction $1995=$ R. S. P. Beekes Comparative Indo-European Linguistics, An Introduction. Amsterdam 1995. Rez.: A. Bammesberger in HS 1091996 p. 310-316; M. Kümmel in PFU 2-3 1996 / 1997 p. 113-125; Ch. de Lamberterie in BSL 92 / 21997 p. 143-149; St. Zimmer in PBB $119 / 21997$ p. 276-282.

Beekes Laryngeals $1969=$ R. S. P. Beekes The Development of the ProtoIndo-European Laryngeals in Greek. The Hague / Paris 1969. Rez.: C. J. Ruijgh in Lingua 261970 / 1971 p. 181-198 (= Scripta Minora I 1991 p. 330-347); H. Rix in Kratylos 141969 [1972] p. 176-187. Vgl. jetzt auch R. S. P. Beekes Laryngeal Developments: A survey in Laryngaltheorie 1988 p. 59-105.

Benedetti Composti radicali $1988=\mathrm{M}$. Benedetti I composti radicali latini: Esame storico e comparativo. Pisa 1988.

Benfey Geschichte der Sprachwissenschaft $1869=$ Th. Benfey Geschichte der Sprachwissenschaft und orientalischen Philologie in Deutschland seit dem Anfange des 19. Jahrhunderts mit einem Rückblick auf die früheren Zeiten. München 1869 (Nachdruck 1965).

Benveniste Hittite et indo-européen 1962 = E. Benveniste Hittite et indoeuropéen, Études comparatives. Paris 1962.

Benveniste Institutions I + II $1969=\mathrm{E}$. Benveniste Le vocabulaire des institutions indo-européennes. 2 Bände Paris 1969. Engl. Übersetzung unter dem Titel „Indo-European Language and Society“, London 1973. Dt. Übersetzung unter dem Titel „Indoeuropäische Institutionen“ von 
W. Bayer, D. Hornig, K. Menke, hrsg. mit einem Nachwort von St. Zimmer. Frankfurt / New York 1993. Rez.: R. Schmitt in Kratylos 39 1994 p. $183 f$.

Benveniste Noms d'agent 1948 = E. Benveniste Noms d'agent et noms d'action en indo-européen. Paris 1948.

Benveniste Origines $1935=\mathrm{E}$. Benveniste Origines de la formation des noms en indo-européen. Paris 1935.

Benveniste Problèmes I 1966 II 1974 = E. Benveniste Problèmes de linguistique générale. Paris Band I 1966, Band II 1974.

Benveniste s. auch unter Colloque E. Benveniste.

Berlinische Lebensbilder - Geisteswissenschaftler 1989 = Berlinische Lebensbilder, hrsg. von W. Ribbe: Band 4 Geisteswissenschaftler, hrsg. von M. Erbe. Berlin 1989.

Bibliographie d. Hethitologie 1-3 1996 (1998) = Systematische Bibliographie der Hethitologie 1915-1995, 3 Teilbände, zusammengestellt von V. Souček und J. Siegelová. Prag 1996.

Bile Crétois $1988=\mathrm{M}$. Bile Le dialecte crétois ancien, Étude de la langue des inscriptions, Recueil des inscriptions postérieures aux IC (= Inscriptiones Creticae). Paris 1988.

Binnig Gotisches Elementarbuch $1999=$ W. Binnig Gotisches Elementarbuch. Berlin 1999 (Dies de Gruyter Studienbuch ersetzt H. Hempel Gotisches Elementarbuch, Grammatik, Texte mit Übersetzungen und Erläuterungen, Berlin 1966, Sammlung Göschen Band 79/79a).

$\mathrm{BiOr}=$ Bibliotheca Orientalis.

Birkhan Kelten $1997=$ H. Birkhan Kelten. Wien 1997. Rez.: J. Uhlich in CMCS 392000 p. 65-73.

Bittel Hattusha $1970=\mathrm{K}$. Bittel Hattusha, The Capital of the Hittites. Oxford 1970. S. auch unten Neve Hattuša 1996.

Bittel Hethiter $1976=\mathrm{K}$. Bittel Die Hethiter: Die Kunst Anatoliens vom Ende d. 3. bis zum Anfang d. 1. Jahrtausends v. Christus. München 1976.

Biville Emprunts I 1990 II 1995 = F. Biville Les emprunts du latin au grec. Approche phonétique. Louvain und Paris: Band I (Introduction et consonantisme) 1990; Band II (Vocalisme et conclusion) 1995.

$\mathrm{BL}=$ Bibliographie linguistique / Linguistic Bibliography. Boston / London.

Blažek Numerals $1999=$ V. Blažek Numerals: Comparative-Etymological Analysis of Numerals Systems and their Implications. Brno 1999. Rez: M. de Vaan in Sprache 39 / 21997 [2000] p. 239-245; V. Bubenik in JES 282000 p. 450-454. 
Bloch Suppletive Verba $1940=$ A. Bloch Zur Geschichte einiger suppletiver Verba im Griechischen. Basel 1940.

Blümel Aiol. Dialekte $1982=$ W. Blümel Die aiolischen Dialekte, Phonologie und Morphologie der inschriftlichen Texte aus generativer Sicht. Göttingen 1982 (= Ergänzungsheft ZVS Nr. 30).

Blümel Untersuchungen $1972=$ W. Blümel Untersuchungen zu Lautsystem und Morphologie des vorklassischen Lateins. München 1972 (= MSS, Beiheft, Neue Folge 8).

$\mathrm{BNF}=$ Beiträge zur Namenforschung.

Bohl Besitzverhältnis $1980=\mathrm{S}$. Bohl Ausdrucksmittel für ein Besitzverhältnis im Vedischen und Griechischen. Louvain-la-Neuve 1980.

Boisacq DELG $1950=$ Boisacq Dictionnaire étymologique de la langue grecque étudiée dans ses rapports avec les autres langues indoeuropéennes. 4. éd. augm. d'un index par Helmut Rix. Heidelberg 1950.

Boley Hittite hark-construction $1984=\mathrm{J}$. Boley The Hittite harkconstruction. Innsbruck 1984 (= IBS 44).

Boley Sentence Particles $1989=$ J. Boley The Sentence Particles and the Place words in Old and Middle Hittite. Innsbruck 1989 (= IBS 60). Vgl. dies. The Hittite Particle -z / -za. Innsbruck 1993 (= IBS 79).

Bopp Albanesisch $1855=\mathrm{F}$. Bopp Über das Albanesische in seinen verwandtschaftlichen Beziehungen. Berlin 1855 (= Abhandl. d. Preuß. Akad. d. Wiss., Phil-hist. Kl.).

Bopp Conjugationssystem $1816=\mathrm{F}$. Bopp Über das Conjugationssystem der Sanskritsprache in Vergleichung mit jenem der griechischen, lateinischen, persischen und germanischen Sprache. Neben Episoden des Ramajan und Mahabharat in genauen metrischen Übersetzungen aus dem Originaltext und einigen Abschnitten aus den Veda's. Frankfurt 1816.

Bopp-Symposium 1992 [1994] = Bopp-Symposium 1992 der HumboldtUniversität zu Berlin, Akten der Konferenz von 1992 aus Anlaß von Franz Bopps zweihundertjährigem Geburtstag am 14. 9. 1991, hrsg. von R. Sternemann. Heidelberg 1994.

Boretzky Historische Linguistik $1977=$ N. Boretzky Einführung in die historische Linguistik. Reinbek bei Hamburg (Rowohlt) 1977.

Bornemann / Risch Gr. Gr. 1978 = E. Bornemann und E. Risch Griechische Grammatik. 2. Aufl. Frankfurt 1978. Dazu vgl. W. Kastner Sprachgeschichtliche Erläuterungen zur Griechischen Grammatik. Frankfurt 1988. 
Bräuer Slav. Sprachw. I 1961 II 1969 III $1969=$ H. Bräuer Slavische Sprachwissenschaft. 3 Bände. Berlin 1961-1969: I (Einleitung, Lautlehre) 1961, II (Formenlehre, 1. Teil) 1969, III (Formenlehre, 2. Teil) 1969 (= Sammlung Göschen Nr. 1191, 1192 und 1236).

Brandenstein / Mayrhofer Altpersisch 1964 = W. Brandenstein und M. Mayrhofer Handbuch des Altpersischen. Wiesbaden 1964. Dazu s.u. Mayrhofer Supplement 1978.

Braunmüller Skandinav. Sprachen $1991=\mathrm{K}$. Braunmüller Die skandinavischen Sprachen im Überblick. Tübingen 1991 (= UTB 1635). Rez.: J. A. Harđarson in PFU 41998 p. 85-96.

Braune / Ebbinghaus Got. Gr. 1981= W. Braune Gotische Grammatik. 19. Aufl., neu bearbeitet von E. A. Ebbinghaus. Tübingen 1981.

Brixhe Grec anatolien $1987=$ C. Brixhe Essai sur le grec anatolien au début de notre ère. Nouvelle édition revue et augmentée, Nancy 1987.

Brixhe Koiné I 1993 = La Koiné grecque antique I: Une langue introuvable, hrsg. von C. Brixhe. Nancy 1993.

Brixhe Pamphylie $1976=\mathrm{C}$. Brixhe Le dialecte grec de Pamphylie, Documents et grammaire. Paris 1976.

Brixhe Phonétique et phonologie $1996=\mathrm{C}$. Brixhe Phonétique et phonologie du grec ancien I, Quelques grandes questions. Paris 1996 (= Bibliothèque des Cahiers de l' Institut de Linguistique de Louvain Nr. 82).

Brixhe / Lejeune Paléo-phrygien $1984=$ C. Brixhe Corpus des inscriptions paléo-phrygiennes. 2 Bände Paris 1984.

Brugmann Einfacher Satz $1925=$ K. Brugmann Die Syntax des einfachen Satzes im Indogermanischen. Berlin / Leipzig 1925.

Brugmann Grundriß I 1897 II-1 1906 II-2 1911 II-3 1916 = K. Brugmann [und B. Delbrück] Grundriß der vergleichenden Grammatik der indogermanischen Sprachen. Zweite Bearbeitung. Straßburg: Band I 1897 (Einleitung, Lautlehre: die erste Hälfte p. 1-622; die zweite Hälfte p. 623-1098; unveränderter Neudruck der beiden Hälften 1930); Band II mit drei Teilen, nämlich II-1 1906 (Allgemeines, Zusammensetzung [Komposita], Nominalstämme: p. 1-688), II-2 1911 (Zahlwörter, Genera, Kasus- und Numerusbildung, Pronomina, Adjektiv, Adverbia, Präpositionen: p. 1-997) und II-3 1916 (Verbum finitum und infinitum, Partikeln im einfachen Satz: die erste Hälfte p. 1-496, die zweite Hälfte p. 497-1052). Nachdruck Berlin / New York 1967. Zu den Bänden III V s.u. Delbrück Vgl. Syntax.

Brugmann Kurze vgl. Gramm. 1902-1904 = K. Brugmann Kurze vergleichende Grammatik der indogermanischen Sprachen. Straßburg: 1. Lie- 
ferung (Einleitung und Lautlehre: p. 1-280) 1902, 2. Lieferung (Lehre von den Wortformen und ihrem Gebrauch: p. 281-622) 1903, 3. Lieferung (Lehre von den Satzgebilden und Sach- und Wörterverzeichnis: p. 623-677) 1904. Unveränderter Neudruck Leipzig 1933, Nachdruck 1970.

Brugmann / Thumb Gr. Gr. $1913=$ K. Brugmann Griechische Grammatik. 4. Aufl. von A. Thumb. München 1913.

Brunner Aengl. Gr. $1965=\mathrm{K}$. Brunner Altenglische Grammatik nach der angelsächsischen Grammatik von Eduard Sievers. 3. Aufl. Tübingen 1965.

Bryce Lycians $1986=$ T. R. Bryce The Lycians in Literary and Epigraphic Sources. Kopenhagen 1986 (= Band I des Werkes von T. R. Bryce und J. Zahle The Lycians, A Study of Lycian History and Civilisation to the Conquest of Alexander the Great).

Bryce Kingdom $1998=\mathrm{T}$. Bryce The Kingdom of the Hittites. Oxford 1998.

$\mathrm{BSL}=$ Bulletin de la société de linguistique. Paris.

Buchholz / Fiedler Alban. Gramm. 1987 = O. Buchholz und W. Fiedler Albanische Grammatik. Leipzig 1987.

Buck Comparative Grammar $1963=$ C. D. Buck Comparative Grammar of Greek and Latin. 9. Aufl. Chicago / London 1963.

Buck Dict. of select. Syn. $1949=$ C. D. Buck A Dictionary of Selected Synonyms in the principal Indo-European Languages. Chicago 1949.

Buck Greek Dialects $1955=$ C. D. Buck The Greek Dialects, Grammar, Selected Inscriptions, Glossary. 2. Aufl. Chicago / London 1955 (und Nachdruck).

Bühler Sprachtheorie $1934=$ K. Bühler Sprachtheorie. Die Darstellungsfunktion der Sprache. Jena 1934.

Burkert Griechische Religion $1977=$ W. Burkert Griechische Religion der archaischen und klassischen Epoche. Stuttgart 1977. Engl. Übersetzung: Greek Religion. Cambridge / Mass. 1985.

Burkert Orientalisierende Epoche $1984=$ W. Burkert Die orientalisierende Epoche in der griechischen Religion und Literatur, vorgetragen am 8. Mai 1982, Heidelberg 1984 (= SbHAW 1984 / 1). Engl. Übersetzung: The Orientalizing Revolution, Near Eastern Influence on Greek Culture in the Early Archaic Age. Cambridge / Mass. 1992.

Bussmann Lexikon d. Sprachw. 2. Aufl. $1990=$ H. Bussmann Lexikon der Sprachwissenschaft. 2., völlig neu bearbeitete Aufl. Stuttgart1990.

Bynon Hist. Linguistics 1977 bzw. Hist. Linguistik $1981=$ Th. Bynon Historical Linguistics. Cambridge 1977 [und Nachdrucke]) = Histori- 
sche Linguistik, Eine Einführung. München 1981 (= überarbeitete und erweiterte Ausgabe des engl. Originals). Rez. der dt. Ausgabe: J. Udolph in IF 961991 p. 258-262.

Campanile Ricostruzione $1990=$ E. Campanile La ricostruzione della cultura indoeuropea. Pisa 1990.

Cas et prépositions en grec ancien $1994=$ Cas et prépositions en grec ancien, Actes du colloque international de Saint-Étienne 1993, hrsg. von B. Jacquinod. Saint-Étienne 1994.

Cardona Them. Aorists $1960=$ G. Cardona The Indo-European Thematic Aorists. Ann Arbor 1960.

Cario 1993 [1994] = La decifrazione del cario, Atti del $1^{\circ}$ Simposio Internazionale 1993 in Rom, hrsg. von M. E. Giannotta, R. Gusmani, L. Innocente, D. Marcozzi, M. Salvini, M. Sinatra, P. Vannicelli. Rom 1994 (= Consiglio Nazionale delle Ricerche, Monografie Scientifiche).

Carling Lokale Kasus im Toch. $2000=$ G. Carling Die Funktionen der lokalen Kasus im Tocharischen. Berlin / New York 2000.

Carruba Palaisch $1970=0$. Carruba Das Palaische: Texte, Grammatik, Lexikon. Wiesbaden 1970 (= StBoT 10).

Causatives and Transitivity $1993=$ Causatives and Transitivity, hrsg. von B. Comrie and M. Polinsky. Amsterdam / Philadelphia 1993 (=Studies in Language Companion Series 23).

$\mathrm{CEG}=$ Chronique d'étymologie grecque, s.u. bei Chantraine DELG.

Celtic Languages 1992 = The Celtic Languages, hrsg. von D. Macaulay. Cambridge 1992 (in der Reihe Cambridge Language Surveys).

Celtic Languages 1993 = The Celtic Languages, hrsg. von M. J. Ball zusammen mit J. Fife. London / New York 1993 (Routledge).

CFS $=$ Cahiers Ferdinand de Saussure

Chadwick Documents $1973=$ J. Chadwick Documents in Mycenaean Greek. 2. Aufl. Cambridge 1973.

Chantraine DELG 1968-1980 = P. Chantraine Dictionnaire étymologique de la langue grecque, Histoire des mots. Paris I 1968, II 1970, III 1974, IV / 1 1977, IV / 2 1980. Chantraine DELG ist seit 1999 als einbändiger Nachdruck in leicht verkleinertem Format mit einem Supplément (= CEG 1-3, s.u.) erhältlich. Reichhaltige Addenda und Corrigenda finden sich u.a. bei Ruijgh Scripta Minora I 1991 p. 571-632 und bei Szemerényi Scripta Minora III 1987 p. 1559-1607. Hinzuzuziehen ist jetzt auch die laufende Chronique d'étymologie grecque (= CEG), hrsg. von A. Blanc, Ch. de Lamberterie und J. L. Perpillou: CEG 1 in RPh 701996 [1997] p. 103-138; CEG 2 in RPh 711997 [1998] p.147-179; 
CEG 31998 [1999] in RPh 721998 [1999] p. 119-148; CEG 41999 [2000] in RPh 731999 [2000] p. 79-108.

Chantraine Formation des noms $1933=\mathrm{P}$. Chantraine La formation des noms en grec ancien. Paris 1933 (und Nachdrucke).

Chantraine Gramm. hom. I 1958 II $1953=$ P. Chantraine Grammaire homérique. 2 Bände Paris: I (Phonétique et Morphologie) 3. Aufl. 1958, II (Syntaxe) 1. Aufl. 1953.

Chantraine Morphologie 2. Aufl. $1961=$ P. Chantraine Morphologie historique du grec. 2. Aufl. Paris 1961 (und Nachdrucke).

$\mathrm{CHD}=$ The Hittite Dictionary of the Oriental Institute of the University of Chicago, hrsg. von H. G. Güterbock und H. A. Hoffner. Heute verfügbar sind: L-N 1989; P-1 (pa - parā) 1994; P-2 (parā - (UZU)pattar A) 1995; P-3 ((UZU)pattar A - putkiya-) 1997.

CILL s.u. IKLL.

Clackson Armenian and Greek $1994=$ J. Clackson The Linguistic Relationship between Armenian and Greek. Oxford / Cambridge 1994. Rez.: Ch. de Lamberterie in Kratylos 421997 p. 71-78.

CMCS $=$ Cambrian Medieval Celtic Studies.

Collinge Laws $1985=\mathrm{N}$. E. Collinge The laws of Indo-European. Amsterdam / Philadelphia 1985. Eine Bestandesaufnahme bis 1998 von dems. in JIES 271999 p. 355-377.

Coll. Myc. 1975 [1979] = Colloquium Mycenaeum, Actes du sixième Colloque International 1975 in Chaumont, hrsg. von E. Risch und H. Mühlestein. Neuchâtel / Genf 1979.

Colloque E. Benveniste I / II 1983 [1984] = E. Benveniste aujourd'hui, Actes du colloque Tours 1983, hrsg. von G. Serbat. 2 Bände Paris 1984.

Colloque P. Chantraine 1989 [1992] = La langue et les textes en grec ancien, Actes du colloque P. Chantraine Grenoble 1989, hrsg. von F. Létoublon. Amsterdam 1992.

Colloquium Caricum 1997 [1998] = Colloquium Caricum, Akten der Internationalen Tagung über die karisch-griechische Bilingue von Kaunos 1997 in Feusisberg bei Zürich, publiziert als Kadmos 371998.

Coll. Raur. 21991 = Colloquium Rauricum, Band 2, Zweihundert Jahre Homer-Forschung, Rückblick und Ausblick, hrsg. von J. Latacz. Stuttgart / Leipzig 1991. Rez.: R. Schmitt in Kratylos 381993 p. 73-79.

Compendium Ling. Iran. $1989=$ Compendium Linguarum Iranicarum, hrsg. von R. Schmitt. Wiesbaden 1989.

Complétives 1998 [1999] = Les complétives en grec ancien, Colloque Saint-Étienne 1998, hrsg. von B. Jacquinod. Saint-Étienne 1999. 
Convegno Udine (Restsprachen) 1981 [1983] = Le lingue indoeuropee di frammentaria attestazione, Die indogermanischen Restsprachen, Atti del Convegno della Società Italiana di Glottologia e della Idg. Gesell. 1981 in Udine, hrsg. von E. Vineis. Pisa 1983.

Coseriu Synchronie, Diachronie 1974 = E. Coseriu Synchronie, Diachronie und Geschichte, Das Problem des Sprachwandels. München 1974.

Cotticelli-Kurras Heth. 'sein' $1991=$ P. Cotticelli-Kurras Das hethitische Verbum 'sein'. Heidelberg 1991 (= Texte der Hethiter 18).

Cowgill Einleitung $1986=$ W. Cowgill Einleitung, ins Deutsche übersetzt und bibliographisch bearbeitet von A. Bammesberger und $\mathrm{M}$. Peters = 1. Halbband von Band I der Idg. Gr. (s.u.). Heidelberg 1986. $\mathrm{CR}=$ Classical Review.

$\mathrm{CRAI}=$ Comptes rendus de l'Académie des Inscriptions et Belles-Lettres. Crystal Enzyklopädie 1995 = D. Crystal Die Cambridge-Enzyklopädie der Sprache. Frankfurt / New York 1995 (= Dt. Übersetzung des engl. Originals The Cambridge Encyclopedia of Language. Cambridge / New York / Melbourne 1987).

Darms Vrłddhi 1978 = G. Darms Schwäher und Schwager, Hahn und Huhn. Die Vrddhi-Ableitung im Germanischen. München 1978 (= MSS Beiheft 9, Neue Folge).

De Boel Goal accusative $1988=\mathrm{G}$. De Boel Goal accusative and object accusative in Homer. A contribution to the theory of transitivity. Brüssel 1988;

Debrunner Gr. Wortbildung $1917=$ A. Debrunner Griechische Wortbildungslehre. Heidelberg 1917.

Debrunner s. auch unter Schwyzer / Debrunner und Wackernagel / Debrunner.

Degrassi Inscriptiones I-II 1965-1972 = A. Degrassi Inscriptiones Latinae Liberae Rei Publicae. 2. Aufl. Florenz: I (mit Nr. 1-503) 1965 (und Nachdrucke); II (mit Nr. 504-1277 und Indizes) 1972. Dazu ders. Imagines. Berlin 1965.

Delaunois Syntaxe $1988=$ M. Delaunois Essai de syntaxe grecque classique, Réflexions et recherches. Leuven / Bruxelles 1988.

Delbrück Ablativ Localis Instrumentalis $1867=$ B. Delbrück Ablativ Localis Instrumentalis. Berlin 1867.

Delbrück Ai. Syntax $1888=$ B. Delbrück Altindische Syntax. Halle a. d. S. 1888 (Nachdruck Darmstadt 1968).

Delbrück Conj. und Opt. $1871=$ B. Delbrück Der Gebrauch des Conjunktivs und Optativs im Sanskrit und Griechischen. Halle 1871. 
Delbrück Einleitung $1904=$ B. Delbrück Einleitung in das Studium der indogermanischen Sprachen. 4. Aufl. Leipzig 1904.

Delbrück Gr. Syntax $1879=$ B. Delbrück Die Grundlagen der griechischen Syntax. Halle a.d.S. 1879.

Delbrück Synkretismus 1907 = B. Delbrück Synkretismus. Ein Beitrag zur germanischen Kasuslehre. Straßburg 1907.

Delbrück Vgl. Syntax I 1893 II 1897 III 1900 = B. Delbrück Vergleichende Syntax der indogermanischen Sprachen. 3 Teile, Straßburg: I 1893, II 1897, III 1900. In Brugmanns Grundriß werden die 3 Teile als Bände III - V dazugezählt. Sie sind 1967 zusammen mit Brugmanns Grundriß wieder abgedruckt worden.

DELG s.o. Chantraine DELG.

DELL s.u. Ernout / Meillet DELL.

Demiraj (B.) Alban. Etymologien 1997 = B. Demiraj Albanische Etymologien, Untersuchungen zum albanischen Erbwortschatz. Amsterdam / Atlanta 1997. Rez.: G. Bonnet in BSL 93 / 21998 p. 256-262.

Demiraj (S.) Albanisch $1993=$ S. Demiraj Historische Grammatik der albanischen Sprache. Wien 1993.

Denniston Greek Particles 1954 = J. D. Denniston The Greek Particles. 2. Aufl., korrigiert von K. J. Dover. Oxford 1954.

Der Neue Pauly $=$ DNP $=$ Enzyklopädie der Antike, hrsg. von H. Cancik u. H. Schneider. Stuttgart: Mir vorliegend Band 1 (A - Ari) 1996; Band 2 (Ark - Ci) 1997; Band 3 (Cl - Epi) 1997; Band 4 (Epo - Gro) 1998; Band 5 (Gru - Iug) 1998; Band 6 (Iul - Lee) 1999; Band 7 (Lef - Men) 1999; Band 8 (Mer - Op) 2000; Band 9 (Or - Poi) 2000; Band 10 (Pol Sal) 2001. Ferner bereits erschienen Rezeptions- und Wissenschaftsgeschichte mit Band 13 (A-Fo) 1999 und Band 14 (Fr - Ky) 2000.

Deutschsprachige Keltologen 1992 [1993] = Akten des Ersten Symposiums deutschsprachiger Keltologen 1992 Gosen bei Berlin, hrsg. von M. Rockel und St. Zimmer. Tübingen 1993. Ferner s.u. KeltologenSymposium II 1997 [1999].

Devoto Lingua di Roma $1940=$ G. Devoto Storia della lingua di Roma. Bologna 1940 (Nachdruck 1944, ferner 1983 mit Premessa von A. L. Prosdocimi; deutsche Übersetzung von I. Opelt unter dem Titel „Geschichte der Sprache Roms“. Heidelberg 1968).

$\mathrm{DGE}=$ Diccionario griego-español. Madrid, unter der Leitung von F. R. Adrados. Band I ( $\alpha$ - $\dot{\alpha} \lambda \lambda \dot{\alpha})$ 1980. Inzwischen steht das Werk mit Band

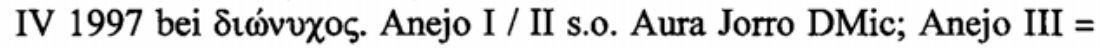
Repertorio bibliográfico de la lexicografia griega 1998. 
Diachrony within Synchrony 1990 [1992] = Diachrony within Synchrony: Language History and Cognition, Papers from the International Symposium 1990 in Duisburg, hrsg. von G. Kellermann und M. D. Morrissey. Frankfurt usw. 1992 (= Duisburger Arbeiten zur Sprach- und Kulturwissenschaft 14).

Dialectes indo-aryennes 1986 [1989] = Dialectes dans les littératures indo-aryennes, hrsg. von C. Caillat. Paris 1989.

Dialectologica Graeca 1991 [1993] = Dialectologica Graeca, Actas del II Coloquio Internacional de Dialectología Griega Madrid 1991, hrsg. von E. Crespo, J. L. García Ramón, A. Striano. Madrid 1993. Zum III. Kolloquium vgl. unten Katà diálekton 1996 [1999]. Die Akten des I. Kolloquium (Rencontre internationale) von Nancy / Pont-à-Mousson sind in Verbum 101987 publiziert.

Dialektologie 1198221983 = Ein Handbuch zur deutschen und allgemeinen Dialektforschung, hrsg. von W. Besch, U. Knoop, W. Putschke, H. E. Wiegand. Berlin / New York. 2 Halbbände: 1 1982; 2 1983 (= HSK 1.1 und 1.2).

Diehl Altlat. Inschriften $1965=$ E. Diehl Altlateinische Inschriften, mit Indizes. 5. Aufl. Berlin 1964 (= Kleine Texte, begründet von H. Lietzmann, Nr.38 / 40).

Di Giovine s.u. Giovine.

Dionysios Thrax (2. Jh. v. Chr.) Grammatik = La grammaire de Denys le Thrace, traduite et annotée par Jean Lallot. 2. Auflage Paris 1998.

Disterheft Infinitive $1977=\mathrm{D}$. Disterheft The Syntax of the Infinitive in Indo-European: Evidence from Indo-Iranian, Celtic, and Hittite. Ph.-D. Diss. University of California, Los Angeles 1977 (Mikrofilm Ann Arbor 1979).

$\mathrm{DNP}=$ s.o. Der Neue Pauly.

Dobias-Lalou Cyrène $2000=$ C. Dobias-Lalou Le dialecte des inscriptions grecques de Cyrène. Paris 2000.

Dressler Verb. Pluralität $1968=$ W. Dressler Studien zur verbalen Pluralität, Iterativum, Distributivum, Intensivum in der allgemeinen Grammatik, im Lateinischen und Hethitischen. Wien 1968.

dtv-Atlas Dt. Sprache 1998 = dtv-Atlas Deutsche Sprache 1998. München 1. Aufl. 1978, 12. Aufl. 1998.

Dubois Arcadien $1986=\mathrm{L}$. Dubois Recherches sur le dialecte arcadien. Louvain-La-Neuve 1986: I (Grammaire), II (Corpus dialectal), III (Notes, Index, Bibliographie).

Duden Grammatik 1995 = Der Duden in 12 Bänden, Bd. 4. Grammatik der deutschen Gegenwartssprache, 5., völlig neu bearbeitete und er- 
weiterte Auflage, hrsg. und bearbeitet von G. Drosdowski in Zusammenarbeit mit P. Eisenberg, H. Gelhaus, H. Henne, H. Sitta und H. Wellmann. Mannheim / Leipzig / Wien / Zürich 1995.

Egetmeyer Wörterbuch 1992 = M. Egetmeyer Wörterbuch zu den Inschriften im kyprischen Syllabar. Berlin 1992.

Egli Gelenkheteroklisie 1954 = J. Egli Heteroklisie im Griechischen mit besonderer Berücksichtigung der Fälle von Gelenkheteroklisie. Zürich 1954.

Eichner Numeralia $1982=\mathrm{H}$. Eichner Studien zu den indogermanischen Numeralia (2-5). (Ungedruckte) Habilitationsschrift Regensburg 1982.

Einhauser Junggrammatiker 1989 = E. Einhauser Die Junggrammatiker, Ein Problem für die Sprachwissenschaftsgeschichtsforschung. Trier 1989.

Ernout Recueil $1947=$ A. Ernout Recueil de textes latins archaïques, Textes épigraphiques et littéraires. 2. Aufl. Paris 1947 (und Nachdrucke).

Ernout $/$ Meillet DELL 1959 = A. Ernout und A. Meillet Dictionnaire étymologique de la langue latine. Histoire des mots. 4. éd., rev., corr. et augm. d'un index. Paris 1959.

Ethnogenese 1985 = Studien zur Ethnogenese, Abhandlungen der Rheinisch-Westfälischen Akademie der Wissenschaften Band 72. Opladen 1985.

Etruschi e Roma 1979 [1981] = Gli Etruschi e Roma, Atti dell' incontro di studio in onore di Massimo Pallottino Rom 1979, hrsg. von G. Colonna. Rom 1981. Rez.: D. Steinbauer in GGA 2351983 p. 210-232.

Etrusker 1985 = Die Etrusker, hrsg. von M. Christofani. Stuttgart / Zürich 1985.

Etter Fragesätze 1985 = A. Etter Die Fragesätze im Rgveda. Berlin / New York 1985. Rez.: J. S. Klein in Kratylos 331988 p. 79-83.

Etymologisches Wörterbuch 1983 = Das etymologische Wörterbuch, Fragen der Konzeption und Gestaltung, hrsg. von A. Bammesberger. Regensburg 1983 (= Eichstätter Beiträge 8).

Euler Gemeinsamkeiten 1979 = W. Euler Indoiranisch-griechische Gemeinsamkeiten der Nominalbildung und deren indogermanische Grundlagen. Innsbruck 1979 (= IBS Nr. 30).

Evidence for Laryngeals 1965 = Evidence for Laryngeals, hrsg. von W. Winter. London / The Hague / Paris 1965.

EWAhd $=$ Etymologisches Wörterbuch des Althochdeutschen. Göttingen / Zürich. I (-a - bezzisto) 1988 von A. L. Lloyd und O. Springer; II (bî - 
ezzo) 1998 von A. L. Lloyd, R. Lühr und O. Springer. Zu Band I gehören ferner als eigenes Heft mit Wörterverzeichnissen.

EWAia s.u. Mayrhofer EWAia.

Explanation in Historical Linguistics $1992=$ Explanation in Historical Linguistics, hrsg. von G. W. Davis und G. K. Iverson. Amsterdam / Philadelphia 1992 (= Amsterdam Studies in the Theory and History of Linguistic Science, IV Current Issues in Linguistic Theory 84).

Fachtagung Berlin 1983 [1985] = Grammatische Kategorien, Funktion und Geschichte, Akten der VII. Fachtagung der Idg. Gesellschaft 1983 in Berlin, hrsg. von B. Schlerath. Wiesbaden 1985.

Fachtagung Bern 1969 [1973] = Indogermanische und allgemeine Sprachwissenschaft, Akten der IV. Fachtagung der Idg. Gesellschaft 1969 in Bern, hrsg. von G. Redard. Wiesbaden 1973.

Fachtagung Innsbruck 1961 [1962] = Akten der II. Fachtagung der Idg. Gesellschaft 1961 in Innsbruck. Innsbruck 1962.

Fachtagung Innsbruck 1996 [1998] = Sprache und Kultur der Indogermanen, Akten der X. Fachtagung der Idg. Gesellschaft 1996 in Innsbruck. Innsbruck 1998 (= IBS Nr. 93).

Fachtagung Leiden 1987 [1992] = Relative Chronologie, Akten der VIII. Fachtagung der Idg. Gesellschaft 1987 in Leiden, hrsg. von R. S. P. Beekes. Innsbruck 1992. Rez.: B. Forssman in Kratylos 391994 p. 4855 (p. 53-55 verdienstvolles Wortverzeichnis als kleiner Ersatz für das fehlende Register).

Fachtagung Regensburg 1973 [1975] = Flexion und Wortbildung, Akten der V. Fachtagung der Idg. Gesellschaft 1973 in Regensburg, hrsg. von H. Rix. Wiesbaden 1975.

Fachtagung Tocharisch Berlin 1990 [1994] = Tocharisch, Akten der Fachtagung der Idg. Gesellschaft 1990 in Berlin, hrsg. von B. Schlerath. Reikjavík 1994 (= TIES, Suppl. Ser. 4).

Fachtagung Wien 1978 [1980] = Lautgeschichte und Etymologie, Akten der VI. Fachtagung der Idg. Gesellschaft 1978 in Wien, hrsg. von M. Mayrhofer, M. Peters, O. E. Pfeiffer. Wiesbaden 1980.

Fachtagung Zürich 1992 [1994] = Früh-, Mittel-, Spätindogermanisch, Akten der IX. Fachtagung der Idg. Gesellschaft 1992 in Zürich, hrsg. von G. E. Dunkel, G. Meyer, S. Scarlata, Chr. Seidl. Wiesbaden 1994. Rez.: J. S. Klein in Kratylos 421997 p. 24-32.

Feist Got. Wörterbuch $1939=$ S. Feist Vergleichendes Wörterbuch der gotischen Sprache. 3., neubearb. u. verm. Aufl. Leiden 1939. S. auch Lehmann Gothic Etymological Dictionary 1986. 
Feist Indogermanen $1913=$ S. Feist Kultur, Ausbreitung und Herkunft der Indogermanen. Berlin 1913.

Floreant Studia Mycenaea 1995 [1999] = Floreant Studia Mycenaea, Akten des X. Internationalen Mykenologischen Colloquiums Salzburg 1995, hrsg. von S. Deger-Jalkotzy, S. Hiller und O. Panagl. 2 Bände, Wien 1999 (= Denkschriften 274, Österr. Ak. der Wissenschaften).

FoL $=$ Folia Linguistica.

Formazione dell' Europa linguistica 1993 = La formazione dell' Europa linguistica, Le lingue d'Europa tra la fine del I e del II millennio, hrsg. von E. Banfi. Florenz 1993. Darin u.a. Le lingue germaniche von M. Meli; Le lingue slave von A. Cantarini; Le lingue baltiche von P. U. Dini; Le lingue celtiche von P. Cuzzolin; La lingua greca von E. Banfi; La lingua albanese von S. Demiraj.

Forssman Pindar 1966 = B. Forssman Untersuchungen zur Sprache Pindars. Wiesbaden 1966.

Forssman s.auch unten Hoffmann / Forssman.

Fraenkel Lit. etym. Wörterbuch 1962-1965 = E. Fraenkel Litauisches etymologisches Wörterbuch. Heidelberg 1962-1965.

Fraenkel Syntax der lit. Kasus 1928 = E. Fraenkel Syntax der litauischen Kasus. Kaunas 1928.

Fraenkel Syntax der lit. Postpositionen und Präpositionen $1929=\mathrm{E}$. Fraenkel Syntax der litauischen Postpositionen und Präpositionen. Heidelberg 1929.

Friedrich (J.) Elementarbuch I $1960=$ J. Friedrich Hethitisches Elementarbuch. I (Kurzgefaßte Grammatik). 2. Auflage 1960.

Friedrich (J.) Kleinas. Sprachdenkmäler 1932 = J. Friedrich Kleinasiatische Sprachdenkmäler. Berlin 1932.

Friedrich (J.) / Kammenhuber HW = J. Friedrich Hethitisches Wörterbuch. 2., völlig neubearbeitete Auflage von A. Kammenhuber auf der Grundlage der edierten hethitischen Texte. Heidelberg. Lief. 11974. Stand Ende 1998: Lief. 13 (H) 1998.

Friedrich (P.) Syntax 1975 = P. Friedrich Proto-Indo-European Syntax: The Order of Meaningful Elements. Washington 1975 (= JIES, Monograph 1).

Frigi e Frigio 1995 [1997] = Frigi e Frigio, Atti del $1^{\circ}$ Simposio Internazionale Rom 1995, hrsg. von R. Gusmani, M. Salvini, P. Vannicelli. Rom 1997 (= Consiglio Nazionale delle Ricerche, Monografie Scientifiche).

Frisian Runes 1994 [1996] = Frisian Runes and Neighbouring Traditions, Proceedings of the First International Symposium on Frisian Runes at 
the Fries Museum 1994 in Leeuwarden, hrsg. von T. Looijenga und A. Quak. Amsterdam 1996 (= Amsterdamer Beiträge zur älteren Germanistik, Band 45).

Frisk GEW 1960-1972 = H. Frisk Griechisches etymologisches Wörterbuch. Heidelberg 3 Bände 1960-1972: I (A - Ko) 1960, II (Kp - $\Omega$ ) 1972, III (Nachträge, Wortregister, Corrigenda, Nachwort) 1972. Dazu Nachdrucke.

Fritz Lokalpartikel $1997=$ M. Fritz Die syntaktischen und semantischen Relationen der Lokalpartikeln mit drei Kasus bei Homer. Berlin (= Diss. FU) 1997.

FS = Festschrift: Zur Vereinfachung wird nur der Name des Geehrten und das Erscheinungsdatum der Schrift genannt. Eine größere Liste von Festschriften findet sich bei Mayrhofer EWAia I p. XXV - XXX und II p. XIII - XV. Einige Festschriften neueren Datums werden hier extra verzeichnet.

FS Beekes 1997 = Sound Law and Analogy, Papers in Honor of R. S. P. Beekes, hrsg. von A. Lubotsky. Amsterdam / Atlanta 1997.

FS Belardi I 1994 = Miscellanea di studi linguistici in onore di Walter Belardi, hrsg. von P. Cipriano, P. di Giovine, M. Mancini. Rom Band I (Linguistica indoeuropea e non indoeuropea) 1994.

FS Dihle 1993 = Philanthropia kai Eusebeia, Festschrift für Albrecht Dihle zum 70. Geburtstag, hrsg. von G. W. Most, H. Petersmann und A. M. Ritter. Göttingen 1993.

FS Forssman 1999 = gering und doch von Herzen, 25 indogermanistische Beiträge B. Forssman zum 65. Geburtstag, hrsg. von J. Habisreitinger, R. Plath, S. Ziegler. Wiesbaden 1999.

FS Hamp 1990 = Celtic Language, Celtic Culture: A Festschrift for Eric P. Hamp, hrsg. von A. T. E. Matonis und D. F. Melia. Van Nuys, California 1990.

FS Hamp I / II 1997 = Festschrift for Eric P. Hamp. Washington 1997 (= JIES Monographs 23 und 25).

FS Hoenigswald 1987 = Festschrift for Henry M. Hoenigswald, hrsg. von G. Cardona und N. H. Zide. Tübingen 1987.

FS Knobloch 1985 = Sprachwissenschaftliche Forschungen, Festschrift für J. Knobloch, hrsg. von H. M. Ölberg, G. Schmidt. Innsbruck 1985 (= IBS 23).

FS Kuiper 1968 = Pratidānam, Indian, Iranian and Indo-European Studies Presented to Franciscus Bernardus Jacobus Kuiper on his sixtieth birthday, hrsg. von J. C. Heesterman, G. H. Schokker, V. I. Subramoniam. Den Haag / Paris 1968. 
FS Lejeune 1978 = Etrennes de septantaine, Travaux de linguistique et de grammaire comparée offerts à Michel Lejeune, hrsg. von einer Gruppe seiner Schüler. Paris 1978 (= Études et Commentaires 91).

FS Meid *60 1989 = Indogermanica Europea, Festschrift für W. Meid zum 60. Geburtstag, hrsg. von K. Heller, O. Panagl, J. Tischler. Graz 1989.

FS Meid *70 1999 = Studia Celtica et Indogermanica, Festschrift für W. Meid zum 70. Geburtstag, hrsg. von P. Anreiter, E. Jerem. Budapest 1999.

FS Narten $2000=$ Anusantatyai, Festschrift J. Narten, hrsg. von A. Hintze, E. Tichy. Dettelbach 2000 (= MSS, Beiheft 19. N.F.).

FS Neumann 1982 = Serta Indogermanica, Festschrift für Günter Neumann zum 60. Geburtstag, hrsg. von J. Tischler. Innsbruck 1982.

FS Otten $1973=$ Festschrift Heinrich Otten, hrsg. von E. Neu und Chr. Rüster. Wiesbaden 1973.

FS Otten 1988 = Documentum Asiae Minoris Antiquae. Festschrift für Heinrich Otten zum 75. Geburtstag, hrsg. von E. Neu und Chr. Rüster. Wiesbaden 1988.

FS Palmer $1976=$ Studies in Greek, Italic, and Indo-European Linguistics offered to Leonard R. Palmer, hrsg. von A. Morpurgo Davies und W. Meid. Innsbruck 1976.

FS Puhvel I 1997 = Studies in Honor of J. Puhvel. I: Ancient Languages and Philology, hrsg. von D. Disterheft, M. Huld and J. Greppin. Washington 1997 (= JIES Monograph 20).

FS Ramat $1998=$ Ars Linguistica, Studi offerti a Paolo Ramat, hrsg. von G. Bernini, P. Cuzzolin, P. Molinelli. Rom 1998.

FS Risch 1986 = o-o-pe-ro-si, Festschrift für Ernst Risch zum 75. Geburtstag, hrsg. von A. Etter. Berlin / New York 1986.

FS Rix 1993 = Indogermanica et Italica, Festschrift für Helmut Rix zum 65. Geburtstag, hrsg. von G. Meiser. Innsbruck 1993.

FS Schlerath 1992 [1994] = Die Indogermanen und das Pferd, Akten des Internationalen interdisziplinären Kolloquiums an der Freien Universität Berlin, 2.-3. Juli 1992 [= Festschrift für Bernfried Schlerath], hrsg. von B. Hänsel und St. Zimmer. Budapest 1994. Kurzbericht: St. Zimmer in Ethnographisch-archäologische Zeitschrift 331992 [1993] p. 297-301.

FS Schmeja 1998 = Wort - Text - Sprache und Kultur, Festschrift für Hans Schmeja zum 65. Geburtstag, hrsg. von P. Anreiter und H. M. Ölberg. Innsbruck 1998 (= IBK 103). 
FS Schmid $1999=$ Florilegium Linguisticum, Festschrift für Wolfgang P. Schmid, hrsg. von E. Eggers, J. Becker, J. Udolph, D. Weber. Bern, Frankfurt a.M. u.a.O. 1999.

FS (K. H.) Schmidt 1994 = Indogermanica et Caucasica, Festschrift für Karl Horst Schmidt zum 65. Geburtstag, hrsg. von R. Bielmeier und R. Stempel. Berlin / New York 1994.

FS Seebold 1999 = Grippe, Kamm und Eulenspiegel, Festschrift für Elmar Seebold zum 65. Geburtstag, hrsg. von W. Schindler und J. Untermann. Berlin 1999.

FS Stimm 1982 = Fakten und Theorien, Beiträge zur romanischen und allgemeinen Sprachwissenschaft, Festschrift für Helmut Stimm zum 65. Geburtstag, hrsg. von S. Heinz und U. Wandruszka. Tübingen 1982 (= TBL 191).

FS Strunk $1995=$ Verba et structurae, Festschrift für Klaus Strunk zum 65. Geburtstag, hrsg. von H. Hettrich, W. Hock, P.-A. Mumm und N. Oettinger. Innsbruck 1995. Rez.: R. S. P. Beekes in Kratylos 421997 p. 36-39.

FS Szemerényi *65 I / II 1979 = Studies in Diachronic, Synchronic, and Typological Linguistics, Festschrift for Oswald Szemerényi, hrsg. von B. Brogyanyi. 2 Bände Amsterdam 1979.

FS Szemerényi *75 I / II 1992, III 1993 = Prehistory, History and Historiography of Language, Speech and Linguistic Theory, Papers in Honor of Oswald Szemerényi I, hrsg. von B. Brogyanyi; Historical Philology: Greek, Latin, and Romance, Papers in Honor of Oswald Szemerényi II, hrsg. von B. Brogyanyi und R. Lipp; ComparativeHistorical Linguistics: Indo-European and Finno-Ugric, Papers in Honor of Oswald Szemerényi III, hrsg. von B. Brogyanyi und R. Lipp. 3 Bände Amsterdam / Philadelphia 1992-1993 (= Current Issues in Linguistic Theory, Nr. 64, 87 und 97). Rez.: M. Egetmeyer in PFU (= PFU) 11994 [1995] p. 47-53 und p. 55-61; 41998 p. 69-76.

FS Thomas $1988=$ Studia Indogermanica et Slavica. Festgabe für Werner Thomas zum 65. Geburtstag, hrsg. von P. Kosta. München 1988.

FS Untermann 1993 = Sprachen und Schriften des antiken Mittelmeerraumes, Festschrift für Jürgen Untermann, hrsg. von F. Heidermanns, H. Rix und E. Seebold. Innsbruck 1993 (= IBS 78).

FS Watkins 1998 = Mir Curad, Studies in Honor of Calvert Watkins, hrsg. von J. Jasanoff, H. Craig Melchert, L. Oliver. Innsbruck 1998 (= IBS 92).

FS Zaic 1989 = Phonophilia, Untersuchungen zu Phonetik und Phonologie, F. Zaic zum 60. Geburtstag, hrsg. von W. Grosser. Salzburg 1989. 
Fulk Quantitative Ablaut $1986=\mathrm{R}$. D. Fulk The Origins of IndoEuropean Quantitative Ablaut. Innsbruck 1986 (= IBS 49). Rez.: G. Schmidt in Kratylos 321987 p. 37-46.

Gaedicke Accusativ im Veda $1880=$ C. Gaedicke Der Accusativ im Veda. Breslau 1880.

Gamkrelidze / Ivanov IE and IEs $1995=$ T. V. Gamkrelidze und V. V. Ivanov Indo-European and the Indo-Europeans. A Reconstruction and Historical Analysis of a Proto-Language and a Proto-Culture. 2 Bände Berlin / New York 1995. Das Werk ist die engl. Übersetzung des bereits 1984 in Tbilissi auf Russisch publizierten Werkes Indoevropejskij jazyk i indoevropejcy. Die Übersetzung von 1995 steht auf dem Stand von 1984. Rez.: M. Mayrhofer in Kratylos 421997 p. 21-24; J. Gippert in BNF 331998 p. 39-54.

Gāters Lettische Syntax 1993 = A. Gāters Lettische Syntax, Die Dainas, posthum hrsg. von H. Radtke. Frankfurt a.M. u.a.O. 1993.

Geiger Pāli 1916 = W. Geiger Pāli, Literatur und Sprache. Straßburg 1916.

Geldner RV Übersetzung 1951-1957 = Der Rig-Veda, Aus dem Sanskrit ins Deutsche übersetzt und mit einem laufenden Kommentar versehen von K. F. Geldner. 4. Bde. Leipzig 1951-1957. Die Übersetzung lag bereits 1923 vor, widrige Umstände haben sie aber erst nach dem Zweiten Weltkrieg erscheinen lassen, s. das Vorwort von J. Nobel zu Band IV p. V-VII.

Germanenprobleme in heutiger Sicht $1986=$ Germanenprobleme in heutiger Sicht, hrsg. von H. Beck. Berlin / New York 1986.

GGA = Göttingische Gelehrte Anzeigen.

Giacomelli Lingua falisca 1963 = G. Giacomelli La lingua falisca. Florenz 1963.

Giacomelli Lingua latina $1993=\mathrm{R}$. Giacomelli Storia della lingua latina. Rom 1993 (in der Reihe Guide allo studio della Civiltà romana IV. 1)

Giannakis Reduplicated Presents $1997=$ G. K. Giannakis Studies in the Syntax and Semantics of the Reduplicated Presents of Homeric Greek and Indo-European. Innsbruck 1997 (= IBS 90). Rez.: E. F. Tucker in Kratylos 452000 p. 111-116.

Giovine Perfetto I 1990 II / III 1996 = P. Di Giovine Studio sul Perfetto Indoeuropeo. Rom: Parte I 1990 (La funzione originaria del perfetto studiata nella documentazione delle lingue storiche); Parte II 1996 (La posizione del perfetto all' interno del sistema verbale indoeuropeo); Parte III 1996 (Indici); ferner dazu ders., Le lingue anatoliche e il per- 
fetto indoeuropeo: Una ,petitio principii“" ? in FS W. Belardi I. Rom 1994 p. 113-130. Rez.: J. A. Harđarson in Kratylos 462001 p. 36-44.

Gippert Infinitive $1978=$ J. Gippert Zur Syntax der infinitivischen Bildungen in den indogermanischen Sprachen. Frankfurt / Bern / Las Vegas 1978.

Gippert Iranica 1993 = J. Gippert Iranica Armeno-Iberica, Studien zu den iranischen Lehnwörtern im Armenischen und Georgischen. 2 Bände Wien 1993 (= SbÖAW Nr. 606).

Glotta $=$ Glotta. Zeitschrift für griechische und lateinische Sprache. Göttingen.

Gmür Mémoire $1986=\mathrm{R}$. Gmür Das Schicksal von F. de Saussures "Mémoire". Eine Rezeptionsgeschichte. Bern 1986. Rez.: M. Mayrhofer in Kratylos 331988 p.1-15 = Kleine Schriften II 1996 p. 271-285.

Godel Classical Armenian $1975=\mathrm{R}$. Godel An Introduction to the Study of Classical Armenian. Wiesbaden 1975.

Gonda Indo-European Moods $1956=\mathrm{J}$. Gonda The Character of the IndoEuropean Moods. Wiesbaden 1956. Rez.: E. Risch in Gnomon 331961 p. 174-178; J. Kuryłowicz und Hj. Seiler in Kratylos 11956 p. 123135.

GORILA I - V 1976-1985 = L. Godart, J.-P. Olivier Recueil des inscriptions en linéaire A. Paris: I (Tablettes éditées avant 1970) 1976; II (Nodules, Scellés et rondelles édités avant 1970) 1979; III (Tablettes, nodules et rondelles édités en 1975 et 1976) 1976; IV (Autres documents) 1982; V (Addenda, Corrigenda, Concordances, Index et planches des signes) 1985 (= École Française d'Athènes, Études Crétoises Nr. 21, 1-5).

Gotō I. Präsensklasse 1987 = T. Gotō Die "I. Präsensklasse" im Vedischen. Untersuchung der vollstufigen thematischen Wurzelpräsentia. Wien 1987. Die 2. Aufl. 1996 bringt Verbesserungen und Nachträge. Rez. der 2. Aufl.: St. W. Jamison in Kratylos 341989 p. 59-65.

Gotō Materialien Nr. 1-3 1990 Nr. 4-7 1991 Nr. 8-15 1993 Nr. 16-29 $1997=$ T. Gotō, Materialien zu einer Liste altindischer Verbalformen. Bulletin of the National Museum of Ethnology, Osaka (Japan): Nr. 1-3 (1. $\left.a m^{i}, 2 . a y / i, 3 . a s / s\right)$ in Vol. $15 / 41990$ p. 987-1012; Nr. 4-7 (4. dogh/dugh/doh/duh, 5. sav/su, 6. ${ }^{1} s a v i / s \bar{u}, 7 .{ }^{2}(s a v i /) s \bar{u}$ in Vol. $16 / 3$ 1991 p. 681-707; Nr. 8-15 (8. ard/rd, 9. is , 10. ukș, 11. eș/iș, 12. eși/iși 13. ok/ocluc, 14. kan, 15. vaks/uks) in Vol.18 / 11993 p. 119-141; Nr. 16-29 (16. chad, 17. chand/chad, 18. chard/chrd, 19. dagh/dhag, 20. dveș/dvis, 21. bandh/badh, 22. ${ }^{1} \mathrm{man}, 23 .{ }^{2} \mathrm{man}, 24 . \mathrm{mna}, 25 .{ }^{1} \mathrm{yav} / y u$, 
26. ${ }^{2} y a v / y u$, 27. $s a n^{i}, 28 . ~ s t a r / s t r$, 29. $s t a r^{i} /$ stṛ $)$ in Vol. $22 / 41997$ [1998] p.1001-1059.

Grammatica ittita 1992 = Per una grammatica ittita, Towards a Hittite Grammar, hrsg. von O. Carruba. Pavia 1992 (=Studia Mediterranea 7). Grassmann Wörterbuch $1873=\mathrm{H}$. Grassmann Wörterbuch zum RigVeda. Leipzig 1873 (und Nachdrucke). 6., überarbeitete und ergänzte Aufl. von M. Kozianka 1996. Rez. zur 6. Aufl.: Th. Zehnder in PFU 4 1998 p. 77-84.

Graz (125 Jahre Idg.) $2000=125$ Jahre Indogermanistik in Graz, Festband anläßlich des 125 jährigen Bestehens der Forschungs-einrichtung "Indogermanistik“ an der Karl-Franzens-Universität Graz, hrsg. von M. Ofitsch und Chr. Zinko, Graz 2000.

Greek Language in Cyprus 1988 = The History of the Greek Language in Cyprus, Proceedings of an International Symposium Larnaca 1986, hrsg. von J. Karageorghis / O. Masson. Nicosia 1988.

Greek Particles 1996 [1997] = New Approaches to Greek Particles, Proceedings of the Colloquium Amsterdam 1996, hrsg. von A. Rijksbaron. Amsterdam 1997.

Greek Personal Names I 1987 II 1994 III A 1997 = A Lexicon of Greek Personal Names, hrsg. von P. M. Fraser, E. Matthews. Oxford. Band I (The Aegean Islands, Cyprus, Cyrenaica) 1987; Band II (Attica, hrsg. von M. J. Osborne, S. G. Byrne) 1994; Band III A (The Peloponnese, Western Greece and Magna Graecia) 1997.

Größere altkelt. Sprachdenkmäler 1993 [1996] = Die größeren altkeltischen Sprachdenkmäler, Akten des Kolloquiums 1993 in Innsbruck, hrsg. von W. Meid und P. Anreiter. Innsbruck 1996 (= IBK, Sonderheft 95). Rez.: J. Uhlich in Kratylos 441999 p. 144-154.

Gr. Philologie 1997 = Einleitung in die griechische Philologie, hrsg. von H.-G. Nesselrath. Stuttgart / Leipzig 1997.

GS = Gedenkschrift; ein Verzeichnis bietet Mayrhofer EWAia I p. XXXII f., II p. XVII.

GS Brandenstein 1968 = Studien zur Sprachwissenschaft und Kulturkunde, Gedenkschrift für W. Brandenstein, hrsg. von M. Mayrhofer. Innsbruck 1968 (= IBK Nr. 14).

GS Cowgill $1987=$ Studies in Memory of Warren Cowgill (1929-1985), Papers from the Fourth East Coast Indo-European Conference 1985, hrsg. von C. Watkins. Berlin / New York 1987 (= Untersuchungen zur Indogermanischen Sprach- und Kulturwissenschaft, N.F. 3).

GS Katz 2001 = Fremd und Eigen, Untersuchungen zu Grammatik und Wortschatz des Uralischen und Indogermanischen, in memoriam 
Hartmut Katz, hrsg. von H. Eichner, P.-A. Mumm, O. Panagl, E. Winkler. Wien 2001.

GS Kronasser 1982 = Investigationes Philologicae et Comparativae. Gedenkschrift für Heinz Kronasser. Wiesbaden 1982.

GS Kuryłowicz I / II 1995 = Kuryłowicz Memorial Volume, Band I, hrsg. von W. Smoczynski. Krakau 1995. Band II ist erschienen als Band 4 1995 von Linguistica Baltica. Rez. von I: A. Christol in BSL 92 / 2 1997 p. 131-135.

GS Schindler 1999 = Compositiones indogermanicae in memoriam Jochem Schindler, hrsg. von H. Eichner und H. Chr. Luschützky. Prag 1999.

GS van Windekens 1991 = Studia etymologica indoeuropea, Memoriae A. J. van Windekens (1915-1989) dicata, hrsg. von L. Isebaert. Leuven 1991.

Guiraud Phrase nominale $1962=\mathrm{Ch}$. Guiraud La phrase nominale en grec. Paris 1962.

Gusmani Lyd. Wörterbuch $1964=$ R. Gusmani Lydisches Wörterbuch. Heidelberg 1964.

Gusmani Lyd. Wb. Erg. 1986 = R. Gusmani Lydisches Wörterbuch. Ergänzungsband. Heidelberg 1986.

Haas Heth. Religion 1994 = V. Haas Geschichte der hethitischen Religion. Leiden / New York / Köln 1994.

Hackstein Sigmat. Präsensstammbildungen 1995 = O. Hackstein Untersuchungen zu den sigmatischen Präsensstammbildungen des Tocharischen. Göttingen 1995 (= HS, Ergänzungsheft Nr. 38). Rez.: J. H. W. Penney in Kratylos 431998 p. 92-96; H. Craig Melchert in TIES 9 2000 p. 145f.; G.-J. Pinault in BSL 95 / 22000 p. 157-163.

Hahn Naming-Constructions 1969 = E. A. Hahn Naming-Constructions in some Indo-European Languages. Ann Arbor 1969.

Hahn Subjunctive and Optative 1953 = E. A. Hahn Subjunctive and Optative, Their origin as futures. New York 1953.

Hajnal Lyk. Vokalismus 1995 = I. Hajnal Der lykische Vokalismus: Methode und Erkenntnisse der vergleichenden anatolischen Sprachwissenschaft, angewandt auf das Vokalsystem einer Kleincorpussprache. Graz 1995. Rez.: G. Neumann in HS 1111998 p.372-376.

Hajnal Myk. Kasussystem 1995 = I. Hajnal Studien zum mykenischen Kasussystem. Berlin / New York 1995. Rez.: N. Guilleux (-Maurice) in BSL 92 / 21997 p. 200-216. 
Hajnal Myk. u. hom. Lexikon 1998 = I. Hajnal Mykenisches und homerisches Lexikon, Übereinstimmungen, Divergenzen und der Versuch einer Typologie. Innsbruck 1998 (= IBS, Vorträge und kl. Schriften 69).

Hajnal Sprachschichten 1997 = I. Hajnal Sprachschichten des Mykenischen Griechisch. Salamanca 1997 (= Minos Supl. 14).

Hamm Sappho und Alkaios 1957 = E.-M. Hamm Grammatik zu Sappho und Alkaios. Berlin 1957.

Handbuch der Onomastik 11995 = Namenforschung, Name Studies, Les noms propres, Ein internationales Handbuch zur Onomastik, hrsg. von E. Eichler, G. Hilty, H. Löffler, H. Steger, L. Zgusta. 1. Teilband. Berlin / New York 1995.

Happ Grundfragen $1976=\mathrm{H}$. Happ Grundfragen einer Dependenzgrammatik des Lateinischen. Göttingen 1976.

Harđarson Wurzelaorist 1993 = J. A. Harđarson Studien zum indogermanischen Wurzelaorist und dessen Vertretung im Indoiranischen und Griechischen. Innsbruck 1993. Rez.: K. Strunk in Kratylos 391994 p. 55-68; M. Peters in Idg. Chr. 35 Nr. A 789.

Haudry Cas en védique $1977=\mathrm{J}$. Haudry L'emploi des cas en védique. Introduction à l'étude des cas en indo-européen. Lyon 1977. Rez.: G. Cardona in Kratylos 231978 [1979] p. 71-82.

Haudry Les indo-européens $1985=\mathrm{J}$. Haudry Les indo-européens. Paris 1. Aufl. 1981, 2. Aufl. 1985 (= Collection Que sais-je ? Nr. 1965).

Haudry L'indo-européen 1979 = J. Haudry L'indo-européen. Paris 1979 (= Collection Que sais-je ? Nr. 1798).

Hauri -ena 1963 = Ch. Hauri Zur Vorgeschichte des Ausgangs -ena des Instr. Sing. der a-Stämme des Altindischen. Göttingen 1963 (= ZVS, Ergänzungsheft Nr. 17).

Hauri Futur $1975=\mathrm{H}$. W. Hauri Kontrahiertes und sigmatisches Futur. Einflüsse von Lautstruktur und Aktionsart auf die Bildung des griechischen Futurs. Göttingen 1975 (= ZVS, Ergänzungsheft Nr. 24). Rez.: C. J. Ruijgh in Kratylos 201975 [1977] p. 82-91 (= Scripta Minora I 1991 p. 368-377); F. M. J. Waanders in Mnemosyne 331980 p. 369374.

Hauschild s.u. Thumb / Hauschild.

Haverling sco-Verbs $2000=\mathrm{G}$. Haverling On sco-Verbs, Prefixes and Semantic Functions. Göteborg 2000.

Havers Erklärende Syntax $1931=$ W. Havers Handbuch der erklärenden Syntax, Ein Versuch zur Erforschung der Bedingungen und Triebkräfte in Syntax und Stilistik. Heidelberg 1931. 
Havers Kasussyntax $1911=$ W. Havers Untersuchungen zur Kasussyntax der indogermanischen Sprachen. Straßburg 1911.

Havers Sprachtabu 1946 = W. Havers Neuere Literatur zum Sprachtabu. Wien 1946.

Hawkins Corpus 12000 / 21999 = D. Hawkins Corpus of Hieroglyphic Luwian inscriptions. Berlin / New York. Band 1 (in 3 Teilen: Inscriptions from the Iron Age) von D. Hawkins 2000; Band 2 (KaratepeAslantas: the inscriptions; facsimile edition) von H. Çambel 1999.

HED s.u. Puhvel HED.

HEG s.u. Tischler HEG.

Hehn Cultivated Plants and Domesticated Animals (1885) $1976=\mathrm{V}$. Hehn Cultivated Plants and Domesticated Animals in their Migration from Asia to Europe, Historico-linguistic studies, New edition prepared with a bio-bibliographical account of Hehn and a survey of the research in Indo-European prehistory, hrsg. von J. P. Mallory. Amsterdam 1976.

Heidermanns Germ. Primäradjektive $1993=$ F. Heidermanns Etymologisches Wörterbuch der germanischen Primäradjektive. Berlin / New York 1993.

Hethitisch und Indogermanisch 1979 = Hethitisch und Indogermanisch, Vergleichende Studien zur historischen Grammatik und zur dialektgeographischen Stellung der indogermanischen Sprachgruppe Altkleinasiens, hrsg. von E. Neu und W. Meid. Innsbruck 1979 (= IBS Nr. 25).

Hettrich Agens $1990=\mathrm{H}$. Hettrich Der Agens in passivischen Sätzen altindogermanischer Sprachen. Göttingen 1990 (=NAWG 1990 / 2).

Hettrich Hypotaxe $1988=\mathrm{H}$. Hettrich Untersuchungen zur Hypotaxe im Vedischen. Berlin / New York 1988. Rez.: S. W. Jamison in JAOS 110 1990 p. $535 f$.

Hettrich Kontext und Aspekt $1976=\mathrm{H}$. Hettrich Kontext und Aspekt in der altgriechischen Prosa Herodots. Göttingen 1976. Rez.: C. J. Ruijgh in Gnomon 511979 p. 217-227 (= Scripta Minora I 1991 p. 764-774).

Heubeck Kleine Schriften $1984=$ A. Heubeck Kleine Schriften zur griechischen Sprache und Literatur. Erlangen 1984. Für Ergänzungen vgl. B. Forssman und R. Plath in HS 1031990 p. 249-260.

Heubeck Schrift $1979=$ A. Heubeck Schrift. Göttingen 1979 (= Archaeologia Homerica Band III, Kapitel X).

Hiersche Grundzüge $1970=\mathrm{R}$. Hiersche Grundzüge der griechischen Sprachgeschichte bis zur klassischen Zeit. Wiesbaden 1970. 
Hiersche Tenues aspiratae $1964=\mathrm{R}$. Hiersche Untersuchungen zur Frage der Tenues aspiratae im Indogermanischen. Wiesbaden 1964. Rez.: Mayrhofer Kleine Schriften II 1996 p. 298 Anm. 17.

Hiller / Panagl Frühgr. Texte aus myk. Zeit $1976=$ S. Hiller und O. Panagl Die frühgriechischen Texte aus mykenischer Zeit. Darmstadt 1976. 2., durchges. Aufl. 1986. Rez. der 2. Aufl.: C. J. Ruijgh in Mnemosyne 311978 p. 294-298.

Hilmarsson Nasal Prefixes in Tocharian $1991=$ J. Hilmarsson The Nasal Prefixes in Tocharian, A Study in Word Formation. Reykjavík 1991 (= TIES, Suppl. Ser. 3).

Hilmarsson Tocharian Dictionary 1996 = J. Hilmarsson Materials for a Tocharian Historical and Etymological Dictionary. Reykjavík 1996 (= TIES, Suppl. Ser. 5).

Hintze Zamyād Yašt 1994 = A. Hintze Zamyād Yašt, Avestan Text, English Translation, Glossary. Wiesbaden 1994 (= Beiträge zur Iranistik 7). Vgl. zum selben Text auch H. Humbach und Pallan R. Ichaporia Zamyād Yasht, Yasht 19 of the Younger Avesta, Text, Translation, Commentary. Wiesbaden 1998.

Hinüber Älteres Mittelindisch $1986=0$. von Hinüber Das ältere Mittelindisch im Überblick. Wien 1986 (= SbÖAW, 467. Band).

Hirt Gr. Laut- und Formenlehre $1912=\mathrm{H}$. Hirt Handbuch der griechischen Laut- und Formenlehre. 2., umgearb. Aufl. Heidelberg 1912.

Hirt Hauptprobleme $1939=\mathrm{H}$. Hirt Die Hauptprobleme der indogermanischen Sprachwissenschaft, hrsg. von H. Arntz. Halle 1939.

Hirt Idg. Gramm. I - VII 1927-1937 = H. Hirt Indogermanische Grammatik. 7 Teile Heidelberg: I (Einleitung, Etymologie, Konsonantismus) 1927; II (Vokalismus) 1921; III (Nomen) 1927; IV (Doppelung, Zusammensetzung, Verbum) 1928; V (Akzent) 1929; VI (Syntax I, Syntaktische Verwendung der Kasus und der Verbalformen) 1934; VII (Syntax II, Die Lehre vom einfachen und zusammengesetzten Satz) posthum 1937.

Hirt Indogermanen I 1905 II $1907=\mathrm{H}$. Hirt Die Indogermanen, Ihre Verbreitung, ihre Urheimat und ihre Kultur. 2 Bände Straßburg 19051907.

Hirt Urgerm. I-III 1931-1934 = H. Hirt Handbuch des Urgermanischen. Heidelberg 1931-1934.

Historical Linguistics Papers 1985 [1987] = Historical Linguistics, Papers from the $7^{\text {th }}$ International Conference on Historical Linguistics Pavia 1985, hrsg. von A. G. Ramat, O. Carruba und G. Bernini. Amsterdam / Philadelphia 1987 (= Current Issues in Linguistic Theory 48). 
Historical Linguistics Papers 1989 [1993] = Historical Linguistics, Papers from the $9^{\text {th }}$ International Conference on Historical Linguistics Rutgers University 1989, hrsg. von H. Aertsen und R. J. Jeffers. Amsterdam / Philadelphia 1993 (= Current Issues in Linguistic Theory 106).

Historical Linguistics Problems 1993 = Historical Linguistics: Problems and Perspectives, hrsg. von Ch. Jones. London / New York 1993 (= Longman Linguistics Library).

Historical Morphology $1980=$ Historical Morphology, hrsg. von J. Fisiak. The Hague / Paris / New York 1980 (= Trends in Linguistics, Studies and Monographs 17).

Historical Syntax 1984 = Historical Syntax, hrsg. von J. Fisiak. Berlin u.a.O. 1984 (= Trends in Linguistics, Studies and Monographs 23).

$\mathrm{HL}=$ Historiographia linguistica.

Hock Historical Linguistics $1986=\mathrm{H}$. H. Hock Principles of Historical Linguistics. Berlin usw. 1986.

Hock Language History $1996=\mathrm{H}$. H. Hock Language History, Language Change and Language Relationship: An Introduction to Historical and Comparative Linguistics. Berlin / New York 1996. Rez.: Th. Krisch in Kratylos 441999 p. 174-176.

Hodot Éolien $1990=\mathrm{R}$. Hodot Le dialecte éolien d'Asie. La langue des inscriptions, VIIe s. a. C. - IVe s. p. C. Paris 1990.

Hoenigswald Historical linguistics $1973=\mathrm{H}$. M. Hoenigswald Studies in Formal Historical Linguistics. Dordrecht / Boston 1973.

Hoenigswald Language Change $1960=\mathrm{H}$. M. Hoenigswald Language Change and Linguistic Reconstruction. Chicago 1960.

Hoffmann Aufsätze I 1975 II 1976 III 1992 = K. Hoffmann Aufsätze zur Indoiranistik. Wiesbaden 1975-1992.

Hoffmann Gedenkfeier 1996 [1997] = Akademische Gedenkfeier für Professor Dr. Karl Hoffmann am 11. Juli 1996. Erlangen 1997 (= Akademische Reden und Kolloquien, Friedrich-Alexander-Universität Erlangen-Nürnberg, Bd. 12).

Hoffmann Injunktiv $1967=\mathrm{K}$. Hoffmann Der Injunktiv im Veda. Eine synchronische Funktionsuntersuchung. Heidelberg 1967.

Hoffmann / Forssman Av. Laut- und Flexionslehre $1996=\mathrm{K}$. Hoffmann und B. Forssman Avestische Laut- und Flexionslehre. Innsbruck 1992 (= IBS Nr. 84). Rez.: X. Tremblay in BSL 92 / 21997 p. 180-184; R. S. P. Beekes in Kratylos 441999 p. 62-71.

Hoffmann / Narten Sasanid. Archetypus 1989 = K. Hoffmann und J. Narten Der Sasanidische Archetypus, Untersuchungen zu Schreibung und Lautgestalt des Avestischen. Wiesbaden 1989. 
Hofmann Lat. Umgangssprache $1936=\mathrm{J}$. B. Hofmann Lateinische Umgangssprache. Heidelberg 2. Aufl. 1936, 4. Aufl. mit Index 1978.

Hofmann s. auch s.v. Hofmann / Szantyr Syntax bzw. Leumann / Hofmann / Szantyr Lat. Gr. bzw. Walde / Hofmann LEW.

Hofmann / Szantyr Syntax 1965 = J. B. Hofmann Lateinische Syntax und Stilistik, neubearbeitet von A. Szantyr. München 1965 (=2. Band von Leumann / Hofmann / Szantyr Lat. Gr. im Handbuch der Altertumswissenschaft).

Homeric Questions 1995 = Homeric Questions, Essays in Philology, Ancient History and Archaeology, hrsg. von J. P. Crielaard. Amsterdam 1995.

Homers Ilias Gesamtkommentar 2000ff. s.u. Homers Ilias Prolegomena.

Homers Ilias Prolegomena $2000=$ Homers Ilias, Gesamtkommentar, hrsg. von J. Latacz. Prolegomena als eigenständiger Band von F. Graf, I. de Jong, J. Latacz, R. Nünlist, M. Stoevesandt, R. Wachter, M. L. West. München / Leipzig 2000. Gesamtkommmentar: Band I, 1. Gesang (Faszikel 1 Text und Übersetzung; Faszikel 2 Kommentar) 2000.

Hooker Linear B $1980=$ J. T. Hooker Linear B, An Introduction. Bristol 1980.

Hooker Scripta Minora 1996 = J. T. Hooker Scripta Minora, Selected essays on Minoan, Mycenaean, Homeric and Classical Greek subjects, hrsg. von F. Amory, P. Considine, S. Hooker. Amsterdam 1996.

Horrocks Greek $1997=$ G. Horrocks Greek, A History of the Language and its Speakers. London 1997.

Horrocks Space and Time $1981=$ G. C. Horrocks Space and Time in Homer. Prepositional and Adverbial Particles in the Greek Epic. New York 1981.

Houwink ten Cate Luwian Population Groups $1965=\mathrm{Ph}$. H. J. Houwink ten Cate The Luwian Population Groups of Lycia and Cilicia Aspera during the Hellenistic Period. Leiden 1965.

HS = Historische Sprachforschung, Göttingen; vor Band 100 lautete die Bezeichnung ZVS = Zeitschrift für Vergleichende Sprachforschung; zunächst üblich aber war das Kürzel KZ i.e. Kuhns Zeitschrift. Für die Bände 1-100 steht jetzt ein Register (Sachindex) zur Verfügung, hrsg. von A. Bammesberger, bearbeitet von I. Hajnal, Chr. Schaefer, G. Schaufelberger und S. Ziegler. Göttingen 1997. Auf der aktuellen Homepage der Englischen und Vergleichenden Sprachwissenschaft der Katholischen Universität Eichstätt stellt A. Bammesberger zusätzlich ein Wortregister für die hundert Bände zur Verfügung. 
HSK $=$ Handbücher zur Sprach- und Kommunikationswissenschaft: Berlin / New York. Band 1.1 und 1.2 s.o. Dialektologie 1-2 1982-1983; Band 2.1 und 2.2 s.u. Sprachgeschichte 1-2 1998-1985; Band 5.1 und 5.2 s.u. Wörterbücher 1-3 1989-1991; Band 9.1 und 9.2 s.u. Syntax 1-2 1993-1995; Band 10.1 und 10.2 s.u. Schrift und Schriftlichkeit 1-2 1994-1996; Band 11.1 und 11.2 s.u. Namenforschung 1-2 1995-1996.

Hübschmann Casuslehre $1875=\mathrm{H}$. Hübschmann Zur Casuslehre. München 1875.

Hübschmann Kleine Schriften $1976=\mathrm{H}$. Hübschmann Kleine Schriften zum Armenischen, hrsg. von R. Schmitt. Hildesheim / New York 1976. Vgl. ferner R. Schmitt Schriftenverzeichnis Heinrich Hübschmann in HS 1111998 p. 185-190.

IBK = Innsbrucker Beiträge zur Kulturwissenschaft.

IBS = Innsbrucker Beiträge zur Sprachwissenschaft.

ICLL s.u. IKLL.

Idg. Chr. = Indogermanische Chronik in Sprache, seit Band 131967 mit Zählung 13a. Zuletzt mir vorliegend Idg. Chr. 35 / II in Sprache 37 / 3 1995.

Idg. Gr. I / 11986 I / 21986 II 1968 III / 11969 = Indogermanische Grammatik, begründet von J. Kuryłowicz, hrsg. von M. Mayrhofer. Heidelberg: I / 1 (Einleitung) 1986 s.o. Cowgill Einleitung 1986; I / 2 (Lautlehre) 1986 s.u. Mayrhofer Lautlehre 1986; II (Akzent . Ablaut) 1968 s.u. Kuryłowicz Akzent . Ablaut 1968; III (Formenlehre) / 1 (Geschichte der indogermanischen Verbalflexion) 1969 s.u. Watkins Verbalflexion 1969.

IE and IEs $1970=$ Indo-European and Indo-Europeans, hrsg. von G. Cardona, H. M. Hoenigswald, A. Senn. Philadelphia 1970.

IE Subgrouping 1999 = Special Session on Indo-European Subgrouping and Internal Relations, hrsg. von B. K. Bergen, M. C. Plauché, A. C. Bailey. Berkely 1998 (= Berkely Linguistic Society, Proceedings of the Twenty-Fourth Annual Meeting).

IEW s.u. Pokorny IEW.

IF $=$ Indogermanische Forschungen.

IIJ = Indo-Iranian Journal.

IKLL (ICLL / CILL) I 1981 (1983); IV 1987 [1991]; V 1989; VII 1993 [1996]; VIII 1995 [1996]= Internationales Kolloquium zur lateinischen Linguistik [IKLL] (International Colloquium on Latin Linguistics [ICLL]/ Colloque international de linguistique latine [CILL]): - I 1981 [1983] Latin Linguistics and Linguistic Theory, Proceedings of 
the $1^{\text {st }}$ ICLL Amsterdam 1981, hrsg. von H. Pinkster. Amsterdam / Philadelphia 1983. - IV 1987 [1991]: New Studies in Latin Linguistics, Selected papers from the $4^{\text {th }}$ ICLL Cambridge 1987, hrsg. von R. Coleman. Amsterdam / Philadelphia 1991. - V 1989: Actes du V CILL Louvain-la-Neuve / Borzée 1989, hrsg. von M. Lavency und D. Longré. Louvain-la-Neuve 1989. - VII 1993 [1996] s.o. Aspects of Latin 1996. - VIII 1995 [1996]: Akten des VIII. IKLL Eichstätt 1995, hrsg. von A. Bammesberger und F. Heberlein. Heidelberg 1996.

Iliad I-VI 1985-1993 = The Iliad, A Commentary, hrsg. von G. S. Kirk. Cambridge: I (Books 1-4) und II (Books 5-8) von G. S. Kirk; III (Books 9-12) von B. Hainsworth; IV (Books 13-16) von R. Janko; V (Books 17-20) von M. W. Edwards; VI (Books 21-24) von N. Richardson.

Illič-Svityč Nominal Accentuation $1979=$ V. M. Illič-Svityč Nominal Accentuation in Baltic and Slavic, übersetzt aus dem Russ. von R. L. Leed und R. F. Feldstein. Cambridge / Mass. 1979.

Indo-European Languages 1998 = The Indo-European Languages, hrsg. von A. G. Ramat und P. Ramat. London 1998. Zum italienischen Original s. unter Lingue indoeuropee 1994.

Indo-Europeanization of Northern Europe 1996 = The Indo-Europeanization of Northern Europe, Papers Presented at the International Conference in Vilnius 1994, hrsg. von K. Jones-Bley und M. E. Huld. Washington 1996 (= JIES, Monograph 17). Rez.: B. Hänsel und B. Schlerath in Kratylos 462001 p. 55-62.

Indogermanische Dichtersprache $1968=$ Indogermanische Dichtersprache, hrsg. von R. Schmitt. Darmstadt 1968 (= Wege der Forschung CLXV).

Indologie 1979 = Einführung in die Indologie, Stand, Methoden, Aufgaben, hrsg. von H. Bechert und G. von Simson. 1. Aufl. 1979, 2. Aufl. 1993.

InL $=$ Incontri Linguistici.

Insler Gāthās 1975 = S. Insler The Gāthās of Zarathustra. Teheran / Lüttich / Leiden 1975 (= Acta Iranica 8). Rez.: H.-P. Schmidt in IIJ 21 1979 p. 83-115.

Iranisches Personennamenbuch $=$ Iranisches Personennamenbuch, hrsg. von M. Mayrhofer und R. Schmitt. Wien. Band I 1979: M. Mayrhofer Die altiranischen Namen (darin die av. und ap. Namen: vgl. ders. Zum Namengut des Avesta. Wien 1977 [= SbÖAW Band 308, Abhandlung 5]). Das Iranische Personennamenbuch ist eine großangelegte Unternehmung mit insgesamt 10 Bänden. Neben Band I sind weitere Faszi- 
kel und Bände bereits erschienen, vgl. u.a. Band II Faszikel $21986 \mathrm{Ph}$. Gignoux Noms propres sassanides en moyen-perse épigraphique; Band V Faszikel 41982 R. Schmitt Iranische Namen in den indogermanischen Sprachen Kleinasiens (Lykisch, Lydisch, Phrygisch); Band V Faszikel 6a $1990 \mathrm{Ph}$. Huyse Iranische Namen in den griechischen Dokumenten Ägyptens.

Italia alumna 1990 = Italia omnium terrarum alumna, La civiltà dei Veneti, Reti, Liguri, Celti, Piceni, Umbri, Latini, Campani e Iapigi. Mailand: 1. Aufl. 1988, 2. Aufl. 1990 (= Credito Italiano, Antica Madre, Collana di studi sull' Italia antica Band 11, Direttore G. P. Carratelli).

Italia parens $1991=$ Italia omnium terrarum parens, La civiltà degli Enotri, Choni, Ausoni, Sanniti, Lucani, Brettii, Sicani, Siculi, Elimi. Mailand: 1. Aufl. 1989, 2. Aufl. 1991 (= Credito Italiano, Antica Madre, Collana di studi sull' Italia antica Band 12, Direttore G. P. Carratelli).

Jackson Early Britain $1953=\mathrm{K}$. Jackson Language and History in Early Britain, A Chronological Survey of the Brittonic Languages First to Twelfth Century a. D. Edinburgh 1953.

Jacquinod Double accusatif en grec $1989=$ B. Jacquinod Le double accusatif en grec d'Homère à la fin du $\mathrm{V}^{\mathrm{e}}$ siècle avant J.-C. Louvain-LaNeuve 1989

Jamison -áya- $1983=\mathrm{S}$. W. Jamison Function and Form in the -áyaFormations of the Rig Veda and Atharva Veda. Göttingen 1983 (= ZVS, Ergänzungsheft Nr. 31). Rez.: G. Pinault in Kratylos 291984 [1985] p. 47-51; M. Peters in Idg. Chr. 30a Nr. 242.

Janda Stock und Stein 1997 = M. Janda Über „Stock und Stein“, Die indogermanischen Variationen eines universalen Phraseologismus. Diss. Wien 1995 = MSS, Beiheft 18, N.F. 1997.

Janda Eleusis 1999 = M. Janda Eleusis, Das indogermanische Erbe der Mysterien. Innsbruck 1999 (= IBS 96).

Jankuhn Passive Bedeutung $1969=\mathrm{H}$. Jankuhn Die passive Bedeutung medialer Formen untersucht an der Sprache Homers. Göttingen 1969 (= Ergänzungshefte zur ZVS 21).

Jasanoff Stative and Middle $1978=$ J. H. Jasanoff Stative and Middle in Indo-European. Innsbruck 1978.

JAOS $=$ Journal of the American Oriental Society.

Jensen Altarm. Gr. 1959 = H. Jensen Altarmenische Grammatik. Heidelberg 1959.

JIES = Journal of Indo-European Studies. Zuletzt Washington (D. C.). 
Joachim Mehrfachpräsentien $1978=$ U. Joachim Mehrfachpräsentien im Rgveda. Frankfurt a.M. / Bern / Las Vegas 1978 (= Europäische Hochschulschriften Reihe XXI Band 4).

Joki Uralier und Indogermanen $1973=$ A. J. Joki Uralier und Indogermanen. Die älteren Berührungen zwischen den uralischen und indogermanischen Sprachen. Helsinki 1973.

Jokl Albanisch $=$ N. Jokl Linguistisch-kulturhistorische Untersuchungen aus dem Bereiche des Albanischen. Berlin / Leipzig 1923.

Kadmos $=$ Kadmos. Zeitschrift für vor- und frühgriechische Epigraphik. Berlin.

Kammenhuber Arier 1968 = A. Kammenhuber Die Arier im Vorderen Orient. Heidelberg 1968.

Kammenhuber Kleine Schriften 1993 = A. Kammenhuber Kleine Schriften zum Altanatolischen und Indogermanischen (1. Teilband 19551968, 2. Teilband 1969-1990) Heidelberg 1993. Rez. mit zahlreichen Ergänzungen und Hinweisen: J. Catsanicos in BSL 92 / 21997 p. 156179.

Kastner Adjektive 1967 = W. Kastner Die griechischen Adjektive zweier Endungen auf -OL. Heidelberg 1967. Rez.: E. Neu in IF 741969 p. 235-242.

Katà diálekton 1996 [1999] = Katà diálekton, Atti del III Colloquio Internationale di Dialectologia Greca Neapel / Fiaiano d'Ischia 1996, hrsg. von A. C. Cassio, Neapel 1999 (= Annali dell' Istituto Universitario Orientale di Napoli, Sezione Filologico-Letteraria, 19 [1997]). Vgl. oben Dialectologica Graeca 1991 [1993].

Katičić Languages of the Balkans $1976=\mathrm{R}$. Katičić Ancient Languages of the Balkans I. The Hague / Paris 1976. Rez.: C. de Simone in Kratylos 221977 [1978] p. 113-119.

Katz (H.) Lehnwörter $1985=$ H. Katz Studien zu den älteren indoiranischen Lehnwörtern in den uralischen Sprachen. Habilitationsschrift München 1985. Eine posthume Publikation durch R.-P. Ritter im Verlag Winter ist in Vorbereitung.

Katz (J.) Personal Pronouns $1998=$ J. T. Katz Topics in Indo-European Personal Pronouns. Diss. Harvard 1998. Ders. in Rez. von Schrijver Celtic Pronouns and Particles 1997 in Kratylos 462001 p. 1-23.

Kellens Noms racines $1974=\mathrm{J}$. Kellens Les noms-racines de l'Avesta. Wiesbaden 1974 (= Beiträge zur Iranistik Band 7). Rez.: R. Schmitt in Kratylos 191974 [1975] p. 56-60; J. Schindler in Sprache 251979 p. 57-60. 
Kellens Verbe avestique $1984+1994=\mathrm{J}$. Kellens Le verbe avestique. Wiesbaden 1984; ders. Liste du verbe avestique. Wiesbaden 1994.

Kellens / Pirart Textes vieil-avestiques I 1988 II 1990 III $1991=$ J. Kellens, E. Pirart Les textes vieil-avestiques. Wiesbaden: Band I (Introduction, texte et traduction) 1988; Band II (Répertoires grammaticaux et lexique) 1990; Band III (Commentaire) 1991. Rez. zu I 1988: P. O. Skjærvø in JAOS 1111991 p. 659-662; S. W. Jamison in IIJ 361993 p. 244-251. Rez. zu I-III: N. Oettinger in Kratylos 381993 p. 43-49.

Keller (M.) Verbes latins à infectum en -sc- $1992=$ M. Keller Les verbes latins à infectum en -sc-, Étude morphologique à partir des informations attestées dès l'époque préclassique. Bruxelles 1992 (= Collection Latomus 216).

Keller (R.) Sprachwandel $1994=$ R. Keller Sprachwandel, Von der unsichtbaren Hand in der Sprache. 2. Aufl. Tübingen und Basel 1994 (= UTB Nr. 1567).

Keltologen-Symposium II 1997 [1999] = Akten des Zweiten Deutschen Keltologen-Symposiums in Bonn 1997, hrsg. von St. Zimmer, R. Ködderitzsch, A. Wigger. Tübingen 1999. Vgl. oben Deutschsprachige Keltologen 1992 [1993].

KEWA s.u. Mayrhofer KEWA.

Keydana Absol. Konstr. 1997 = G. Keydana Absolute Konstruktionen in altindogermanischen Sprachen. Göttingen 1997 (= Ergänzungsheft HS Nr. 40).

Kieckers Gr. Gr. III-IV 1926 = E. Kieckers Historische Grammatik des Griechischen. 4 Teile. Berlin / Leipzig (Sammlung Göschen: Bände 117, 118, 924, 925) 1925-1926: I (Lautlehre) 1925; II (Formenlehre) 1926; III (Syntax, erster Teil) 1926; IV (Syntax, zweiter Teil) 1926.

Kieckers Stellung des Verbs $1911=$ E. Kieckers Die Stellung des Verbs im Griechischen und in den verwandten Sprachen, Erster Teil: Die Stellung des Verbs im einfachen Hauptsatze und im Nachsatze nach den griechischen Inschriften und der älteren griechischen Prosa, verglichen mit den verwandten Sprachen. Straßburg 1911.

Kienle Histor. LFL d. Dt. $1965=$ R. von Kienle Historische Laut- und Formenlehre des Deutschen. 2. Aufl. Tübingen 1965.

Kilian Indogermanen 1983 = L. Kilian Zum Ursprung der Indogermanen, Forschungen aus Linguistik, Prähistorie und Anthropologie. Bonn 1983. Rez.: F. Lochner von Hüttenbach in Kratylos 291984 [1985] p. 160-163.

Kimball Hittite Historical Phonology 1999 = S. E. Kimball Hittite Historical Phonology. Innsbruck 1999 (= IBS 95). 
Klaproth Asia polyglotta 1823 = J. Klaproth Asia polyglotta. Paris 1823 . Die Tragweite dieses Pionierwerkes darf nicht unterschätzt werden, vgl. G. Bolognesi in FS Belardi I 1994 p. 334ff.

Klein Discourse Grammar $1985=$ J. S. Klein Toward a Discourse Grammar of the Rigveda. 2 Teile. Heidelberg 1985. Rez.: H. Hettrich in Kratylos 331988 p. 72-79.

Klein Particle u $1978=$ J. S. Klein The Particle $u$ in the Rigveda, A Synchronic and Diachronic Study. Göttingen 1978 (= ZVS, Ergänzungsheft 27).

Klein Personal Deixis $1996=$ J. S. Klein On Personal Deixis in Classical Armenian, A Study of the Syntax and Semantics of the n-, s- and dDemonstratives in Manuscripts E and M of the Old Armenian Gospels. MSS, Beiheft 17, N.F. 1996.

Klein Verbal Accentuation 1992 = J. S. Klein On Verbal Accentuation in the Rigveda. New Haven 1992. Rez.: S. Migron in Kratylos 401995 p. 190-192.

Klingenschmitt Altarm. Verbum $1982=$ G. Klingenschmitt Das Altarmenische Verbum. Wiesbaden 1982. Rez.: G. R. Solta in Kratylos 29 1984 [1985] p. 59-74.

Kl. Pauly $=$ Der Kleine Pauly, Lexikon der Antike. 5 Bände Stuttgart / München 1964-1975 (= dtv 1979 Nr. 5963). S. auch oben unter DNP.

Kluge Stammbildungslehre $1926=\mathrm{F}$. Kluge Nominale Stammbildungslehre der altgermanischen Dialekte. 3. Aufl. Halle 1926.

Kluge Urgermanisch 1913 = F. Kluge Urgermanisch, Vorgeschichte der altgermanischen Dialekte. Straßburg 1913.

Kluge / Seebold $1995=$ F. Kluge Etymologisches Wörterbuch der Deutschen Sprache. Bearb. von E. Seebold. 23., erweiterte Auflage Berlin / New York 1995.

Koch Aksl. Verbum I / II $1990=$ Ch. Koch Das morphologische System des altkirchenslavischen Verbums. München 1990: Band I (Text); Band II (Anmerkungen).

Kölver Sekundäre Kasus 1965 = B. Kölver Der Gebrauch der sekundären Kasus im Tocharischen. Diss. Frankfurt 1965.

Koerner Practicing Linguistic Historiography $1989=$ K. Koerner Practicing Linguistic Historiography, Selected Essays. Amsterdam / Philadelphia 1989 (= Amsterdam Studies in the Theory and History of Linguistic Science 50).

Kohrt Problemgeschichte $1985=$ M. Kohrt Problemgeschichte des Graphembegriffs und des frühen Phonembegriffs. Tübingen 1985 (= Reihe germanistische Linguistik Nr. 61). 
Koiné I 1993 II 1996 III 1998 = La koiné grecque antique, sous la direction de Cl. Brixhe. Nancy (= Études anciennes 10, 14, 17). Band I 1993 (une langue introuvable ?); II 1996 (La concurrence); III 1998 (Les contacts).

Koivulehto Uralische Evidenz für die Laryngaltheorie $1991=$ J. Koivulehto Uralische Evidenz für die Laryngaltheorie. Wien 1991 (= SbÖAW, 566. Band). Rez.: T. Hofstra und O. Nikkilä in Kratylos 38 1993 p. 36-39; R. P. Ritter in PFU 11994 / 1995 p. 3-8.

Kolb Rom 1995 = F. Kolb Rom, Die Geschichte der Stadt in der Antike. München 1995.

Kolloquium Delbrück Madrid 1994 [1997] = Berthold Delbrück y la sintaxis indoeuropea hoy, Actas del Coloquio de la Idg. Gesellschaft 1994 in Madrid, hrsg. von E. Crespo und J.-L. García-Ramón. Wiesbaden 1997.

Kolloquium Germanisch Freiburg 1981 [1984] = Das Germanische und die Rekonstruktion der indogermanischen Grundsprache, Akten des Freiburger Kolloquiums der Idg. Gesellschaft 1981 in Freiburg, hrsg. von J. Untermann und B. Brogyanyi. Amsterdam / Philadelphia 1984.

Kolloquium Idg., Slaw. u. Balt. Jena 1989 [1992] = Indogermanisch, Slawisch und Baltisch, Materialien des Kolloquiums Jena 1989, hrsg. von B. Barschel, M. Kozianka, K. Weber. München 1992.

Kolloquium Keltisch Bonn 1976 [1977] = Indogermanisch und Keltisch, Kolloquium der Idg. Gesellschaft 1976 in Bonn, hrsg. von K. H. Schmidt. Wiesbaden 1977.

Kolloquium Kühner Amsterdam 1986 [1988] = In the Footsteps of R. Kühner, Proceedings of the International Coll. in Commemoration of the 150th Anniversary of the Publication of R. Kühner's Ausführliche Grammatik II: Syntaxe 1986 in Amsterdam, hrsg. von A. Rijksbaron, H. A. Mulder, G. C. Wakker. Amsterdam 1988.

Kolloquium Lat. u. Idg. Salzburg 1986 [1992] = Latein und Indogermanisch, Akten des Kolloquiums der Idg. Gesellschaft 1986 in Salzburg, hrsg. von O. Panagl und Th. Krisch. Innsbruck 1992.

Kolloquium Pedersen Kopenhagen 1993 [1994] = In honorem Holger Pedersen, Kolloquium der Idg. Gesellschaft 1993 in Kopenhagen, hrsg. von J. E. Rasmussen. Wiesbaden 1994.

Kolloquium Syntax Pavia 1979 [1980] = Linguistic Reconstruction and Indo-European Syntax, Proceedings of the Colloquium of the "Indogermanische Gesellschaft" 1979 in Pavia, hrsg. von P. Ramat. Amsterdam 1980. 
Kolloquium Wackernagel Basel 1988 [1990] $=$ Sprachwissenschaft und Philologie, Jacob Wackernagel und die Indogermanistik heute, Kolloquium der Idg. Gesellschaft 1988 in Basel, hrsg. von H. Eichner und H. Rix. Wiesbaden 1990.

Kortlandt Slavic Accentuation $1975=$ F. H. H. Kortlandt Slavic Accentuation, A Study in Relative Chronology. Lisse / Holland 1975.

Krahe Idg. Sprachw. I 1966 II $1969=$ H. Krahe Indogermanische Sprachwissenschaft. Berlin: Band I (Einleitung und Lautlehre) 5. Aufl. 1969 (= Sammlung Göschen Nr. 59); Band II (Formenlehre) 5. Aufl. 1969 (= Sammlung Göschen Nr. 64). 6., unveränderte Aufl. in einem Band 1985 (= Sammlung Göschen Nr. 2227). Über die älteren Auflagen und über das vorangehende Werk von R. Meringer orientiert das Vorwort oben p. VII.

Krahe Illyrier I 1955 II $1964=$ H. Krahe Die Sprache der Illyrier. Wiesbaden: Band I (Die Quellen) 1955; Band II 1964 (enthält Die messapischen Inschriften von $\mathrm{C}$. de Simone und Die messapischen Personennamen von J. Untermann).

Krahe Vergl. Syntax $1972=\mathrm{H}$. Krahe Grundzüge der vergleichenden Syntax der indogermanischen Sprachen, hrsg. von W. Meid und H. Schmeja. Innsbruck 1972 (= IBS 8).

Krahe / Meid Germ. Sprachw. I 1969 II 1969 III $1967=$ H. Krahe und W. Meid Germanische Sprachwissenschaft. 3 Bände Berlin: I (Einleitung und Lautlehre) 4. Aufl. 1969; II (Formenlehre) 4. Aufl. 1969; III (Wortbildungslehre) 1. Aufl. 1967 (= Sammlung Göschen Nr. 238, $780,1218)$.

Kratylos $=$ Kratylos. Kritisches Berichts- und Rezensionsorgan für indogermanische und allgemeine Sprachwissenschaft. Wiesbaden.

Krause Handb. d. Got. 1968 = W. Krause Handbuch des Gotischen. 3. Auflage München 1968.

Krause / Thomas Toch. Elementarbuch I 1960 II $1964=$ W. Krause und W. Thomas Tocharisches Elementarbuch. Heidelberg: Band I 1960; Band II (von W. Thomas) 1964.

Kretschmer Einleitung $1896=$ P. Kretschmer Einleitung in die Geschichte der griechischen Sprache. Göttingen 1896.

Krisch Konditionalsätze $1986=\mathrm{Th}$. Krisch Überlegungen zur Herkunft und Entwicklung der irrealen Konditionalsätze des Altgriechischen. Innsbruck 1986 (= IBS, Vorträge und Kleinere Schriften 38).

Krisch Konstruktionsmuster $1984=$ Th. Krisch Konstruktionsmuster und Bedeutungswandel indogermanischer Verben. Anwendungsversuche von Valenztheorie und Kasusgrammatik auf Diachronie und Rekon- 
struktion. Frankfurt a.M. u.a.O. 1984. Rez.: Chr. Koch in Anzeiger für Slavische Philologie 171986 p. 187-198.

Krisch Perfekta mit langem Reduplikationsvokal $1996=$ Th. Krisch Zur Genese und Funktion der altindischen Perfekta mit langem Reduplikationsvokal, Mit kommentierter Materialsammlung. Innsbruck 1996 (= IBS 87). Rez.: G.-J. Pinault in BSL 93 / 21998 p. 139-143; St. W. Jamison in Kratylos 441999 p. 59-62.

Krogh Stellung des Altsächsischen 1996 = S. Krogh Die Stellung des Altsächsischen im Rahmen der germanischen Sprachen. Göttingen 1996 (= Studien zum Althochdeutschen 29).

$\mathrm{KS}=$ Kleine Schriften .

Kühner / Blass Ausführliche Gramm. d. gr. Sprache I / 11890 I / $21892=$ R. Kühner Ausführliche Grammatik der griechischen Sprache. Hannover: Erster Teil (Elementar- und Formenlehre) neu bearbeitet von F. Blass, 3. Aufl. in 2 Bänden 1890 und 1892.

Kühner / Gerth Ausführliche Gramm. d. gr. Sprache II / 11898 II / 21904 $=$ R. Kühner Ausführliche Grammatik der griechischen Sprache. Hannover / Leipzig: Zweiter Teil (Satzlehre) neu bearbeitet von B. Gerth, 3. Aufl. in 2 Bänden 1898 und 1904.

Kühner / Holzweissig Ausführliche Gramm. d. lat. Sprache I $1912=\mathrm{R}$. Kühner Ausführliche Grammatik der lateinischen Sprache. Erster Band (Elementar-, Formen- und Lautlehre) neubearbeitet von F. Holzweissig.

Kühner / Stegmann Ausführliche Gramm. d. lat. Sprache II / 1 und II / 2 $1955=$ R. Kühner Ausführliche Grammatik der lateinischen Sprache, Satzlehre, neu bearbeitet von C. Stegmann, 2 Teile. 3. Aufl. durchgesehen von A. Thierfelder. Leverkusen 1955.

Kümmel Perfekt $2000=$ M. Kümmel Das Perfekt im Indoiranischen, Eine Untersuchung der Form und Funktion einer erebten Kategorie des Verbums und ihrer Weiterbildung in den altindoeuropäischen Sprachen. Wiesbaden 2000.

Kümmel Stativ und Passivaorist $1996=$ M. Kümmel Stativ und Passivaorist im Indoiranischen. Göttingen 1996 (= HS Ergänzungsheft 39). Rez.: I. Hajnal in Kratylos 441999 p. 50-54.

Kuhn Letztes Indogermanisch $1978=\mathrm{H}$. Kuhn Das letzte Indogermanisch. Mainz 1978 (= AAWL 1978 Nr. 4). Kritische Rez.: B. Schlerath in Kratylos 231978 [1979] p. 44-57.

Kuiper Nasalpräsentia 1937 = F. B. J. Kuiper Die indogermanischen Nasalpräsentia. Ein Versuch zu einer morphologischen Analyse. Amsterdam 1937 (zuerst 1934 in einer kürzeren Version als Diss. erschienen). 
Kuiper Selected Writings $1997=$ F. B. J. Kuiper Selected Writings on Indian Linguistics and Philology, hrsg. von A. Lubotsky, M. S. Oort, M. Witzel. Amsterdam 1997.

Kuiper Ved. Noun-Inflexion $1942=$ F. B. J. Kuiper Notes on Vedic Noun-Inflexion. Amsterdam 1942 (wieder abgedruckt in Selected Writings 1997 p. 437-530); s.u. F 314 Abs. 5.

Kuryłowicz Accentuation $1952=\mathrm{J}$. Kuryłowicz L'accentuation des langues indo-européennes. Kraków 1952, 2.Aufl. 1956.

Kuryłowicz Akzent . Ablaut $1968=\mathrm{J}$. Kuryłowicz Akzent . Ablaut $=$ Band II der Idg. Gr. (s.o.). Heidelberg 1968.

Kuryłowicz Apophonie $1956=\mathrm{J}$. Kuryłowicz L'apophonie en indoeuropéen. Wrocław 1956.

Kuryłowicz Esquisses I 1973 II 1975 = J. Kuryłowicz Esquisses linguistiques. 2 Bände München: I 1. Aufl. 1960, 2. Aufl. 1973; II 1975.

Kuryłowicz Études I 1935 = J. Kuryłowicz Études indo-européennes I. Krakau 1935.

Kuryłowicz Inflectional Categories $1964=$ J. Kuryłowicz The Inflectional Categories of Indo-European. Heidelberg 1964.

Kuryłowicz s. auch oben GS Kuryłowicz 1995.

$\mathrm{KZ}=$ Zeitschrift für Vergleichende Sprachforschung. Begründet von A. Kuhn. Zuletzt Göttingen, s.o. HS.

LALIES $=$ LALIES. Actes des sessions de linguistique et de littérature. Paris.

Lambert Langue gauloise $1994=$ P.-Y. Lambert La langue gauloise. Paris 1994.

Lamberterie Adj. en -v $1990=\mathrm{Ch}$. de Lamberterie Les adjectifs grecs en -vc. 2 Bände Louvain-la-Neuve 1990. Rez.: J. L. Perpillou in RPh 64 1990 [1992] p. 197-200; F. Bader und L. Dubois in BSL 86 / 21991 p. 145-149; M. Peters in Idg. Chr. 34 Nr. G 601; F. Mawet in REArm 24 1993 p. 301-305.

Lamberterie Arménien classique $1992=\mathrm{Ch}$. de Lamberterie Introduction à l'arménien classique in LALIES 101992 p. 234-289.

langues indo-européennes 1994 = langues indo-européennes, hrsg. von F. Bader. Paris 1994. Neudruck (mit Ergänzungen) 1997. Rez.: A. Blanc in BSL 92 / 21997 p. 141-143.

Language Typology 1988 [1991] = Language Typology 1988, Typological Models in the Service of Reconstruction, hrsg. von W. P. Lehmann und H. J. Hewitt. Amsterdam / Philadelphia 1991 (= Amsterdam Stu- 
dies in the Theory and History of Linguistic Science, Series IV: Current Issues in Linguistic Theory 81).

Lanszweert Balt. Grundwortschatz $1984=$ R. Lanszweert Die Rekonstruktion des baltischen Grundwortschatzes. Frankfurt a.M. 1984.

La Roche Accusativ $1861=\mathrm{J}$. La Roche Homerische Studien, Der Accusativ im Homer. Wien 1861

Laroche Hiéroglyphes hittites I $1960=$ E. Laroche Les hiéroglyphes hittites I (L'écriture). Paris 1960.

Laroche Hourrite 1980 = E. Laroche Glossaire de la langue hourrite. Paris 1980.

Laroche Louvite 1959 = E. Laroche Dictionnaire de la langue louvite. Paris 1959.

Laryngales $1990=\mathrm{La}$ reconstruction des laryngales, hrsg. v. J. Kellens. Liège 1990. Rez.: G.-J. Pinault in BSL 86 / 21991 [1992] p. 116-118; F. O. Lindeman in Kratylos 371992 p. 58-62.

Laryngaltheorie 1988 = Die Laryngaltheorie und die Rekonstruktion des indogermanischen Laut- und Formensystems, hrsg. v. A. Bammesberger. Heidelberg 1988. Register von S. Ziegler 1990. Rez.: M. Peters in Idg. Chr. 33 Nr. G 231; F. O. Lindeman in HS 1021989 p. 268-297; R. S. P. Beekes in Amsterdamer Beiträge zur Älteren Germanistik 33 1991 p. 237-245.

Latacz Homer 1989 = J. Latacz Homer, Der erste Dichter des Abendlandes. 2. Aufl. München / Zürich 1989.

Latacz Troia und Homer $2001=\mathrm{J}$. Latacz Troia und Homer, Der Weg zur Lösung eines alten Rätsels. München / Berlin 2001.

Lat. Philologie 1996 = Einleitung in die lateinische Philologie, hrsg. von F. Graf. Stuttgart / Leipzig 1996. Rez.: W. Pfaffel in Kratylos 441999 p. 94-98.

LAW 1965 = Lexikon der Alten Welt. Zürich / Stuttgart 1965.

LDIA 1978 = Lingue e dialetti dell' Italia antica, hrsg. von A. L. Prosdocimi. Rom 1978. Aggiornamento e indici von A. Marinetti 1982.

Lehmann (Chr.) Relativsatz $1984=$ Chr. Lehmann Der Relativsatz, Typologie seiner Strukturen, Theorie seiner Funktionen, Kompendium seiner Grammatik. Tübingen 1984 (= Language Universals Series 3).

Lehmann (W. P.) Gothic Etymological Dictionary $1986=$ W. P. Lehmann, A Gothic Etymological Dictionary, based on the third edition of Feist Got. Wörterbuch. Leiden 1986.

Lehmann (W. P.) Idg. Forschung 1992 = W. P. Lehmann Die gegenwärtige Richtung der indogermanischen Forschung. Budapest 1992. Rez.: M. Kümmel in PFU 41998 p. 51-59. 
Lehmann (W. P.) PIE Syntax 1974 = W. P. Lehmann Proto-IndoEuropean Syntax. Austin 1974.

Leisi Sprach-Knigge 1992 = I. und E. Leisi Sprach-Knigge oder Wie und was soll ich reden ? 1. Aufl. Tübingen 1992 (3. Aufl. 1993).

Leisi Streiflichter $1995=$ E. Leisi Streiflichter: unzeitgemäße Essays zu Kultur, Sprache und Literatur. Tübingen 1995.

Leisi Wortinhalt $1974=$ E. Leisi Der Wortinhalt. 4. Aufl. Heidelberg 1974.

Lejeune Lepontica 1971 = M. Lejeune Lepontica. Paris 1971 (= Monographies Linguistiques 1).

Lejeune Mémoires I 1958 II 1971 III 1972 IV $1997=$ M. Lejeune Mémoires de philologie mycénienne. 4 Serien. Paris: I (1955-1957) 1958; Rom: II (1958-1963) 1971; III (1964-1968) 1972; IV (19691996) 1997.

Lejeune Notice $1993=\mathrm{M}$. Lejeune Notice biographique et bibliographique, suivie de l'exposé "D'Alcoy à Espanca: Réflexions sur les écritures paléo-hispaniques". Leuven 1993.

Lejeune Phonétique $1972=\mathrm{M}$. Lejeune Phonétique historique du mycénien et du grec ancien. 2. Aufl. Paris 1972.

Lejeune Vénète $1974=$ M. Lejeune Manuel de la langue vénète. Heidelberg 1974.

Leskien Handb. d. abulg. (aksl.) Sprache $1962=$ A. Leskien Handbuch der altbulgarischen Sprache. Heidelberg 1962.

Lesky Gr. Lit. 1957-1958 = A. Lesky Geschichte der griechischen Literatur. 1. Aufl. Bern 1957-1958, 3. Aufl. Bern und München 1971.

Leukart Frühgr. Nomina $1994=$ A. Leukart Die frühgriechischen Nomina auf -tās und -ās, Untersuchungen zu ihrer Herkunft und Ausbreitung (unter Vergleich mit den Nomina auf -eús). Wien 1994 (= SbÖAW 558). Rez.: J.-L. Perpillou in Kratylos 421997 p. 81-86.

Leumann Homerische Wörter $1950=$ M. Leumann Homerische Wörter. Basel 1950 (und Nachdruck).

Leumann Kleine Schriften $1959=$ M. Leumann Kleine Schriften, hrsg. von H. Haffter, E. Risch und W. Rüegg. Zürich 1959.

Leumann LLFL 1977 = M. Leumann Lateinische Laut- und Formenlehre. Neuausgabe München 1977 (= Erster Band von Leumann / Hofmann / Szantyr Lat. Gr.). Die Neuausgabe ersetzt eine erste Version aus der Feder von M. Leumann aus den Jahren 1926-1928. Die Version von 1926-1928 zählt als 5. Aufl. der Lateinischen Laut- und Formenlehre im Rahmen des Handbuchs der Altertumswissenschaft und war als 
gründliche Erneuerung der 4. Aufl. von F. Stolz abgefaßt worden. Sie ist in ihrer Kürze und Prägnanz unübertroffen.

Leumann Neuerungen $1952=$ M. Leumann Morphologische Neuerungen im altindischen Verbalsystem. Amsterdam 1952.

Leumann / Hofmann / Szantyr Allg. Teil 1965 = M. Leumann, J. B. Hofmann und A. Szantyr Allgemeiner Teil. Dieser bietet die allgemeinen Bemerkungen zu Leumann / Hofmann / Szantyr Lat. Gr. und befindet sich als Anhang in Hofmann / Szantyr Lat. Syntax 1965.

Leumann / Hofmann / Szantyr Lat. Gr. = M. Leumann, J. B. Hofmann und A. Szantyr Lateinische Grammatik. München 1977 und 1965 (im Rahmen des Handbuch der Altertumswissenschaft). Der erste Band ist hier als Leumann LLFL 1977 verzeichnet, der zweite Band als Hofmann / Szantyr Lat. Syntax 1965. Der zu beiden Bänden gehörige allgemeine Teil steht hier als Leumann / Hofmann / Szantyr Allg. Teil 1965.

LEW $=\mathrm{A}$. Walde Lateinisches etymologisches Wörterbuch. 3., neubearb. Aufl. von J. B. Hofmann. 3 Bände Heidelberg 1938-1956.

Lewandowski Linguist. Wörterbuch 1-3 $1994=$ Th. Lewandowski Linguistisches Wörterbuch. 6. Aufl. Heidelberg / Wiesbaden 1994 (= UTB 1518): 1 (A-H), 2 (I-R), 3 (S-Z).

Lex(icon) Gramm(aticorum) 1996 = Lexicon Grammaticorum, Who's Who in the History of World Linguistics, General Editor H. Stammerjohann. Tübingen 1996.

LfgrE $=$ Lexikon des frühgriechischen Epos, hrsg. vom Thesaurus Linguae Graecae in Hamburg. Begründet von B. Snell. Göttingen: Lieferung 1 ( $\dot{\alpha}-\dot{\alpha} \varepsilon \iota \kappa \eta ́ \varsigma)$ 1955. Die Lieferungen 1-9 sind als Band I (A) 1979 zusammengefaßt, die Lieferungen 10-14 als Band II (B- $\Lambda) 1991$.

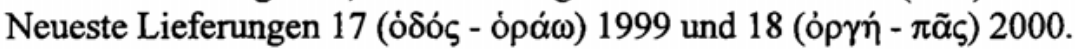
Lindeman Laryngeal Theory $1997=$ F. O. Lindeman Introduction to the "Laryngeal Theory". Rev. and augm. Edition der Ausgabe Oslo 1987. Innsbruck 1997 (= IBS Nr. 91). Rez.: B. Forssman in Kratylos 452000 p. 68-75. Rez. der Ausgabe von 1987: H. Rix in IF 961991 p. 269274; M. Mayrhofer in Kratylos 361991 p. 92-95. Vgl. ferner F. O. Lindeman in HS 1021989 p. 268-297 (Rez. von Laryngaltheorie 1988).

Lingue e dialetti 1978 = Lingue e dialetti dell' Italia antica, hrsg. von A. L. Prosdocimi. Aggiornamento e indici a cura di A. Marinetti. Padua 1982.

Lingue indoeuropee 1994 = Le lingue indoeuropee, hrsg. von A. Giacalone Ramat und P. Ramat. Bologna 1994. Rez.: B. Schirmer in Kratylos 
421997 p. 39-43. Zur englischen Übersetzung s.o. unter IndoEuropean Languages 1998.

Linguistic Change and Reconstruction Methodology $1990=$ Linguistic Change and Reconstruction Methodology, hrsg. von Ph. Baldi. Berlin / New York 1990 (= Trends in Linguistics, Studies and Monographs 45). Lipp Palatale $1994=$ R. Lipp Die indogermanischen Palatale im Indoiranischen. Diss. Freiburg 1994. Eine Publikation ist in Vorbereitung.

LIV 1998 = Lexikon der indogermanischen Verben, Die Wurzeln und ihre Primärstammbildungen, unter Leitung von $\mathrm{H}$. Rix, bearbeitet von $\mathrm{M}$. Kümmel, Th. Zehnder, R. Lipp, B. Schirmer. Wiesbaden 1998; s.u. F 203. Neuauflage s.u. LIV 2001. LIV 2001 konnte nicht mehr berücksichtigt werden. Alle Verweise auf LIV beziehen sich auf LIV 1998. Rez. von LIV 1998: E. Seebold in IF 1041999 p. 287-299; Ch. de Lamberterie in BSL 95 / 22000 p. 139-145.

LIV 2001 = Lexikon der indogermanischen Verben. Neuauflage bearbeitet von H. Rix und M. Kümmel. Wiesbaden 2001.

Lockwood Idg. Sprachw. $1982=$ W. B. Lockwood Indogermanische Sprachwissenschaft. Tübingen 1982. Das englische Original: IndoEuropean Philology. London 1969.

Lockwood Überblick $1979=$ W. B. Lockwood Überblick über die indogermanischen Sprachen. Tübingen 1979. Das engl. Original: A Panorama of Indo-European languages. London 1972.

Lohmann Genus und Sexus 1932 = J. Lohmann Genus und Sexus, Eine morphologische Studie zum Ursprung der indogermanischen nominalen Genus-Unterscheidung. Göttingen 1932.

Lommel Kleine Schriften $1978=$ H. Lommel Kleine Schriften. Wiesbaden 1978.

Lubotsky Nominal Accentuation $1988=$ A. M. Lubotsky The System of Nominal Accentuation in Sanskrit and Proto-Indo-European. Leiden 1988. Rez.: S. W. Jamison in JAOS 1111991 p. 419-422.

Lubotsky RV Word Concordance 1997 = A. Lubotsky A Rgvedic Word Concordance. 2 Teile New Haven 1997 (= American Oriental Series 82-83).

Lühr Egill $2000=$ R. Lühr Die Gedichte des Skalden Egill. Dettelbach 2000 (= Jenaer Indogermanistische Textbearbeitung 1).

Lühr Expressivität $1988=$ R. Lühr Expressivität und Lautgesetz im Germanischen. Heidelberg 1988.

Lühr Hildebrandlied I / II 1982 = R. Lühr Studien zur Sprache des Hildebrandliedes. Frankfurt a. M. 1982: Teil I (Herkunft und Sprache); Teil II (Kommentar). 
Lühr Neuhochdeutsch $1986=$ R. Lühr Neuhochdeutsch, Eine Einführung in die Sprachwissenschaft. 4. Aufl. München 1986.

Luraghi Casi e preposizioni $1996=$ S. Luraghi Studi su casi e preposizioni nel greco antico. Pavia 1996.

Luraghi Hittite 1997 = S. Luraghi Hittite. München / New Castle 1997 (= Languages of the World, Materials 114).

Luraghi Old Hittite Sentence Structure $1990=$ S. Luraghi Old Hittite Sentence Structure. London / New York 1990.

MacDonell Vedic Grammar $1910=$ A. A. MacDonell A Vedic Grammar. Straßburg 1910 (davon indische Nachdrucke).

Macqueen Hittites 1986 = J. G. Macqueen The Hittites and their Contemporaries in Asia Minor. 2. Aufl. London 1986. Als Paperback 1996.

Mallory In Search of the Indo-Europeans $1989=\mathrm{J}$. P. Mallory In Search of the Indo-Europeans, Language, Archaeology and Myth. London 1989. Kritische Rez.: B. Schlerath in Praehistorische Zeitschrift 67 1992 p. 132-137.

Mallory / Adams Encyclopedia $1997=$ J. P. Mallory and D. Q. Adams Encyclopedia of Indo-European Culture. London und Chicago 1997. Rez.: St. Zimmer in JIES 271999 p. 105-163 und in Kratylos 452000 p. 46-52; A. Häusler in IF 1052000 p. 314-318.

Mann IE Comparative Dictionary 1984 / $1987=$ S. E. Mann An IndoEuropean Comparative Dictionary. Hamburg 1984 / 1987. Kritische Rez: M. Mayrhofer in Kratylos 341989 p. 41-45 (p. 45: „ein so schlechtes Buch").

Manual de linguistica indoeuropea I-III 1995-1998 = F. R. Adrados, A. Bernabé, J. Mendoza Manual de lingüistica indoeuropea. Madrid: I (Prólogo, introducción fonética) 1995; II (Morfología nominal y verbal) 1996; III (Morfología: pronombres, adverbios, particulas y numerales; Syntaxis; Differenciación dialectal) 1998.

Marazzi Geroglifico 1990 = M. Marazzi Il geroglifico anatolico: Problemi di analisi e prospettive di ricerca. Rom 1990.

Marinetti Iscriz. sudpicene $1985=$ A. Marinetti Le iscrizioni sudpicene, I: Testi. Florenz 1985 (= Lingue e Iscrizioni dell' Italia Antica 5). Rez.: G. Meiser in Kratylos 321987 p. 110-118.

Marouzeau Latin littéraire $1949=\mathrm{J}$. Marouzeau Quelques aspects de la formation du latin littéraire. Paris 1949.

Martínez García Nombres en $-v=F$. J. Martínez García Los nombres en -v del griego. Frankfurt a. M. 1994 (= Europäische Hochschulschriften, Reihe XXI, Band 166). 
Masson (E.) Immortalité 1991 = E. Masson Le combat pour l'immortalité, Héritage indo-européen dans la mythologie anatolienne. Paris 1991.

Masson (O.) Anatolian Languages $1994=0$. Masson Anatolian Languages in Cambridge Ancient History, Band III / 2. 2. Aufl. Cambridge 1991. Zum Phrygischen p. 666-669, zum Lydischen p. 669-671, zum Lykischen p. 671-674, zum Karischen p. 674-676.

Masson (O.) ICS 1961 + Add. $1983=0$. Masson Les inscriptions chypriotes syllabiques, Recueil critique et commenté. Paris 1961. Nachdruck mit Addenda nova 1983. Rez. der ersten Aufl. 1961: E. Risch in Kratylos 101965 p. 88-94.

Matthews Syntax 1981 = P. H. Matthews Syntax. Cambridge u.a.O. 1981 . Maurach Lat. Dichtersprache 1983 = G. Maurach Enchiridion Poeticum, Hilfsbuch zur lateinischen Dichtersprache. Darmstadt 1983.

Mayrhofer Altiranische Namen $1979=$ M. Mayrhofer Die altiranischen Namen. Wien 1979. Das Werk ist Teil des Iranischen Personennamenbuches, s.o. s.v.

Mayrhofer EWAia = M. Mayrhofer Etymologisches Wörterbuch des Altindoarischen. Heidelberg 1986ff.. Für alle unsere Belange sind Band I $(A-D H) 1991$ und Band II $(N-H) 1996$ von entscheidender Bedeutung..

Mayrhofer Indo-Arier $1966=$ M. Mayrhofer Die Indo-Arier im Alten Vorderasien. Mit einer analytischen Bibliographie. Wiesbaden 1966. Dazu vgl. ferner ders. Die Arier im vorderen Orient - ein Mythos? Wien 1974 (= SbÖAW, 294. Band, 3. Abhandlung).

Mayrhofer KEWA = M. Mayrhofer Kurzgefaßtes etymologisches Wörterbuch des Altindischen. 4 Bde. Heidelberg 1956-1980.

Mayrhofer Kleine Schriften I 1979 II 1996 = M. Mayrhofer Ausgewählte Kleine Schriften. Wiesbaden: I 1979 hrsg. von S. Deger-Jalkotzy und R. Schmitt; II 1996 hrsg. von R. Schmitt.

Mayrhofer Lautlehre 1986 = M. Mayrhofer Indogermanische Grammatik, Band I, 2. Halbband, Lautlehre. Heidelberg 1986. Rez.: B. Forssman in Kratylos 331988 p. 56-63.

Mayrhofer Pāli 1951 = M. Mayrhofer Handbuch des Pāli. I. Teil: Grammatik; II. Teil: Texte und Glossar. Heidelberg 1951.

Mayrhofer Sanskrit-Gramm. $1978=$ M. Mayrhofer Sanskrit Grammatik mit sprachvergleichenden Erläuterungen. 3. Aufl. Berlin / New York 1978 (= Sammlung Göschen Nr. 2207).

Mayrhofer Sanskrit und die Sprachen Alteuropas $1983=$ M. Mayrhofer Sanskrit und die Sprachen Alteuropas, Zwei Jahrhunderte des Widerspiels von Entdeckungen und Irrtümern. Göttingen 1983 (= NAWG, Jahrgang 1983, Nr. 5). 
Mayrhofer Supplement $1978=$ M. Mayrhofer Supplement zur Sammlung der altpersischen Inschriften. Wien 1978 (= SbÖAW, 338. Band).

Mayrhofer s. auch oben Brandenstein / Mayrhofer.

McCone Old Irish Nasal Presents $1991=\mathrm{K}$. McCone The Indo-European Origins of the Old Irish Nasal Presents, Subjunctives and Futures. Innsbruck 1992.

McCone Relative Chronology $1996=\mathrm{K}$. McCone Towards a Relative Chronology of Ancient and Medieval Celtic Sound Change. Maynooth 1996 (= Maynooth Studies in Celtic Linguistics I).

McCone / Simms Progress in Medieval Irish Studies $1996=$ K. McCone und K. Simms Progress in Medieval Irish Studies. Maynooth 1996.

Meid Archäologie und Sprachwissenschaft $1989=$ W. Meid Archäologie und Sprachwissenschaft, Kritisches zu neueren Hypothesen der Ausbreitung der Indogermanen. Innsbruck 1989 (= IBS, Vorträge und Kleinere Schriften 43). Kritische Rez.: B. Schlerath in Praehistorische Zeitschrift 671992 p. 137-139.

Meid /b/ 1989 = W. Meid Das Problem von indogermanisch /b/. Innsbruck 1989 (= Vorträge und Kleinere Schriften 44).

Meid Botorrita $1993=\mathrm{W}$. Meid Die erste Botorrita-Inschrift: Interpretation eines keltiberischen Sprachdenkmals. Innsbruck 1993 (= IBS Nr. 76). Vgl. ders. Celtiberian Inscriptions. Budapest 1994 und Kleinere keltiberische Sprachdenkmäler. Innsbruck 1996 (= IBS, Vorträge und kleinere Schriften 64).

Meid Gaulish inscriptions 1992 = W. Meid Gaulish Inscriptions: Their Interpretation in the Light of Archaeological Evidence and their Value as a Source of Linguistic and Sociological Information. Budapest 1992 (2. Rev. Ed. 1994).

Meid s. auch oben unter Krahe / Meid.

Meier-Brügger Gr. Sprachw. I / II $1992=$ M. Meier-Brügger Griechische Sprachwissenschaft. 2 Bände Berlin / New York 1992 (= Sammlung Göschen Nr. 2241 und Nr. 2242): I (Bibliographie, Einleitung, Syntax); II (Wortschatz, Formenlehre, Lautlehre, Indizes).

Meillet Aperçu 1975 = A. Meillet Aperçu d'une histoire de la langue grecque. Paris 1913. Dazu verschiedene Nachdrucke. 8. Aufl. 1975 mit einer Bibliographie von O. Masson. Zur Bewertung dieses epochemachenden Werkes: $\rightarrow$ A. Morpurgo Davies in Meillet et la linguistique de son temps 1988 p. $235-252$.

Meillet Arménien classique $1936=$ A. Meillet Esquisse d'une grammaire comparée de l'arménien classique. 2. édition entièrement remaniée. Wien 1936. 
Meillet Esquisse 1928 = A. Meillet Esquisse d'une histoire de la langue latine. Paris 1928.

Meillet et la linguistique de son temps $1988=$ Antoine Meillet et la linguistique de son temps, hrsg. von S. Auroux. Lille 1988 (= HEL [Histoire, Épistémologie, Langage] 10 / II).

Meillet Introduction $1949=\mathrm{A}$. Meillet Introduction à l'étude comparative des langues indo-européennes. Paris 1949 (Wiederabdruck der 8. Aufl. Alabama 1964).

Meillet Linguistique historique et linguistique générale I 1921 II $1936=$ A. Meillet Linguistique historique et linguistique générale. Paris I 1921, II 1936 (dazu verschiedene Nachdrucke).

Meillet Méthode comparative $1925=\mathrm{A}$. Meillet La méthode comparative en linguistique historique. Oslo / Paris 1925 (und Nachdrucke).

Meillet / Vendryes Grammaire comparée $1924=$ A. Meillet und J. Vendryes Traité de grammaire comparée des langues classiques. Paris 1924. Ein vergleichbares Werk: s.u. unter Sihler New Comparative Grammar 1995.

Meiser (Hist.) Laut- u. Formenlehre (d. lat. Sprache) $1998=$ G. Meiser Historische Laut- und Formenlehre der lateinischen Sprache. Darmstadt 1998. Rez.: B. Vine in Kratylos 462001 p. 118-126.

Meiser Perfekt 1991 = G. Meiser Vorgeschichte und Ausbildung des lateinischen Perfektsystems. Habilitationsschrift Freiburg i. Br. 1991.

Meiser Umbrisch $1986=$ G. Meiser Lautgeschichte der umbrischen Sprache. Innsbruck 1986 (= IBS Nr. 51).

Meister Homer. Kunstsprache $1921=$ K. Meister Die homerische Kunstsprache. Leipzig 1921.

Meisterhans / Schwyzer Att. Inschr. $1900=$ K. Meisterhans Grammatik der attischen Inschriften. 3. Aufl., vermehrt und verbessert von E. Schwyzer. Berlin 1900.

Melchert Abl. and Instr. $1977=$ H. C. Melchert Ablative and Instrumental in Hittite. Diss. Harvard 1977.

Melchert Anatolian Historical Phonology $1994=$ H. C. Melchert Anatolian Historical Phonology. Amsterdam / Atlanta 1994. Rez.: E. Rieken in BiOr 551998 Sp. 473-475; N. Oettinger in Kratylos 431998 p. 96108.

Melchert Cuneiform Luvian $1993=$ H. C. Melchert Cuneiform Luvian Lexicon. Chapel Hill 1993.

Melchert Hittite Historical Phonology $1984=$ H. C. Melchert Studies in Hittite Historical Phonology. Göttingen 1984 (= ZVS, Ergänzungsheft 32). 
Melchert Lycian $1993=$ H. C. Melchert Lycian Lexicon. 2., völlig umgearb. Aufl. Chapel Hill 1993.

Méndez Dosuna Noroeste 1985 = J. Méndez Dosuna Noroeste (Dialectos dorios del noroeste). Salamanca 1985.

Metzler Lexikon Sprache 1993 und $2000=$ Metzler Lexikon Sprache, hrsg. von H. Glück. 1. Aufl. Stuttgart / Weimar 1993. 2., überarbeitete und erweiterte Aufl. 2000.

Meyer Lat. Epigraphik $1973=$ E. Meyer Einführung in die lateinische Epigraphik. Darmstadt 1973.

$\mathrm{MH}=$ Museum Helveticum.

Mikkola Abstraktion 1964 = E. Mikkola Die Abstraktion, Begriff und Struktur, Eine logisch-semantische Untersuchung auf nominalistischer Grundlage unter besonderer Berücksichtigung des Lateinischen. Helsinki 1964.

Mikkola Kompositum I 1971 = E. Mikkola Das Kompositum, Band I (vgl. besonders das erste Kapitel 'Die Zusammensetzung, Begriff und Struktur' p. 5ff. und die Bibliographie p. 56ff.). 2. Aufl. 1971.

Miklosich Vergl. Syntax 1868-1874 = Fr. Miklosich Vergleichende Syntax der slavischen Sprachen. Wien 1868-1874.

Minos $=$ Minos. Revista de filología egea. Salamanca.

Monro Homer. Dialect $1891=$ D. B. Monro A Grammar of the Homeric Dialect. 2. Aufl. Oxford 1892.

Morpurgo Davies Ottocento 1996 = A. Morpurgo Davies La linguistica dell' Ottocento. Bologna 1996.

MSS = Münchener Studien zur Sprachwissenschaft.

Müller Nominativ und Akkusativ $1908=$ C. F. W. Müller Syntax des Nominativs und Akkusativs im Lateinischen. Leipzig / Berlin 1908.

Mutzbauer Gr. Tempuslehre $1189321909=$ C. Mutzbauer Die Grundlagen der griechischen Tempuslehre und der homerische Tempusgebrauch, Ein Beitrag zur historischen Syntax der griechischen Sprache. 2 Bände. Straßburg 1893-1909.

Mutzbauer Konj. und Opt. 1908 = C. Mutzbauer Die Grundbedeutung des Konjunktivs und Optativs und ihre Entwicklung im Griechischen. Leipzig / Berlin 1908.

Mykenaïka 1990 [1992] = Mykenaïka. Actes du IXe Colloque international sur les textes mycéniens et égéens 1990 in Athen. Paris 1992 (= BCH, Suppl. 25).

Nagy $=$ Greek Dialects $1970=$ G. Nagy Greek Dialects and the Transformation of an Indo-European Process. Cambridge / Mass. 1970. Rez.: 
A. Morpurgo Davies in CR 221972 p. 371-374; C. J. Ruijgh in Scripta Minora I 1991 p. 635-650.

Namenforschung 11995 / 21996 = Namenforschung / Name Studies / Les noms propres, Ein internationales Handbuch zur Onomastik, hrsg. von E. Eichler, G. Hilty, H. Löffler, H. Steger, L. Zgusta. Berlin / New York. 2 Teilbände: 1 1995; 21996 (= HSK 11.1 und 11.2). Rez.: R. Bergmann in BNF N.F. 32 / 41997 p. 457-471.

Narten Kleine Schriften I 1995 = J. Narten Kleine Schriften, hrsg. von M. Albino und M. Fritz. Band I Wiesbaden 1995.

Narten Sigmatische Aoriste 1964 = J. Narten Die sigmatischen Aoriste im Veda. Wiesbaden 1964.

Narten Yasna Haptanhāiti 1986 = J. Narten Der Yasna Haptanhāiti. Wiesbaden 1986.

Narten s. auch oben unter Hoffmann / Narten.

NAWG $=$ Nachrichten der Akademie der Wissenschaften in Göttingen.

Neu Aheth. Glossar 1983 = E. Neu Glossar zu den althethitischen Ritualtexten. Wiesbaden 1983 (= StBoT 26).

Neu Aheth. Ritualtexte $1980=$ E. Neu Althethitische Ritualtexte in Umschrift. Wiesbaden 1980 (= StBoT 25).

Neu Anitta 1974 = E. Neu Der Anitta-Text. Wiesbaden 1974 (= StBoT 18). Dazu: $\rightarrow$ G. Steiner Struktur und Bedeutung des sog. AnittaTextes in OA 231984 p. 53-73.

Neu Hurritisch 1988 = E. Neu Das Hurritische: Eine altorientalische Sprache in neuem Licht. Mainz 1988 (= AAWL 1988 Nr. 3).

Neu Interpret. Mediopassiv $1968=$ E. Neu Interpretation der hethitischen mediopassiven Verbalformen. Wiesbaden 1968 (= StBoT 5).

Neu Lokativ 1980 = E. Neu Studien zum endungslosen "Lokativ" des Hethitischen. Innsbruck 1980 (= IBS, Vorträge und kleinere Schriften 23).

Neu Mediopassiv $1968=$ E. Neu Das hethitische Mediopassiv und seine indogermanischen Grundlagen. Wiesbaden 1968 (= StBoT 6).

Neu s. auch Rüster / Neu.

Neumann Indogermanistik $1967=$ G. Neumann Indogermanische Sprachwissenschaft 1816 und 1966. Innsbruck 1967.

Neumann Kleine Schriften 1994 = G. Neumann Ausgewählte kleine Schriften. Hrsg. von E. Badali, H. Nowicki und S. Zeilfelder. Innsbruck 1994 (=IBS 77).

Neumann Phrygisch und Griechisch $1988=$ G. Neumann Phrygisch und Griechisch. Wien 1988 (= SbÖAW 499). 
Neumann Weiterleben $1961=$ G. Neumann Untersuchungen zum Weiterleben hethitischen und luwischen Sprachgutes in hellenistischer und römischer Zeit. Wiesbaden 1962.

Neve Hattuša 1996 = P. Neve Hुattuša - Stadt der Götter und Tempel, Neue Ausgrabungen in der Hauptstadt der Hethiter. 2. Aufl. Mainz 1996 (= Sonderheft der Antiken Welt).

New Sound of Indo-European $1989=$ The New Sound of Indo-European, Essays in Phonological Reconstruction, hrsg. von Th. Vennemann. Berlin 1989 (= Trends in Linguistics 41). Rez.: O. Szemerényi in Diachronica 61989 p. 237-269.

Noreen Altisländisch und Altnorwegisch $1923=$ A. Noreen Altisländische und altnorwegische Grammatik unter Berücksichtigung des Urnordischen. Halle 1923.

Noreen Altschwedisch 1904 = A. Noreen Altschwedische Grammatik, Mit Einschluß des Altgutnischen. Halle 1904.

Nowicki s-Stämme $1976=\mathrm{H}$. Nowicki Die neutralen s-Stämme im indoiranischen Zweig des Indogermanischen. Phil. Diss. Würzburg 1976.

NTS $=$ Norsk Tidskrift for Sprogvidenskap.

Numerals 1992 = Indo-European Numerals, hrsg. von J. Gvozdanović. Berlin / New York 1992 (= Trends in Linguistics, Studies and Monographs 57). Zum Buch s.u. F 500 Abs. 3 b.

Nussbaum Head and Horn 1986 = A. J. Nussbaum Head and Horn in Indo-European. Berlin / New York 1986. Rez.: R. S. P. Beekes in Kratylos 341989 p. 55-59.

Nussbaum Two Studies 1998 = A. J. Nussbaum Two Studies in Greek and Homeric Linguistics. Göttingen 1998 (= Hypomnemata 120). Rez.: B. Forssman in Kratylos 462001 p. 113-117.

Odyssey I (Books i-viii) 1988 II (Books ix-xvi) 1989 III (Books xviixxiv) 1992 = A Commentary on Homer's Odyssey. Oxford: I von A. Heubeck (mit General Introduction), S. West (mit The Transmission of the Text und Books i-iv) und J. B. Hainsworth (mit The Epic Dialect und Books v-viii); II von A. Heubeck (mit Books ix-xii) und A. Hoekstra (mit Books xiii-xvi) 1989; III von J. Russo (mit Books xvii-xx), M. Fernández-Galiano (mit Books xxi-xxii) und A. Heubeck (mit Books xxiii-xxiv) 1992. Der Oxforder Kommentar ist eine "Revised version, without text and translation, of the six-volume edition commissioned by the Fondazione Lorenzo Valla and published by Mondadori Milano 1981-1986". 
Oertel Dativi finales $1941=\mathrm{H}$. Oertel Die Dativi finales abstrakter Nomina und andere Beispiele nominaler Satzfügung in der vedischen Prosa. München 1942.

Oettinger Verbum $1979=\mathrm{N}$. Oettinger Die Stammbildung des hethitischen Verbums. Nürnberg 1979. Eine Ergänzung bietet ders. Die hethitischen Verbalstämme in Grammatica Ittita 1992 p. 214-252.

Ohlstadt 1994 [1996] = Tagungsband „Hellenische Mythologie / Vorgeschichte" (Titel auch neugr.) 1994 in Ohlstadt / Oberbayern, hrsg. von N. Dimoudis und A. Kyriatsoulis. Altenburg 1996 (Veranstalter: Verein zur Förderung der Aufarbeitung der hellenischen Geschichte Weilheim in Oberbayern und Club Griechischer Akademiker München).

Ohlstadt 1996 [1998] = Tagung „Die Geschichte der hellenischen Sprache und Schrift" (Titel auch neugr. und engl.) 1996 in Ohlstadt / Oberbayern, hrsg. von N. Dimoudis und A. Kyriatsoulis. Altenburg 1998 (Veranstalter: Verein zur Förderung der Aufarbeitung der hellenischen Geschichte Weilheim in Oberbayern).

OLD = Oxford Latin Dictionnary. Oxford 1968-1982.

Oldenberg Kleine Schriften $1967=\mathrm{H}$. Oldenberg Kleine Schriften, hrsg. von K. L. Janert. 2 Teile. Wiesbaden 1967.

Oldenberg Noten 1909-1912 = H. Oldenberg Rgveda, Textkritische und exegetische Noten. I - VI Berlin 1909, VII - X Berlin 1912.

Old English Runes 1991 = Old English Runes and their Continental Background, hrsg. von A. Bammesberger. Heidelberg 1991.

Olsen Instrument Noun Suffix $1988=$ B. A. Olsen The Proto-IndoEuropean Instrument Noun Suffix *-tlom and its variants. Copenhagen 1988.

Olsen Noun $1999=$ B. A. Olsen The Noun in Biblical Armenian, Origin and Word-Formation - with special emphasis on the Indo-European heritage. Berlin 1999 (= Trends in Linguistics, Studies and Monographs 119). Rez.: S. Zeilfelder in Sprache 401998 [2000] p. 105-109; R. Schmitt in Kratlos 462001 p. 80-88.

$\mathrm{OLZ}=$ Orientalistische Literaturzeitung.

Palmer Descriptive and Comparative Linguistics $1972=$ L. R. Palmer Descriptive and Comparative Linguistics, A Critical Introduction. London 1972.

Palmer Greek Language $1980=$ L. R. Palmer The Greek Language London / Boston 1980. Dt. Übersetzung von W. Meid. Innsbruck 1986 (= IBS Nr. 50). 
Panzer Slav. Sprachen 1991 = B. Panzer Die slavischen Sprachen in Gegenwart und Geschichte. Sprachstrukturen und Verwandtschaft. Frankfurt a. M. 1991 (= Heidelberger Publikationen zur Slavistik, A. Linguistische Reihe 3).

Partherreich [1996] 1998 = Das Partherreich und seine Zeugnisse / The Arsacid Empire: Sources and Documentation, Beiträge des internationalen Colloquiums 1996 in Eutin, hrsg. von J. Wiesenhöfer. Stuttgart 1998.

PBB = Beiträge zur Geschichte der deutschen Sprache und Literatur. (Halle und) Tübingen (das Kürzel ist hervorgegangen aus H. Paul, W. Braune, Beiträge ... ).

Pedersen Cinquième déclinaison $1926=\mathrm{H}$. Pedersen La cinquième déclinaison latine. Kopenhagen 1926.

Pedersen Hittitisch $1938=\mathrm{H}$. Pedersen Hittitisch und die anderen indoeuropäischen Sprachen. Kopenhagen 1938.

Pedersen Kl. Schr. zum Arm. $1982=$ H. Pedersen Kleine Schriften zum Armenischen, hrsg. von R. Schmitt. Hildesheim / New York 1982.

Pedersen Tocharisch $1941=\mathrm{H}$. Pedersen Tocharisch vom Gesichtspunkt der indoeuropäischen Sprachvergleichung. Kopenhagen 1942.

Pedersen Vgl. Gramm. d. kelt. Spr. I 1909 II $1913=$ H. Pedersen Vergleichende Grammatik der keltischen Sprachen. 2 Bände Göttingen: I (Einleitung und Lautlehre) 1909; II (Bedeutungslehre) 1913.

Pellegrini / Prosdocimi Lingua Venetica I / II $1967=$ G. B. Pellegrini und A. L. Prosdocimi La lingua Venetica. Padova 1967. I: Le iscrizioni von G. B. Pellegrini und A. L. Prosdocimi; II: Studi von A. L. Prosdocimi.

Peters Laryngale $1980=\mathrm{M}$. Peters Untersuchungen zur Vertretung der indogermanischen Laryngale im Griechischen. Wien 1980. Rez.: R. S. P. Beekes in Kratylos 261981 [1982] p. 106-115; J. Catsanicos in BSL 77 / 21982 p. 89-95; B. Forssman in ZVS 961982 [1983] p. 290-292; C. J. Ruijgh in Mnemosyne 361983 p. 373-380.

Petit *sue- 1999 = D. Petit *Sune- en grec ancien: La famille du pronom réfléchi, Linguistique grecque et comparaison indo-européenne. Louvan 1999 (= Collection Linguistique, publiée par la Société de Linguistique de Paris, 79).

Petit Lituanien 1999 = D. Petit Lituanien. Paris 1999 (in LALIES 19, Aussois 1998).

Pfeiffer Klass. Philologie I $1970=$ R. Pfeiffer Geschichte der klassischen Philologie, Von den Anfängen bis zum Ende des Hellenismus. Reinbek bei Hamburg 1970. Die Klass. Philologie ist eine Übersetzung (durch 
M. Arnold) des engl. Originals „History of Classical Scholarship“. Oxford 1968.

PFU $=$ Philologia Fenno-Ugrica .

Pinault Tokharien $1989=$ G.-J. Pinault Introduction au tokharien. Paris

1989 (in LALIES, Actes des sessions de linguistique et de littérature Nr.7, Aussois 1985).

Pinkster Lateinische Syntax 1988 bzw. Latin Syntax $1990=$ H. Pinkster Lateinische Syntax und Semantik. Tübingen 1988 (= UTB Nr. 1462 im Francke Verlag). Der Text ist die Übersetzung des niederländischen Originals von 1984. Eine englische Version ist 1990 in London / New York unter dem Titel Latin Syntax and Semantics erschienen.

Place de l' Arménien 1986 = La place de l'arménien dans les langues indoeuropéennes, hrsg. von M. Leroy und F. Mawet. Louvain 1986.

Plath Streitwagen $1994=$ R. Plath Der Streitwagen und seine Teile im frühen Griechischen. Sprachliche Untersuchungen zu den mykenischen Texten und zum homerischen Epos. Nürnberg 1994 (= Erlanger Beiträge zur Sprache, Literatur und Kunst 76). Rez.: I. Hajnal in Kratylos 421997 p. 78-81.

Poccetti Nuovi Documenti Italici s.u. bei Vetter.

Pokorny IEW 1959-1969 = J. Pokorny Indogermanisches etymologisches Wörterbuch. I / II Bern / München 1959-1969.

Portraits I / II 1966 = Portraits of Linguists, A Biographical Source Book for the History of Western Linguistics, 1764-1963, hrsg. von Th. A. Sebeok. Bloomington / London 1966: I (From Sir William Jones to Karl Brugmann); II (From Eduard Sievers to Benjamin Lee Whorf).

Porzig Gliederung 1954 = W. Porzig Die Gliederung des indogermanischen Sprachgebiets. Heidelberg 1954.

Porzig Satzinhalte $1942=$ W. Porzig Die Namen für Satzinhalte im Griechischen und im Indogermanischen. Berlin 1942 (= Untersuchungen zur indogermanischen Sprach- und Kulturwissenschaft 10).

Porzig Wunder der Sprache 1971 = W. Porzig Das Wunder der Sprache, Probleme, Methoden und Ergebnisse der Sprachwissenschaft. 5. Aufl. durchgesehen von A. Jecklin und H. Rupp. München 1971 (= UTB 32). 8. Aufl. 1986. Die 1. Aufl. dieses großartigen Werkes stammt von 1950.

Prins Hittite neuter 1997 = A. Prins Hittite neuter singular - neuter plural, Some Evidence for a Connection. Leiden 1997.

Probleme der lat. Gramm. 1973 = Probleme der lat. Grammatik, hrsg. von K. Strunk. Darmstadt 1973 (= Wege der Forschung 93). 
Probleme der Namenbildung 1986 [1988] = Probleme der Namenbildung, Rekonstruktion von Eigennamen und der ihnen zugrundeliegenden Appellative, Akten eines internationalen Symposiums 1986 in Uppsala, hrsg. von Th. Andersson. Uppsala 1988.

Puhvel Analecta Indoeuropea $1981=$ J. Puhvel Analecta Indoeuropea, Delectus operum minorum ... annos 1952-1977 complectens. Innsbruck 1981 (= IBS 35).

Puhvel HED 1 / 2 1984, 3 1991, 4 1997, 52001 = J. Puhvel Hittite Etymological Dictionary. Berlin / New York / Amsterdam: Band 1 (Words beginning with $\mathrm{A}$ ) and 2 (Words beginning with $\mathrm{E}$ and I) 1984; Band 3 (Words beginning with $\mathrm{H}$ ) 1991; Band 4 (Words beginning with $\mathrm{K}$ ) 1997; Band 5 (Words beginning with L) 2001. Zu Band 4 vgl. I. Hajnal in HS 1121999 p. 305-315

Puhvel Laryngeals and the IE Verb $1960=\mathrm{J}$. Puhvel Laryngeals and the Indo-European Verb. Berkeley 1960. Rez.: W. Cowgill in Language 39 1963 p. $248-270$.

Radke Archaisches Latein $1981=$ G. Radke Archaisches Latein. Darmstadt 1981 (=Erträge der Forschung 150).

Ramat s.o. Lingue indoeuropee 1994.

Rasmussen Morphophonematik 1989 = J. E. Rasmussen Studien zur Morphophonematik der indogermanischen Grundsprache. Innsbruck 1989 (= IBS Nr. 55).

Rasmussen Selected Papers 1999 = J. E. Rasmussen Selected Papers on Indo-European Linguistics, 2 Bände. Kopenhagen 1999.

Raulwing Horses $2000=$ P. Raulwing Horses, Chariots and IndoEuropeans, Foundations and Methods of Chariotry Research from the Viewpoint of Indo-European Linguistics. Budapest 2000. Rez.: K. Jones-Bley in JIES 282000 p. 440-449.

REArm $=$ Revue des Etudes Arméniennes.

Rédei Idg.-ural. Sprachkontakte $1986=\mathrm{K}$. Rédei $\mathrm{Zu}$ den indogermanischuralischen Sprachkontakten. Wien 1986 (= SbÖAW 468).

Rehder Slav. Sprachw. $1998=$ P. Rehder Einführung in die slavische Sprachwissenschaft. Darmstadt 3. Aufl. 1998.

Reichler-Béguelin Type mēns 1986 = M.-J. Reichler-Béguelin Les noms latins du type mēns. Bruxelles 1986 (= Collection Latomus Band 195). Rez.: F. Mawet in Kratylos 341989 p. 96-102.

$\mathrm{REL}=$ Revue des études latines. 
Renfrew Archaeology and Language $1987=$ C. Renfrew Archaeology and Language: The Puzzle of Indo-European Origins. London 1987. Rez.: E. Campanile in Kratylos 331988 p. 53-56.

Renou Bibliographie 1997 = Bibliographie des travaux de Louis Renou, von G. Pinault. Paris 1997 (= Suppl. zum Bulletin d'études indiennes 13-14 1995-1996 [1997]).

Res Mycenaeae 1981 [1983] = Res Mycenaeae, Akten des VII. Internationalen Mykenologischen Colloquiums 1981 in Nürnberg, hrsg. von A. Heubeck und G. Neumann. Göttingen 1983. Rez.: M. Peters in Idg. Chr. 30a Nr. 581; W. Blümel in GGA 2361984 p. 121-136; F. Bader in Kratylos 301985 p. 105-112.

$\mathrm{RGA}=$ Reallexikon der Germanischen Altertumskunde, begründet von $\mathrm{J}$. Hoops. 2. Aufl., völlig neu bearbeitet und stark erweitert unter Mitwirkung zahlreicher Fachgelehrter und unter redaktioneller Leitung von R. Müller hrsg. von H. Beck, H. Steuer und D. Tiempe. Bis jetzt vorliegend Band 11973 - Band 182001.

Riecke jan-Verben 1996 = J. Riecke Die schwachen jan-Verben des Althochdeutschen, Ein Gliederungsversuch. Göttingen 1996 (= Studien zum Althochdeutschen 32). Rez.: O. W. Robinson in Kratylos 441999 p. 127-130.

Rieken Nom. Stammbildung $1999=$ E. Rieken Untersuchungen zur nominalen Stammbildung des Hethitischen. Wiesbaden 1999 (StBoT 44).

RIG = Recueil des Inscriptions Gauloises. Paris. Band I 1985: M. Lejeune Textes gallo-grecs; Band II 1 1988: M. Lejeune Textes GalloÉtrusques, Textes Gallo-Latins sur pierre; Band III 1986: P.-M. Duval Les Calendriers.

Rijksbaron Verb in Class. Greek $1994=$ A. Rijksbaron The Syntax and Semantics of the Verb in Classical Greek. 2. Aufl. Amsterdam 1994.

Ringe Sound Changes in Tocharian I $1996=$ D. A. Ringe On the Chronology of Sound Changes in Tocharian. I (From Proto-IE to ProtoTocharian). New Haven 1996 (= American Oriental Series 80).

Risch Gerund. $1984=$ E. Risch Gerundivum und Gerundium. Gebrauch im klassischen und älteren Latein. Entstehung und Vorgeschichte. Berlin / New York 1984.

Risch Kleine Schriften 1981 = E. Risch Kleine Schriften. Hrsg. von A. Etter und M. Looser. Berlin / New York 1982.

Risch Wortbildung $1974=$ E. Risch Wortbildung der homerischen Sprache. 2. Aufl. Berlin 1974.

Ritter Armeno antiguo 1996 = R.-P. Ritter Introducción al armeno antiguo. Madrid 1996. 
Rix Etr. Texte I / II $1991=$ H. Rix Etruskische Texte. Editio minor, hrsg. von H. Rix in Zusammenarbeit mit G. Meiser. Tübingen 1991: Band I (Einleitung, Konkordanz, Indizes); Band II (Texte).

Rix Gentilnamensystem $1972=\mathrm{H}$. Rix Zum Ursprung des römischmittelitalischen Gentilnamensystems. In: Aufstieg und Niedergang der römischen Welt, Geschichte und Kultur Roms im Spiegel der neueren Forschung, hrsg. von H. Temporini. Band I / 2. Berlin / New York 1972 p. 700-758.

Rix Hist. Gramm. d. Gr. $1976=$ H. Rix Historische Grammatik des Griechischen. Darmstadt 1976. 2., korr. Aufl. 1992. Rez. der 2. Aufl.: G. Dunkel in AJPh 971976 p. 416-420; M. Peters in Sprache 231977 p. 65-67; F. Bader in BSL 72 / 21977 p. 134-140; C. J. Ruijgh in Mnemosyne 311978 p. 298-307.

Rix Kleine Schriften $2001=\mathrm{H}$. Rix Kleine Schriften, Festgabe für Helmut Rix zum 75. Geburtstag. Bremen 2001.

Rix Modussystem 1986 = H. Rix Zur Entstehung des urindogermanischen Modussystems. Innsbruck 1986 (= IBS, Vorträge und Kleinere Schriften Nr. 36). Rez.: E. Risch in Kratylos 321987 p. 46-50.

Rix Rätisch und Etruskisch $1998=\mathrm{H}$. Rix Rätisch und Etruskisch. Innsbruck 1998 (= IBS, Vorträge und Kleinere Schriften 68).

Rix Termini der Unfreiheit $1994=\mathrm{H}$. Rix Die Termini der Unfreiheit in den Sprachen Alt-Italiens. Stuttgart 1994 (= Forschungen zur Antiken Sklaverei 25).

Rosén Periphrase $1992=$ H. B. Rosén Die Periphrase, Wesen und Entstehung. Innsbruck 1992 (= IBS, Vorträge und kleinere Schriften 57).

$\mathrm{RPh}=$ Revue de Philologie.

Rubio Orecilla Sufijo de derivación nominal $1995=$ F. J. Rubio Orecilla El sufijo de derivación nominal *-iijo-/*-io- en los gerundios y gerundivos del Rg-Veda y el Avesta, Un estudio histórico-comparativo. Zaragoza 1995. Rez.: M. Kümmel in Kratylos 431998 p. 81-83; J. Haudry in BSL 93 / 21995 p. 134-139; s.u. W 202 Abs. 1.

Rüster / Neu Heth. Zeichenlexikon $1989=$ Chr. Rüster und E. Neu Hethitisches Zeichenlexikon, Inventar und Interpretation der Keilschriftzeichen aus den Boğazköy-Texten. Wiesbaden 1989.

Ruijgh Études 1967 = C. J. Ruijgh Études sur la grammaire et le vocabulaire du grec mycénien. Amsterdam 1967.

Ruijgh Scripta Minora I 1991 II $1996=$ C. J. Ruijgh Scripta Minora ad linguam Graecam pertinentia I, hrsg. von J. M. Bremer, A. Rijksbaron, F. M. J. Waanders. Amsterdam 1991; Scripta Minora ad linguam 
Graecam pertinentia II, hrsg. von A. Rijksbaron, F. M. J. Waanders. Amsterdam 1996.

Ruijgh „te épique“ 1971 = C. J. Ruijgh Autour de „te épique“, Études sur la syntaxe grecque. Amsterdam 1972.

Ruipérez Ilias und Odyssee $1999=$ M. S. Ruipérez Anthologie Ilias und Odyssee. Wiesbaden 1999. Übersetzung des span. Originals von 1963.

Ruipérez Opuscula 1989 = M. S. Ruipérez Opuscula selecta, Ausgewählte Arbeiten zur griechischen und indogermanischen Sprachwissenschaft, hrsg. von J. L. García-Ramón. Innsbruck 1989 (= IBS Nr. 58).

Sandhi Phenomena 1986 = Sandhi Phenomena in the Languages of Europe, hrsg. von H. Andersen. Berlin / New York / Amsterdam 1986.

Saussure Cours 1916 = F. Saussure Cours de linguistique générale, hrsg. von Ch. Bally / A. Sechehaye / A. Riedlinger. Paris 1916 (und Nachdrucke). Zum Anteil der Diachronie an diesem Werk: $\rightarrow$ P. Wunderli Principes de diachronie, Contribution à l'exégèse du „Cours“. Frankfurt 1990 (eine Anzeige dazu von M. Mayrhofer in Idg. Chr. 34 Nr. A 89).

Saussure Mémoire $1879=\mathrm{F}$. Saussure Mémoire sur le système primitif des voyelles dans les langues indo-européennes. Leipzig 1879 (Wiederabdruck in Saussure Recueil 1922 p. 1ff.; eigener Nachdruck Hildesheim 1987). Zu diesem Werk und seiner Wirkung: $\rightarrow \mathrm{M}$. Mayrhofer Nach hundert Jahren, Ferdinand de Saussures Frühwerk und seine Rezeption durch die heutige Indogermanistik, Heidelberg 1981 (= SbHAW 1981 / 8). Ferner s.o. Gmür Mémoire 1986 und unten Saussure Saggio.

Saussure Recueil 1922 = F. Saussure Recueil des publications scientifiques de F. de Saussure. Genf 1922 (und Nachdrucke).

Saussure Saggio 1987 = F. Saussure Saggio sul vocalismo indoeuropeo, ital. Ausgabe des „Mémoire“ mit Einleitung und Anmerkungen von G. C. Vincenzi. Bologna 1987.

SbBAW = Sitzungsberichte der Bayerischen Akademie der Wiss., phil.hist. Klasse, München.

SbHAW = Sitzungsberichte der Heidelberger Akademie der Wiss., phil.hist. Klasse, Heidelberg.

SbÖAW = Sitzungsberichte der Österreichischen Akademie der Wiss., phil.-hist. Klasse, Wien.

Scardigli Goten 1973 = P. Scardigli Die Goten, Sprache und Kultur. München 1973. 
Scardigli Weg zur deutschen Sprache $1994=$ P. Scardigli Der Weg zur deutschen Sprache, Von der indogermanischen bis zur Merowingerzeit. Bern u.a.O. 1994 (= German. Lehrbuchsammlung 2).

Scarlata Wurzelkomposita im Rg-Veda $1999=$ S. Scarlata Wurzelkomposita im Rg-Veda. Wiesbaden 1999.

Schaefer Intensivum $1994=\mathrm{Ch}$. Schaefer Das Intensivum im Vedischen (= ZVS Ergänzungsheft 37). Rez.: E. Seebold in IF 1011996 p. $299-$ 302; St. W. Jamison in Kratylos 421997 p. 50-55; A. Lubotsky in JAOS 1171997 p. 558-564.

Scherer Lat. Syntax $1975=$ A. Scherer Handbuch der lateinischen Syntax. Heidelberg 1975.

Schindler Wurzelnomen 1972 = J. Schindler Das Wurzelnomen im Arischen und Griechischen. Dissertation Würzburg 1972.

Schirmer Wortschatz $1998=$ B. Schirmer Studien zum Wortschatz der Iguvinischen Tafeln. Frankfurt a.M. u.a.O. 1998 (= Europäische Hochschulschriften, Reihe XXI Linguistik, Band 205). Rez.: M. Weiss in Kratylos 462001 p. 131-134.

Schleicher Compendium $1866=$ A. Schleicher Compendium der vergleichenden Grammatik der indogermanischen Sprachen, Kurzer Abriß einer Laut- und Formenlehre der indogermanischen Ursprache, des Altindischen, Alteranischen, Altgriechischen, Altitalischen, Altkeltischen, Altslawischen, Litauischen und Altdeutschen. 2. Aufl. Weimar / London / Paris 1866 (1. Aufl. 1861-1862).

Schlerath Indogermanen $1973=$ B. Schlerath Die Indogermanen. Das Problem der Expansion eines Volkes im Lichte seiner Sozialstruktur. Innsbruck 1973 (= IBS, Vorträge 8). Rez.: K. Strunk in BNF N.F. 9 1974 p. $388-390$.

Schlerath Kleine Schriften $2000=$ B. Schlerath Kleine Schriften. 2 Bände. Dettelbach 2000.

Schmid Schriften $1994=$ W. P. Schmid Linguisticae scientiae collectanea, Ausgewählte Schriften, hrsg. von J. Becker. Berlin / New York 1994.

Schmid Studien 1963 = W. P. Schmid Studien zum baltischen und indogermanischen Verbum. Wiesbaden 1963.

Schmidt (G.) Personalpronomina $1978=$ G. Schmidt Stammbildung und Flexion der indogermanischen Personalpronomina. Wiesbaden 1978.

Schmidt (J.) Neutra 1889 = J. Schmidt Die Pluralbildungen der indogermanischen Neutra. Weimar 1889.

Schmidt (J.) Verwantschaftsverhältnisse $1872=$ J. Schmidt Die Verwantschaftsverhältnisse (sic !) der indogermanischen Sprachen. Weimar 1872. 
Schmidt (J.) Vocalismus I 1871 II $1875=$ J. Schmidt Zur Geschichte des indogermanischen Vocalismus. Weimar: I 1871, II 1875.

Schmidt (K. H.) Celtic $1996=$ K. H. Schmidt Celtic: A Western IndoEuropean Language ? Innsbruck 1996 (= IBS, Vorträge und Kleinere Schriften 66).

Schmidt (K. T.) Medium im Toch. = K. T. Schmidt Die Gebrauchsweisen des Mediums im Tocharischen. Göttingen 1974 (= Phil. Diss. Göttingen 1969).

Schmitt Ap. Inschriften $1999=$ R. Schmitt Beiträge zu altpersischen Inschriften. Wiesbaden 1999.

Schmitt Bisitun Inscriptions $1991=$ The Bisitun Inscriptions of Darius the Great, Old Persian Text, hrsg. von R. Schmitt. London 1991 (= School of Oriental and African Studies, Corpus Inscriptionum Iranicarum, Pt. I (Inscriptions of Ancient Iran), Vol. I (The Old Persian Inscriptions, Texts I). Rez.: Ch. H. Werba in Sprache 35 (1991-1993) p. 140-145; S. W. Jamison in IIJ 37 (1994) p. 168-171. Ferner ders. Epigraphischexegetische Noten zu Dareios' Bīsitūn-Inschriften. Wien 1990 (= SbÖAW, 561. Band); ders. Ap. Inschriften 1999.

Schmitt Dichtersprache $1967=$ R. Schmitt Dichtung und Dichtersprache in indogermanischer Zeit. Wiesbaden 1967.

Schmitt Gr. Dialekte $1977=$ R. Schmitt Einführung in die griechischen Dialekte. Darmstadt 1977.

Schmitt Ir. Sprachen $2000=$ R. Schmitt Die iranischen Sprachen in Geschichte und Gegegnwart. Wiesbaden 2000.

Schmitt Klass. Arm. $1981=$ R. Schmitt Grammatik des KlassischArmenischen mit sprachvergleichenden Erläuterungen. Innsbruck 1982 (= IBS Nr. 32).

Schmitt-Brandt Einführung $1998=$ R. Schmitt-Brandt Einführung in die Indogermanistik. Tübingen / Basel 1998 (= UTB Nr. 1506). Rez.: G. Keydana in IF 1041999 p. 281-286; K. Stelter in Kratylos 462001 p. 200-202; s.o. p. X.

Schneider Lautgesetz $1973=\mathrm{G}$. Schneider Zum Begriff des Lautgesetzes in der Sprachwissenschaft seit den Junggrammatikern. Tübingen 1993 (= TBL 46).

Schön Neutrum und Kollektivum 1971 = I. Schön Neutrum und Kollektivum, Das Morphem -a im Lateinischen und Romanischen. Innsbruck 1971 (= IBS Nr. 6). Rez.: A. Morpurgo Davies in CR 251975 p. $248 f$.

Schrift und Schriftlichkeit 1199421996 = Schrift und Schriftlichkeit / Writing and its Use, Ein interdisziplinäres Handbuch internationaler 
Forschung, hrsg. von H. Günther, O. Ludwig. Berlin / New York. 2 Halbbände: 1 1994; 21996 (= HSK 10.1 und 10.2).

Schrijver British Celtic Phonology $1995=$ P. Schrijver Studies in British Celtic Historical Phonology. Amsterdam / Atlanta 1995.

Schrijver Celtic Pronouns and Particles $1997=$ P. Schrijver Studies in the History of Celtic Pronouns and Particles. Maynooth 1997. Rez.: J. T. Katz in Kratylos 462001 p. 1-23.

Schrijver Laryngeals in Latin $1991=$ P. Schrijver The Reflexes of the

Proto-Indo-European Laryngeals in Latin. Amsterdam / Atlanta 1991.

Rez.: H. Rix in Kratylos 411996 p. 153-163.

Schulze Kleine Schriften + Nachtr. 2.Aufl. $1966=$ W. Schulze Kleine Schriften, hrsg. vom Idg. Seminar der Universität Berlin. 2. Aufl. mit Nachträgen, hrsg. von W. Wissmann. Göttingen 1966.

Schulze-Thulin o-stufige Kausativa / Iterativa und Nasalpräsentien $2001=$ B. Schulze-Thulin Studien zu den urindogermanischen $o$-stufigen Kausativa / Iterativa und Nasalpräsentien im Kymrischen. Innsbruck 2001 (= IBS 99).

Schwerdt 2. LV $2000=$ J. Schwerdt Die 2. Lautverschiebung. Heidelberg 2000.

Schwyzer Kleine Schriften 1983 = E. Schwyzer Kleine Schriften, hrsg. von R. Schmitt. Innsbruck 1983 (= IBS 45).

Schwyzer Gr. Gr. I 1939 = E. Schwyzer Griechische Grammatik, Bd. I (Allgemeiner Teil, Lautlehre, Wortbildung, Flexion). München 1939.

Schwyzer / Debrunner Gr. Gr. II $1950=$ E. Schwyzer und A. Debrunner Griechische Grammatik, Bd. II (Syntax und syntaktische Stilistik), vervollständigt und hrsg. von A. Debrunner. München 1950.

Seebold Etymologie 1981= E. Seebold Etymologie. Eine Einführung am Beispiel der deutschen Sprache. München 1981.

Seebold Germ. starke Verben $1970=$ E. Seebold Vergleichendes und etymologisches Wörterbuch der germanischen starken Verben. Den Haag / Paris 1970.

Seebold Halbvokale 1972 = E. Seebold Das System der indogermanischen Halbvokale. Untersuchungen zum sog. "Sieversschen Gesetz" und zu den halbvokalhaltigen Suffixen in den indogermanischen Sprachen, bes. im Vedischen. Heidelberg 1972. Rez.: J. Schindler in Sprache 231977 p. 56-65.

Seebold Personalpronomina 1984 = E. Seebold Das System der Personalpronomina in den frühgermanischen Sprachen. Göttingen 1984 (= ZVS, Ergänzungsheft 34).

Seebold s. auch oben unter Kluge / Seebold. 
SEG $=$ Supplementum Epigraphicum Graecum.

Seiler Relativsatz $1960=\mathrm{Hj}$. Seiler Relativsatz, Attribut und Apposition. Wiesbaden 1960.

Seiler Sprache und Sprachen $1977=\mathrm{Hj}$. Seiler Sprache und Sprachen, Gesammelte Aufsätze. München 1977 (= Structura 11).

Seiler Steigerungsformen $1950=\mathrm{Hj}$. Seiler Die primären griechischen Steigerungsformen. Hamburg 1950.

Senn Handb. d. lit. Sprache 1966 = A. Senn Handbuch der litauischen Sprache. 2 Bde. Heidelberg: I (Grammatik) 1966; II (Lesebuch und Glossar) 1957.

Serbat Cas et fonctions $1981=$ G. Serbat Cas et fonctions, Etude des principales doctrines casuelles du Moyen Age à nos jours. Paris 1981. Rez.: R. Amacker in Kratylos 271982 p. 5-8.

Sergent Indo-Européens 1995 = B. Sergent Les indo-européens, Histoire, langues, mythes. Paris 1995.

Sihler New Comparative Grammar $1995=$ A. L. Sihler New Comparative Grammar of Greek and Latin. New York / London 1995.

SMEA = Studi Micenei ed Egeo-Anatolici.

SMID I 1968 II 19861979 1980-1981= Studies in Mycenaean Inscriptions and Dialect. Das Werk bietet eine umfassende Bibliographie mit Wort- und Sachregistern. - SMID I (1953-1964) zusammengestellt von L. Baumbach aus den SMID-Bänden I-X (erster Verleger: The Institute of Classical Studies of the University of London). Rom 1968. SMID II (1965-1978), zusammengestellt von L. Baumbach aus den SMID-Bänden XI-XXIII (erster Verleger: wie I, bei den letzten Heften The British Association of Mycenaean Studies, Cambridge). Rom 1986. - SMID 1979, hrsg. von E. Sikkenga. University of Texas at Austin, Department of Classics, Program in Aegean Scripts and Prehistory. 1995. - SMID 1980-1981, dito, 1997.

Smyth Greek Grammar $1956=$ H. W. Smyth A Greek Grammar (for Colleges), revised by G. M. Messing. Cambridge / Ma. 1956 (und Nachdrucke).

Solmsen Eigennamen $1922=$ F. Solmsen Indogermanische Eigennamen als Spiegel der Kulturgeschichte, hrsg. von E. Fraenkel. Heidelberg 1922.

Solmsen Untersuchungen $1901=\mathrm{F}$. Solmsen Untersuchungen zur griechischen Laut- und Verslehre. Straßburg 1901.

Solta Balkanlinguistik $1980=$ G. R. Solta Einführung in die Balkanlinguistik mit besonderer Berücksichtigung des Substrats und des Balkanlateinischen. Darmstadt 1980. 
Solta Stellung der lat. Sprache $1974=$ G. R. Solta Zur Stellung der lateinischen Sprache. Wien 1974 (= SbÖAW 291. Band, 4. Abhandlung).

Solta Stellung des Arm. $1960=$ G. R. Solta Die Stellung des Armenischen im Kreise der indogermanischen Sprachen. Eine Untersuchung der indogermanischen Bestandteile des armenischen Wortschatzes. Wien 1960.

Sommer Handbuch 1948 = F. Sommer Handbuch der lateinischen Lautund Formenlehre. Eine Einführung in das sprachwissenschaftliche Studium des Lateins. Heidelberg 1948. Vgl. unten Sommer / Pfister.

Sommer Heth. 1947 = F. Sommer Hethiter und Hethitisch. Stutgart 1947.

Sommer Nachlaß 1977 = F. Sommer Schriften aus dem Nachlaß. München 1977 (= MSS Beiheft 1, Neue Folge).

Sommer Nominalkomposita $1948=$ F. Sommer Zur Geschichte der griechischen Nominalkomposita. München 1948.

Sommer Vergl. Syntax $1931=$ F. Sommer Vergleichende Syntax der Schulsprachen. 3. Aufl. Stuttgart 1931 (= 4., unveränderter Nachdruck Darmstadt 1959).

Sommer / Pfister Lautlehre 1977 = F. Sommer Handbuch der lateinischen Laut- und Formenlehre. Heidelberg 1948. 4., neub. Auflage: Band I (Einleitung und Lautlehre) von R. Pfister. Heidelberg 1977. Der damals geplante Band II ist nie erschienen.

Sonderegger Althochdeutsch $1987=\mathrm{S}$. Sonderegger Althochdeutsche Sprache und Literatur. Eine Einführung in das älteste Deutsch. Darstellung und Grammatik: 2., durchges. und erw. Auflage Berlin / New York 1987.

Sonderegger Deutsche Sprachgeschichte I $1979=$ S. Sonderegger Grundzüge deutscher Sprachgeschichte. Diachronie des Sprachsystems. Band I (Einführung, Genealogie, Konstanten). Berlin / New York 1979.

Sprache $=$ Die Sprache. Zeitschrift für Sprachwissenschaft. Wiesbaden / Wien. Darin wichtig Idg. Chr., s.o. s.v.

Sprache Fünf Vorträge 1991 = Sprache, Fünf Vorträge von H. Kößler, I. Richter, B. Forssman, M. v. Engelhardt und R. Slenczka. Erlangen 1991 (= Erlanger Forschungen, Reihe A Geisteswissenschaften 54).

Sprachen im röm. Reich $1980=$ Die Sprachen im römischen Reich der Kaiserzeit, Kolloquium 1974, hrsg. von G. Neumann und J. Untermann. Köln / Bonn 1980.

Sprachgeschichte 1199821985 = Sprachgeschichte, Ein Handbuch zur Geschichte der deutschen Sprache und ihrer Erforschung, hrsg. von W. Besch, A. Betten, O. Reichmann, S. Sonderegger. Berlin / New York. 
2 Halbbände: 1 (2., vollständig neubearbeitete Aufl.) 1998; 21985 (= HSK 2.1 und 2.2).

Speyer Syntax 1896 = J. S. Speyer Ved. u. Skrt-Syntax. Straßburg 1896.

Stair na Gaeilge 1994 = Stair na Gaeilge in ómós do Pádraig Ó Fiannachta, hrsg. von K. McCone u.a. Maigh Nuad 1994. Darin von K. McCone p. 61-219 eine aktuelle Standortbestimmung der altirischen Laut- und Formenlehre.

Stang Opuscula $1970=$ Ch. S. Stang Opuscula linguistica, Ausgewählte Aufsätze und Abhandlungen. Oslo / Bergen / Tromsø 1970.

Stang Vgl. Gramm. 1966 Ergänzungsband $1975=$ Ch. S. Stang Vergleichende Grammatik der baltischen Sprachen. Oslo / Bergen / Tromsø: Vgl. Gramm. 1966; Ergänzungsband, Register, Addenda und Corrigenda zur Vgl. Gramm. 1975.

Starke Kasus und Adv. im Aheth. 1977 = F. Starke Die Funktionen der dimensionalen Kasus und Adverbien im Althethitischen. Wiesbaden 1977 (= StBoT 23).

Starke Keilschr.-luw. Nomen $1990=$ F. Starke Untersuchungen zur Stammbildung des keilschrift-luwischen Nomens. Wiesbaden 1990 (= StBoT 31).

Starke Keilschrift-luw. Texte $1985=$ F. Starke Die keilschrift-luwischen Texte in Umschrift. Wiesbaden 1985 (= StBoT 30).

Starke Kikkuli 1995 = F. Starke Ausbildung und Training von Streitwagenpferden: Eine hippologisch orientierte Interpretation des KikkuliTextes. Wiesbaden 1995 (= StBoT 41).

StBoT $=$ Studien zu den Boğazköy-Texten .

Steinbauer Denominativa 1989 = D. H. Steinbauer Etymologische Untersuchungen zu den bei Plautus belegten Verben der lateinischen ersten Konjugation. Unter besonderer Berücksichtigung der Denominative. Altendorf bei Bamberg 1989.

Stempel Diathese $1996=$ R. Stempel Die Diathese im Indogermanischen, Formen und Funktionen des Mediums und ihre sprachhistorischen Grundlagen. Innsbruck 1996 (= IBS, Vorträge und Kleinere Schriften 67).

Storia d'Europa II 1994 = Storia d'Europa, Band II (Preistoria e antichità), hrsg. von J. Guilaine und S. Settis. Turin 1994.

Streitberg Got. Bibel $1971=$ Die gotische Bibel, hrsg. von W. Streitberg. 2. Aufl. I. Teil (Der gotische Text und seine griechische Vorlage) Heidelberg 1919; 2. Aufl. II. Teil (Gotisch-griechisch-deutsches Wörterbuch) Heidelberg 1928. 6. Aufl. Heidelberg 1971. 7. Aufl. angekündigt (Teil I mit einem Nachtrag von P. Scardigli). 
Streitberg Urgerm. Gr. 1896 = W. Streitberg Urgermanische Grammatik, Einführung in das vergleichende Studium der altgermanischen Dialekte. Heidelberg 1896 (Nachdruck 1943).

Strunk Lachmanns Regel $1976=$ K. Strunk Lachmanns Regel für das Lateinische. Göttingen 1976 (= ZVS Ergänzungsheft Nr.26). Rez.: A. Morpurgo Davies in CR 291979 p. 259 f.

Strunk Nasalpräsentien und Aoriste $1967=$ K. Strunk Nasalpräsentien und Aoriste. Heidelberg 1967.

Strunk 'Vorhersagbarer' Sprachwandel $1991=$ K. Strunk Zum Postulat 'vorhersagbaren' Sprachwandels bei unregelmäßigen oder komplexen Flexionsparadigmen. München 1991 (= SbBAW 1991, Heft 6).

Studi di linguistica greca 1993 [1995] = Studi di linguistica greca, Materiali linguistici, Akten eines Treffens in Pavia 1993, hrsg. von P. Cuzzolin. Mailand 1995. Rez.: R. Hodot in BSL 93 / 21998 p. 165-168.

Stud. z. idg. Wortschatz $1987=$ Studien zum indogermanischen Wortschatz, hrsg. von W. Meid. Innsbruck 1987. Rez.: J. Untermann in Kratylos 341989 p. 45-54.

Stumpf Westtocharisch $1990=$ P. Stumpf Die Erscheinungsformen des Westtocharischen. Reykjavík 1990 (= TIES, Suppl. Ser. 2).

Svennung Anredeformen 1958 = J. Svennung Anredeformen, Vergleichende Forschungen zur indirekten Anrede in der dritten Person und zum Nominativ für den Vokativ. Uppsala / Wiesbaden 1958.

Syntax 1199321995 = Syntax, Ein internationales Handbuch zeitgenössischer Forschung, hrsg. von J. Jacobs, A. v. Stechow, W. Sternefeld, Th. Vennemann. Berlin / New York. 2 Halbbände: 1 1993; 21995 (= HSK 9.1 und 9.2).

Syntaxe des langues indo-iraniennes anciennes 1993 [1997] = Syntaxe des langues indo-iraniennes anciennes, Colloque international Sitges 1993, hrsg. von E. Pirart. Barcelona 1997.

Szantyr s.o. Hofmann / Szantyr und Leumann / Hofmann / Szantyr.

Szemerényi Einführung 4. Aufl. $1990=0$. Szemerényi Einführung in die vergleichende Sprachwissenschaft. 4., durchges. Aufl. Darmstadt 1990. Die Einführung ist in 1. Aufl. 1970 erschienen, 2. Aufl. 1980, 3. Aufl. 1989. - In ital. Übersetzung „Introduzione alla linguistica indoeuropea“, hrsg. von G. Boccali, V. Brugnatelli und M. Negri. Milano 1985. - Englische Version unter dem Titel „Introduction to Indo-European Linguistics“. Oxford 1996. - Die Anzahl der Rez. ist groß: - Rez. der 1. Aufl. 1970: u.a. W. Meid in Kratylos 161971 [1973] p. 41-49; B. Forssman in Anglia 941976 p. 441-450. - Rez. der 3. Aufl. 1989: u.a. R. Schmitt in Gnomon 621990 p. 365-367; W. Meid in Kratylos 
361991 p. 87-91; E. Eggers in IF 961991 p. 261-266 (in Anm. 1 die in der BL notierten Rez. der 1. und 2. Aufl. bis 1986). - Rez. der 4. Aufl. 1990: u.a. I. Hajnal in PFU 1 1994-1995 p. 39-46.

Szemerényi Lat. Wortschatz $1989=$ O. Szemerényi An den Quellen des lateinischen Wortschatzes. Innsbruck 1989. Rez.: M. Peters in Idg. Chr. 34 Nr. H 659.

Szemerényi Numerals $1960=$ O. Szemerényi Studies in the IndoEuropean System of Numerals. Heidelberg 1960.

Szemerényi Richtungen d. mod. Sprachw. I 1971 II $1982=0$. Szemerényi Richtungen der modernen Sprachwissenschaft. Heidelberg: I (Von Saussure bis Bloomfield, 1916-1950) 1971; II (Die fünfiger Jahre, 1950-1960) 1982. Rez.: M. Mayrhofer in Sprache 291983 p. 182186.

Szemerényi Scripta Minora I 1987 II 1987 III 1987 IV 1991 Suppl. 1992 $=0$. Szemerényi Scripta Minora. Selected Essays in Indo-European, Greek, and Latin, hrsg. von P. Considine und J. T. Hooker. Teile I-III Innsbruck 1987 (= IBS 53 mit 3 Teilen): I (Indo-European) p. 1-588; II (Latin) p. 589-1076; III (Greek) p. 1077-1643; Teil IV (Indo-European Languages other than Latin and Greek) Innsbruck 1991 (= IBS 63). Als Suppl. Word Index 1992. Ders. Summing up a Life, Autobiographie und Schriftenverzeichnis. hrsg. von B. Brogyanyi. Freiburg 1991. Vgl. zu Szemerényi auch oben FS O. Szemerényi *65 1979 und *75 1992. Vgl. ferner HS 1101997 p. 1-3 mit Nachträgen zu O. Szemerényis Veröffentlichungen. Zuletzt B. Brogyanyi Schriftenverzeichnis: O. Szemerényi (1913-1996) in PFU 2-3 1996-1997 p. 53-80.

Szemerényi Syncope $1964=0$. Szemerényi Syncope in Greek and IndoEuropean and the Nature of Indo-European Accent. Neapel 1964. Rez.: G. Cardona in Language 431967 p. 757-773.

Tavola di Agnone 1994 [1996] = La Tavola di Agnone nel contesto italico, Convegno di Studio 1994 in Agnone, hrsg. von L. del Tutto Palma. Florenz 1996 (= Lingue e Iscrizioni dell' Italia Antica 7). Rez.: E. Nieto Ballester in Kratylos 441999 p. 98-106.

TBL $=$ Tübinger Beiträge zur Linguistik.

Tense and Aspect in IE 1997 = Tense and Aspect in Indo-European: Theory, Typology, Diachrony, hrsg. von J. Hewson and V. Bubenik. Amsterdam / Philadelphia 1997. Rez.: E. C. Polomé in JES 251997 p. 482. 
Ternes Phonologie 1987 und 1999 = E. Ternes Einführung in die Phonologie. 1. Aufl. Darmstadt 1987; 2., verbesserte und erweiterte Aufl. 1999.

Tesnière Syntaxe structurale $1959=\mathrm{L}$. Tesnière Eléments de syntaxe structurale. Paris 1959.

Textdatierung 1979 = S. Heinhold-Krahmer, I. Hoffmann, A. Kammenhuber, G. Mauer Probleme der Textdatierung in der Hethitologie. Heidelberg 1979 (= Texte der Hethiter 9).

Thieme Heimat $1954=\mathrm{P}$. Thieme Die Heimat der indogermanischen Gemeinsprache. Wiesbaden 1954.

Thieme Kleine Schriften I 1971 II $1995=$ P. Thieme Kleine Schriften. Wiesbaden: I. Band 1972; II. Band 1995.

Thieme Studien 1952 = P. Thieme Studien zur indogermanischen Wortkunde und Religionsgeschichte. Berlin 1952.

Thomas Der tocharische Obliquus $1983=\mathrm{W}$. Thomas Der tocharische Obliquus im Sinne eines Akkusativs der Richtung. Wiesbaden 1983.

Thomas Erforschung des Toch. 1985 = W. Thomas Die Erforschung des Tocharischen (1960-1984). Stuttgart 1985.

Thomas Vergangenheitstempora $1957=\mathrm{W}$. Thomas Der Gebrauch der Vergangenheitstempora im Tocharischen. Wiesbaden 1957.

Thomas s. auch oben unter Krause / Thomas.

Threatte Attic I 1980 II $1996=\mathrm{L}$. Threatte The Grammar of Attic Inscriptions. Berlin: I (Phonology) 1980; II (Morphology) 1996.

Thumb s.o. unter Brugmann / Thumb.

Thumb / Hauschild Handb. d. Skr. I/ 11958 I / 2 (+3) $1959=$ A. Thumb Handbuch des Sanskrit. Eine Einführung in das sprachwissenschaftliche Studium des Altindischen. 3. Aufl. von R. Hauschild. Heidelberg: I / 1 (Einleitung und Lautlehre) 1958; I / 2 (+3) (Formenlehre, Compositum und Satzbau) 1959.

Thumb / Kieckers Gr. Dial. I 1932 = A. Thumb Handbuch der griechischen Dialekte. Heidelberg. 2. Aufl.: Band I 1932 von E. Kieckers.

Thumb / Scherer Gr. Dial. II 1959 = A. Thumb Handbuch der griechischen Dialekte. Heidelberg. 2. Aufl.: Band II 1959 von A. Scherer.

Thurneysen Old Irish $1946=\mathrm{R}$. Thurneysen A Grammar of Old Irish. Dublin 1946.

Tichy Grundwissen $2001=$ E. Tichy Indogermanistisches Grundwissen für Studierende sprachwissenschaftlicher Disziplinen. Bremen 2001.

Tichy Nom. ag. auf -tar- $1995=$ E. Tichy Die Nomina agentis auf -tar- im Vedischen. Heidelberg 1995. Rez.: H. Hettrich in Kratylos 431998 p. 84-91. 
Tichy Onomatop. Verbalbildungen $1983=$ E. Tichy Onomatopoetische Verbalbildungen des Griechischen. Wien 1983 (= SbÖAW, 409. Bd.). TIES $=$ Tocharian and Indo-European Studies. Von Band 11987 - Band 6 1993 Reykjavík; ab Band 71997 Kopenhagen. Band 71997 beinhaltet die Papiere der Arbeitstagung 100 Jahre Tocharologie Saarbrücken 1995 [1997]. Die Supplementary Series enthält als Band 2 Stumpf Westtocharisch 1990, als Band 3 Hilmarsson Nasal Prefixes in Tocharian 1991, als Band 4 Fachtagung Tocharisch Berlin 1990 [1994], als Band 5 Hilmarsson Tocharian Dictionary 1996.

Tischler HEG $=\mathrm{J}$. Tischler Hethitisches etymologisches Glossar. Innsbruck (= IBS Nr. 20): Teil I (A-K) 1983; Teil II mit Lieferungen 5-6 (L-M) 1990 und Lieferung 7 (N) 1991; Teil III mit Lieferung 8 (T, D / 1) 1991, Lieferung 9 (T, D / 2) 1993 und Lieferung 10 (T, D / 3) 1994.

Tischler Kleinasiatische Hydronymie $1977=\mathrm{J}$. Tischler Kleinasiatische Hydronymie, Semantische und morphologische Analyse der griechischen Gewässernamen. Wiesbaden 1977.

$\mathrm{TPhS}=$ Transactions of the Philological Society. Oxford.

Tract. Myc. 1985 [1987] = Tractata Mycenaea, Proceedings of the Eighth International Colloquium on Mycenaean Studies Ohrid 1985, hrsg. von P. H. Ilievski und L. Crepajac. Skopje 1987.

Tucker Early Greek Verbs $1990=$ E. F. Tucker The Creation of Morphological Regularity: Early Greek Verbs in -éō, -áō, -óō, -úō and -íō. Göttingen 1990 (= HS, Ergänzungsheft 35). Rez.: R. Schmitt in HS 1031990 p. 301-304; M. Peters in Idg. Chr. 34 Nr. G 615.

UCLA IE Conference 1999 [2000] = Proceedings of the Eleventh Annual UCLA IE Conference 1999, hrsg. von K. Jones-Bley, M. E. Huld, A. Della Volpe. Washington 2000.

UCLA IE Studies = University of California Los Angeles Program in IE Studies, hrsg. von V. V. Ivanov und B. Vine. Vol. 11999.

Uhlich Komponierte Personennamen des Air. 1993 = J. Uhlich Die Morphologie der komponierten Personennamen des Altirischen. Witterschlick / Bonn 1993.

Untermann Monumenta (Linguarum Hispanicarum) $=\mathrm{J}$. Untermann Monumenta Linguarum Hispanicarum. Wiesbaden. Band I (Die Münzlegenden: 1. Text, 2. Tafeln) 1975; Band II (Die Inschriften in iberischer Schrift aus Südfrankreich) 1980; Band III (Die iberischen Inschriften aus Spanien: 1. Literaturverzeichnis, Einleitung, Indices, 2. Die Inschriften) 1990; Band IV (Die tartessischen, keltiberischen und lusita- 
nischen Inschriften) 1997. Rez. von Monumenta IV: F. Villar und C. Jordan in Kratylos 462001 p. 166-181.

Untermann Wb. Osk.-Umbr. $2000=$ J. Untermann Wörterbuch des Oskisch-Umbrischen. Heidelberg 2000.

Urheimat 1968 = Die Urheimat der Indogermanen, hrsg. von A. Scherer. Darmstadt 1968 (= Wege der Forschung 116).

UTB = UTB für Wissenschaft, Uni-Taschenbücher.

Väänänen Latin vulgaire $1981=$ V. Väänänen Introduction au latin vulgaire. 2. Aufl. Paris 1967; 3. Aufl. Paris 1981.

Vaillant Vieux slave $1948=$ A. Vaillant Manuel du vieux slave. Paris 1948.

Vasmer REW 1953-1958 = M. Vasmer Russisches etymologisches Wörterbuch. 3 Bände Heidelberg 1953-1958.

Večerka Aksl. Syntax I 1989 II 1993 III 1996 = R. Večerka Altkirchenslavische (altbulgarische) Syntax, unter Mitarbeit von F. Keller und E.Weiher. Freiburg (Monumenta Linguae Slavicae Dialecti Veteris): I (Die lineare Satzorganisation) 1989 (= MLS 17); II (Die innere Satzstruktur) 1993 (= MLS 34); III (Die Satztypen) 1996 (= MLS 36).

Vetter Handb. d. ital. Dialekte I $1953=$ E. Vetter Handbuch der italischen Dialekte. I (Texte mit Erklärung, Glossen, Wörterverzeichnis). Heidelberg 1953. Als Ergänzung ist hinzuzunehmen P. Poccetti Nuovi Documenti Italici, a complemento del Manuale di E. Vetter. Pisa 1979. H. Rix bereitet seit längerem eine Neuauflage von Vetter vor; ferner s.o. Untermann Wb. Osk.-Umbr. 2000.

Villar Celtiberian Grammar 1995 = F. Villar A New Interpretation of Celtiberian Grammar. Innsbruck 1995 (= IBS, Vorträge und Kleinere Schriften 62).

Vine Archaic Latin 1993 = B. Vine Studies in Archaic Inscriptions. Innsbruck 1993 (= IBS Nr. 75). Rez.: R. Gerschner in Sprache 38 / 21996 [1999] p. 231-237.

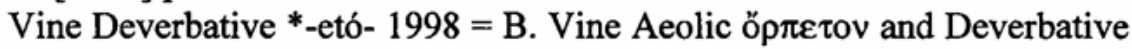
*-etó- in Greek and Indo-European. Innsbruck 1998 (= IBS, Vorträge und Kleinere Schriften 71).

Volkart Brugmanns Gesetz $1994=$ M. Volkart Zu Brugmanns Gesetz im Altindischen. Bern 1994 (= Universität Bern, Institut für Sprachwissenschaft, Arbeitspapiere 33). Rez.: Th. Zehnder in CFS 481994 [1995] p. 177-184; R. Lubotsky in Kratylos 421997 p. 55-59. von Hinüber s.o. Hinüber. 
Vottéro Béotien I $1998=\mathrm{G}$. Vottéro Le dialecte béotien $\left(7^{\mathrm{e}} \mathrm{s} .-2^{\mathrm{e}} \mathrm{s}\right.$. av. J.-C.). Nancy. Band I (L'écologie du dialecte) 1998. Mindestens drei weitere Bände sind angekündigt.

Vries AnordEW $1962=\mathrm{J}$. de Vries Altnordisches etymologisches Wörterbuch. 2., verbesserte Aufl. Leiden 1962 (=3. Aufl. 1977).

Waanders Local Case Relations $1997=$ F. M. J. Waanders Studies in Local Case Relations in Mycenaean Greek. Amsterdam 1997.

Wachter Altlat. Inschriften $1987=\mathrm{R}$. Wachter Altlateinische Inschriften. Sprachliche und epigraphische Untersuchungen zu den Dokumenten bis etwa 150 v. Chr. Bern 1987. Rez:: M. Peters in Idg. Chr. 32b Nr. 1045; M. Lejeune in REL 651987 [1989] p. 285-287.

Wackernagel Kleine Schriften I / II 1969 III $1979=$ J. Wackernagel Kleine Schriften, 3 Bände, hrsg. von der Akademie der Wissenschaften zu Göttingen. I - II (p. 1-1426, hrsg. von K. Latte) 1. Aufl. Göttingen 1953, 2. Aufl. 1969; III (p. 1427-1905, hrsg. von B. Forssman) Göttingen 1979.

Wackernagel Untersuchungen $1916=$ J. Wackernagel Sprachliche Untersuchungen zu Homer. Göttingen 1916.

Wackernagel Vorlesungen I 1926 II $1928=\mathrm{J}$. Wackernagel Vorlesungen über Syntax, 2 Reihen. 2. Aufl. Basel 1926-1928 (1. Aufl. 1920-1924).

Wackernagel s. auch oben unter Kolloquium Wackernagel.

Wackernagel s.auch unten unter Wackernagel / Debrunner.

Wackernagel / Debrunner Ai. Grammatik I + II / 11957 II / 21954 III $1930=$ J. Wackernagel Altindische Grammatik. Göttingen: Band I (Lautlehre), Wiederabdruck der 2. Aufl. 1896 mit einer Einleitung von L. Renou und Nachträgen von A. Debrunner 1957; Band II / 1 (Einleitung zur Wortlehre. Nominalkomposition), Wiederabdruck des Textes von 1905 mit Nachträgen von A. Debrunner 1957; Band II / 2 (Die Nominalsuffixe) von A. Debrunner 1954; Band III (Nominalflexion, Zahlwort, Pronomen) von A. Debrunner und J. Wakkernagel 1930 (von J. Wackernagel stammen die Abschnitte zum Zahlwort und zu den Pronomina, ferner die §§ 83-101 und §159). Das Register zu den Bänden I - III hat R. Hauschild 1964 veröffentlicht. Band IV (Verbum und Adverbium) steht immer noch aus.

Walde Vgl. Wb. 1927-1932 = A. Walde Vergleichendes Wörterbuch der indogermanischen Sprachen, hrsg. von J. Pokorny. Berlin 1927-1932 = Nachdruck 1973. 
Walde / Hofmann LEW = A. Walde Lateinisches etymologisches Wörterbuch, neu bearbeitet ab der 3. Aufl. von J. B. Hofmann. 4. Aufl. Heidelberg 1965 (und Nachdrucke).

Warmington Remains of Old Latin I-IV 1935-1940 = E. H. Warmington Remains of Old Latin, newly edited and translated. 4 Bände Cambridge / Mass.: I (Ennius and Caecilius) 1935 (Nachdruck 1956); II (Livius Andronicus, Naevius, Pacuvius and Accius) 1936 (Nachdruck 1957); III (Lucilius, The Twelve Tables) 1938 (Nachdruck 1957); IV (Archaic Inscriptions) 1940 (Nachdrucke seit 1953)

Wathelet Traits éoliens $1970=P$. Wathelet Les traits éoliens dans la langue de l'épopée grecque. Rom 1970.

Watkins How to kill a dragon $1995=\mathrm{C}$. Watkins How to kill a dragon, Aspects of IE Poetics. New York / Oxford 1995. Rez.: G. E. Dunkel in The Classical Journal 921997 p. 417-422; F. Bader in BSL 93 / 21998 p. 116-130; B. Schlerath in Kratylos 452000 p. 36-46.

Watkins Selected Writings $1994=$ C. Watkins Selected Writings, hrsg. von L. Oliver. 2 Bände Innsbruck 1994 (= IBS 80).

Watkins Verbalflexion $1969=$ C. Watkins Geschichte der indogermanischen Verbalflexion = Band III 1 der Idg. Gr. (s.o.). Heidelberg 1969. $\mathrm{Zu}$ Watkins s. auch oben FS Watkins.

Wegner Hurritisch $2000=$ I. Wegener Einführung in die hurritische Sprache. Wiesbaden 2000.

Weinrich Linguistik der Lüge $1974=\mathrm{H}$. Weinrich Linguistik der Lüge, Kann Sprache die Gedanken verbergen ? 5. Aufl. Heidelberg 1974.

Weinrich Textgrammatik $1993=\mathrm{H}$. Weinrich Textgrammatik der deutschen Sprache. Mannheim / Leipzig / Wien / Zürich 1993.

Weiss Italic Nominal Morphology 1993 = M. Weiss Studies in Italic Nominal Morphology. Ph.D.-Diss. Cornell University 1993.

Weitenberg Heth. u-Stämme $1984=$ J. J. S. Weitenberg Die hethitischen u-Stämme. Amsterdam 1984. Rez.: H. C. Melchert in Kratylos 291984 [1985] p. 79-82.

Werba Verba IndoArica (VIA) I $1997=$ C. Werba Verba IndoArica: Die primären und sekundären Wurzeln der Sanskrit-Sprache. Teil I (Radices primariae). Wien 1997. Rez.: B. Schlerath in HS 1111998 p. 369-371.

West Ilias I 1998 = M. L. West Homerus, Ilias, I. Teil: Rhapsodiae I-XII. Stuttgart / Leipzig 1998.

West Theogony $1966=$ M. L. West Hesiod, Theogony, edited with Prolegomena and Commentary. Oxford 1966. 
West Works \& Days $1978=$ M. L. West Hesiod, Works \& Days, edited with Prolegomena and Commentary. Oxford 1978.

Wheeler Nominalaccent $1885=$ B. I. Wheeler Der griechische Nominalaccent. Straßburg 1885.

Windisch Sanskritphilologie I 1917 II 1920 = E. Windisch Geschichte der Sanskritphilologie. 2 Teile: I Straßburg 1917; II Berlin / Leipzig 1920.

Winkler Germanische Casussyntax I $1896=\mathrm{H}$. Winkler Germanische Casussyntax, I. Der Dativ, Instrumental, örtliche und halbörtliche Verhältnisse. Berlin 1896.

Wissenschaft vom Altertum am Ende des 2. Jt. n. Chr. $1995=$ Die Wissenschaft vom Altertum am Ende des 2. Jahrtausends n. Chr., hrsg. von E.-R. Schwinge. Stuttgart und Leipzig 1995.

Wörterbücher 119892199031991 = Wörterbücher / Dictionaries / Dictionnaires, Ein internationales Handbuch zur Lexikographie, hrsg. von F. J. Hausmann, O. Reichmann, H. E. Wiegand, L. Zgusta. Berlin / New York. 3 Halbbände: 1 1989; 2 1990; 31991 (=HSK 5.1, 5.2, 5.3).

Yoshida (D.) Aheth. Gen. 1987 = D. Yoshida Die Syntax des althethitischen substantivischen Genitivs. Heidelberg 1987 (= Texte der Hethiter 13).

Yoshida (K.) Endings in -ri $1990=\mathrm{K}$. Yoshida The Hittite Mediopassive Endings in -ri. Berlin / New York 1990 (= Untersuchungen zur idg. Sprach- und Kulturwissenschaft, N.F. 5). Rez.: G. Pinault in BSL 86 / 21991 p. 134-141.

$\mathrm{ZCP}=$ Zeitschrift für celtische Philologie.

$\mathrm{ZDL}=$ Zeitschrift für Dialektologie und Linguistik.

ZDMG = Zeitschrift der Deutschen Morgenländischen Gesellschaft.

Zehnder AVP 21999 = Th. Zehnder, Atharvaveda-Paippalāda, Buch 2, Text, Übersetzung, Kommentar, Eine Sammlung altindischer Zaubersprüche vom Beginn des 1. Jahrtausends v. Chr. Idstein 1999.

Zgusta Kleinasiatische Ortsnamen 1984 = L. Zgusta Kleinasiatische Ortsnamen. Heidelberg 1984 (= BNF N.F. Beiheft 21).

Zgusta Kleinasiatische Personennamen $1964=$ L. Zgusta Kleinasiatische Personennamen. Prag 1964.

Ziegler Ogam-Inschriften 1994 = S. Ziegler Die Sprache der altirischen Ogam-Inschriften. Göttingen 1994 (= HS Ergänzungsheft Nr. 36).

Zimmer Satzstellung $1976=$ St. Zimmer Die Satzstellung des finiten Verbs im Tocharischen. The Hague / Paris 1976. 
Zimmer Ursprache $1990=$ St. Zimmer Ursprache, Urvolk und Indogermanisierung. Zur Methode der Indogermanischen Altertumskunde. Innsbruck 1990 (= IBS, Vorträge u. kleinere Schriften Nr. 46). Rez.: J. Untermann in Kratylos 391994 p. 68-70.

Zinsmeister Gr. Gr. I $1954=\mathrm{H}$. Zinsmeister Griechische Grammatik I, Laut- und Formenlehre. München 1954. Neuaufl. Heidelberg 1990.

ZVS s.o. unter HS.

Zweihundert Jahre Homer-Forschung 1991 = Zweihundert Jahre HomerForschung. Rückblick und Ausblick, hrsg. von J. Latacz. Stuttgart / Leipzig 1991.

Zwolanek Anrufungsformen $1970=$ R. Zwolanek ,vắyav índraśca“, Studien zu Anrufungsformen im Vedischen, Avestischen und Griechischen. München 1970 (= MSS, Beiheft 5, N. F.). 